\title{
Post-Mortem Organ Weights at a South African Mortuary
}

Thesis presented in partial fulfilment of the degree of Masters of Medicine in Forensic Pathology.

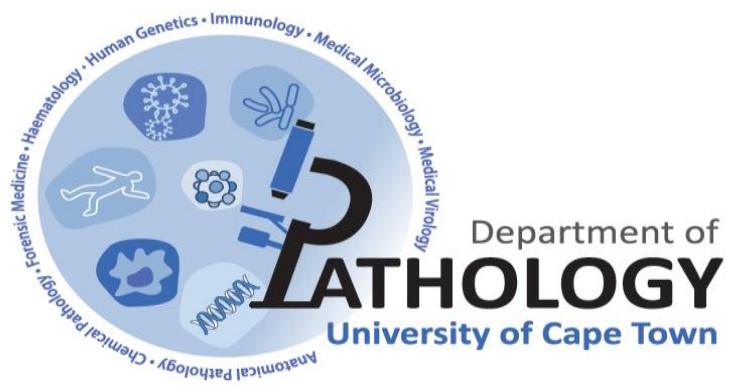

Dr Laura Peddle MBChB(UCT), DipForMed(SA)Path Division of Forensic Medicine and Toxicology

Student number: TYLLAU003 Supervisor: Dr Gavin Kirk University of Cape Town 
The copyright of this thesis vests in the author. No quotation from it or information derived from it is to be published without full acknowledgement of the source. The thesis is to be used for private study or noncommercial research purposes only.

Published by the University of Cape Town (UCT) in terms of the non-exclusive license granted to UCT by the author. 
The copyright of this thesis vests in the author. No quotation from it or information derived from it is to be published without full acknowledgement of the source. The thesis is to be used for private study or non-commercial research purposes only. Published by the University of Cape Town (UCT) in terms of the non-exclusive license granted to UCT by the author. 


\section{DECLARATION}

I, LAURA DAWN PEDDLE, HEREBY DECLARE THAT I KNOW THE MEANING OF PLAGIARISM AND THAT THE WORK ON WHICH THIS DISSERTATION IS BASED IS MY ORIGINAL WORK (EXCEPT WHERE ACKNOWLEDGEMENTS INDICATES OTHERWISE), AND THAT NEITHER THE WHOLE WORK OR ANY PART OF IT HAS BEEN, IS BEING, OR IS TO BE SUBMITTED FOR ANOTHER DEGREE IN THIS OR ANY OTHER UNIVERSITY. I EMPOWER THE UNIVERSITY TO

REPORODUCE THIS WORK FOR THE PURPOSES OF RESEARCH EITHER IN ITS ENTIRETY OR ANY PORTIONS OF THE CONTENTS IN ANY MANNER WHATSOEVER.

SIGNATURE OF PRINCIPAL AUTHOR AND INVESTIGATOR:

Signed by candidate

DATE:

$10 / 01 / 2017$ 


\section{ACKNOWLEGEMENTS}

Dr Gavin Kirk for the calm supervision

My husband, lain Peddle

Dr Mandy Date-Chong for the support and early references she made available 
"When you can measure what you are speaking about, and express it in numbers, you know something about it; but when you cannot... your knowledge is of a meagre and unsatisfactory kind; it may be the beginning of knowledge, but you have scarcely...advanced to the stage of science, whatever the matter may be." Lord Kelvin 


\section{TABLE OF CONTENTS}

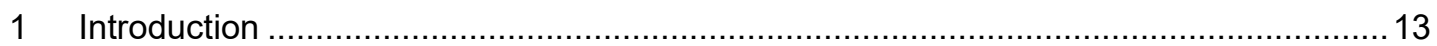

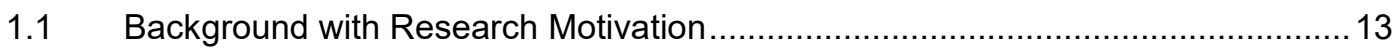

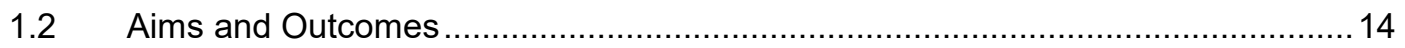

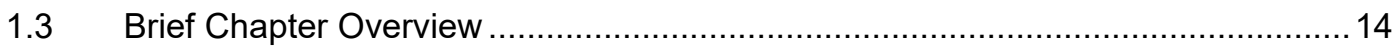

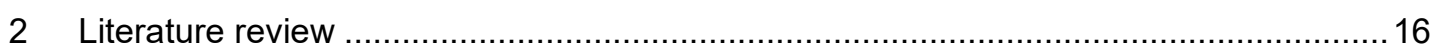

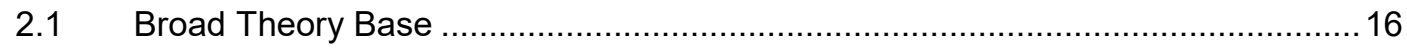

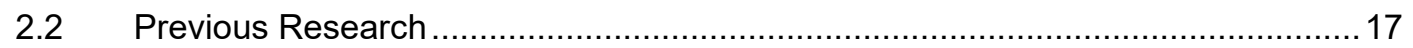

2.2.1 Organ Weights in Standard Textbooks ..........................................................

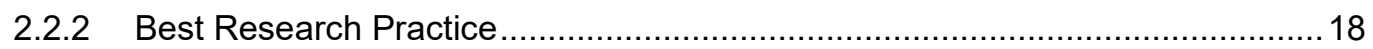

2.2.3 Research on Ethnically Diverse Populations ……........................................ 19

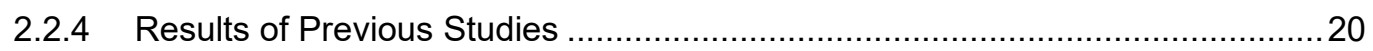

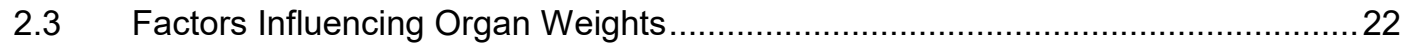

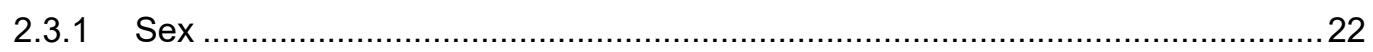

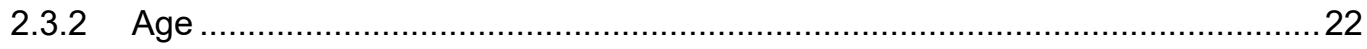

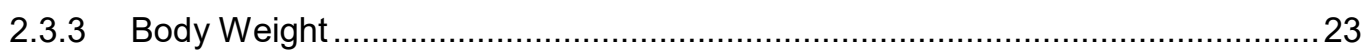

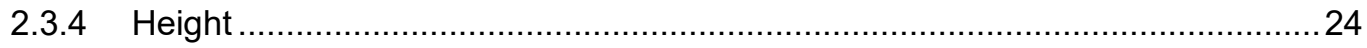

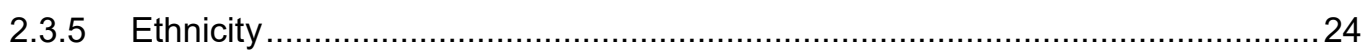

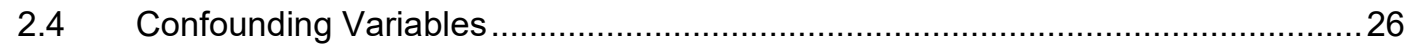

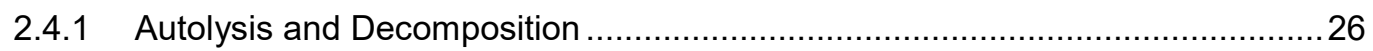

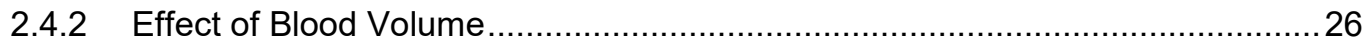

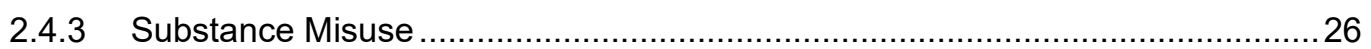

2.4.4 Disease and Agonal Pathological Changes ..............................................2 27

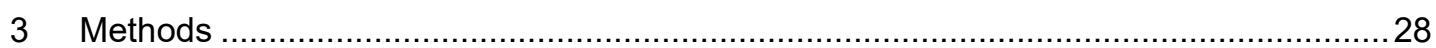

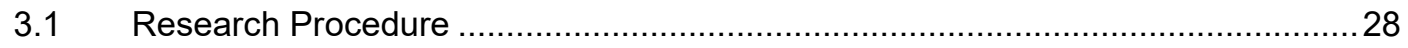

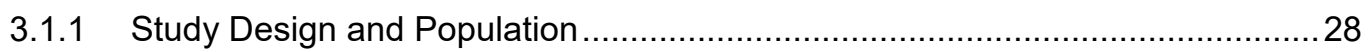

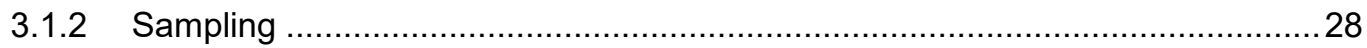

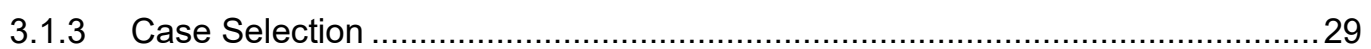

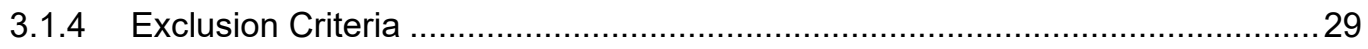

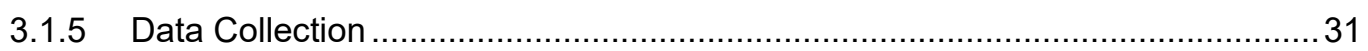

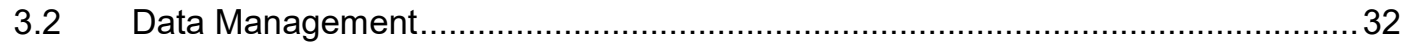

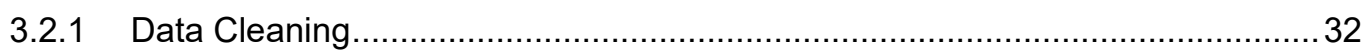

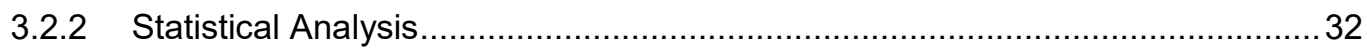

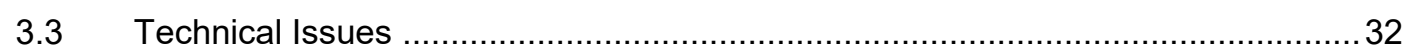

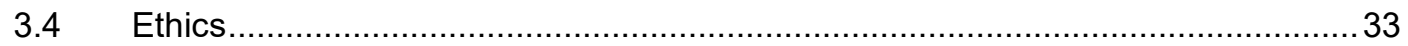

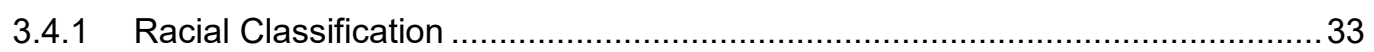

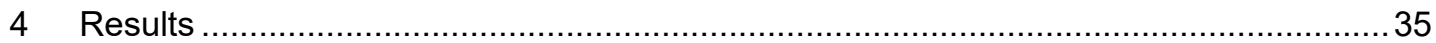

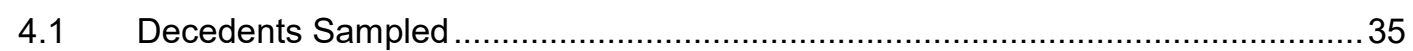

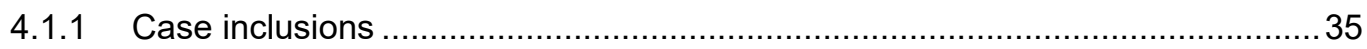




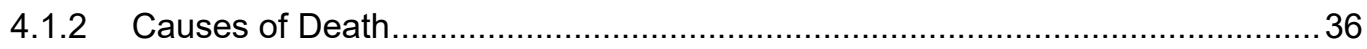

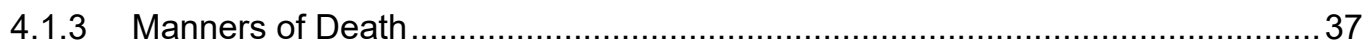

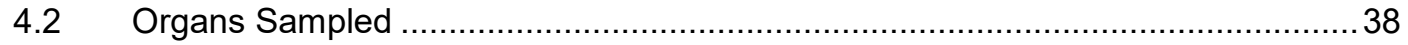

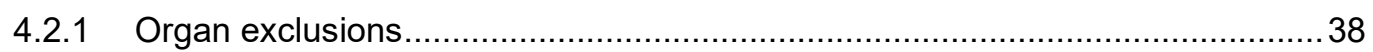

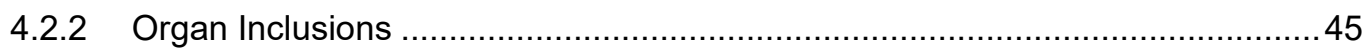

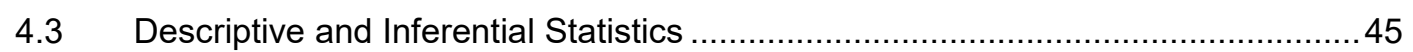

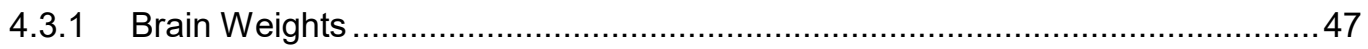

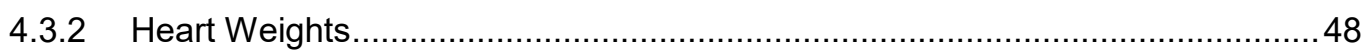

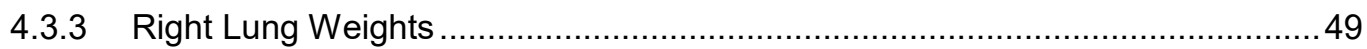

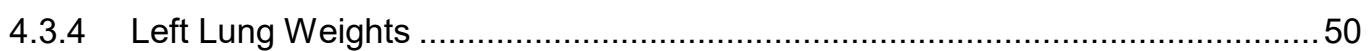

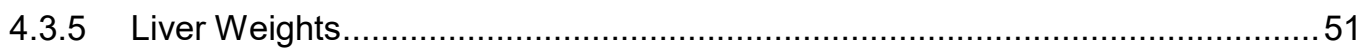

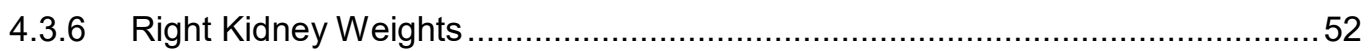

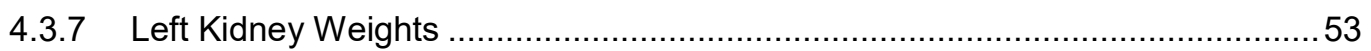

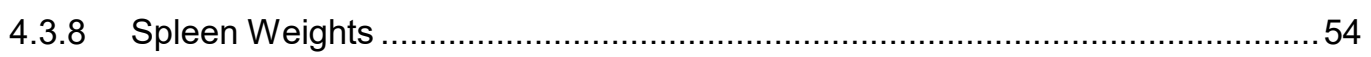

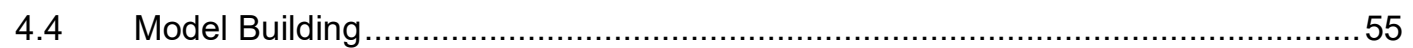

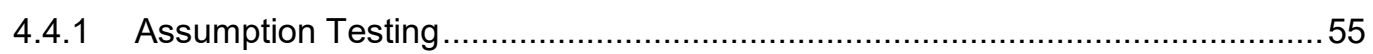

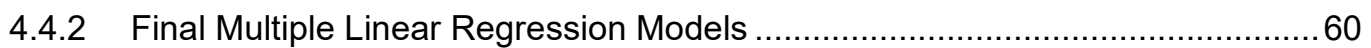

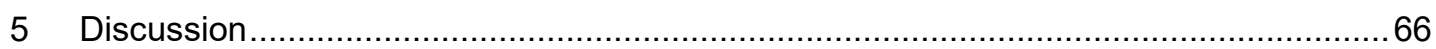

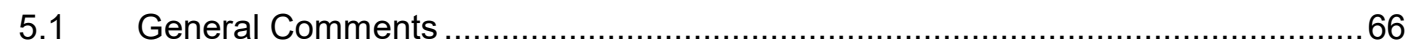

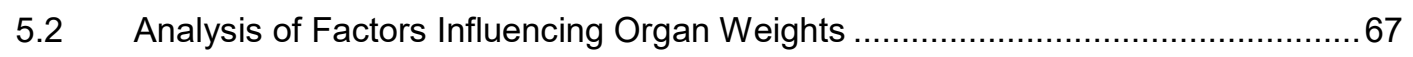

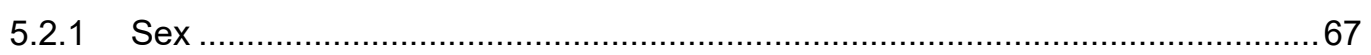

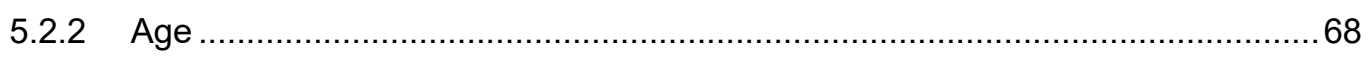

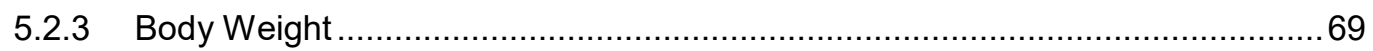

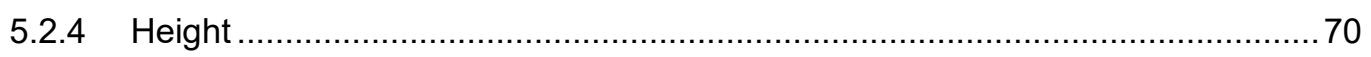

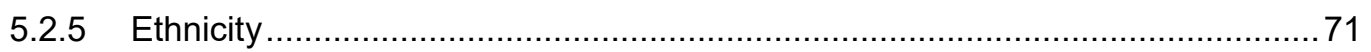

$5.3 \quad$ Organ Weight Reference Ranges ………................................................. 73

5.3.1 Generation of Appropriate Reference Ranges .............................................. 73

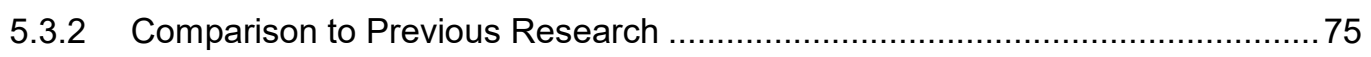

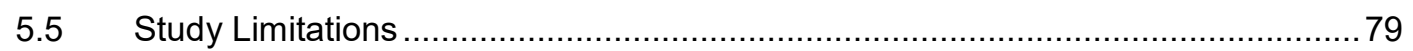

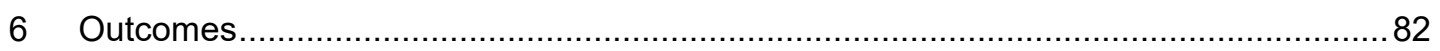

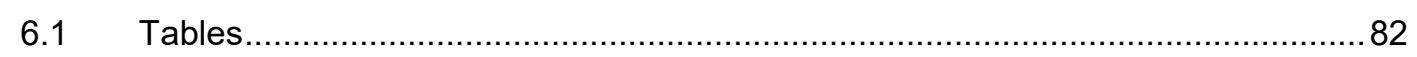

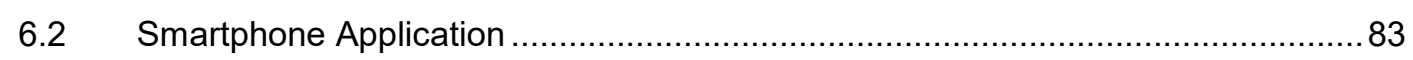

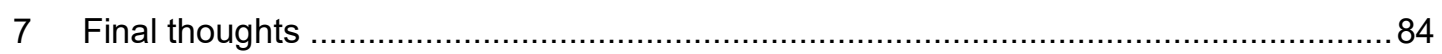

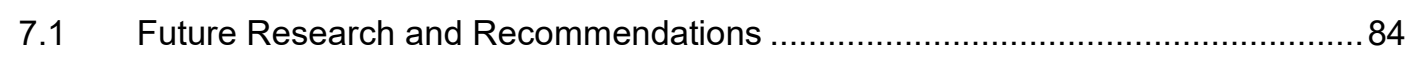

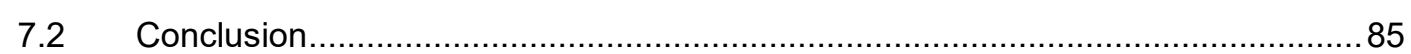




\section{LIST OF TABLES}

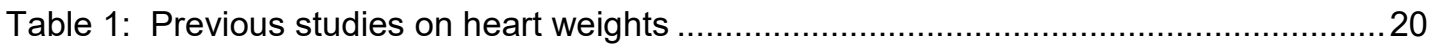

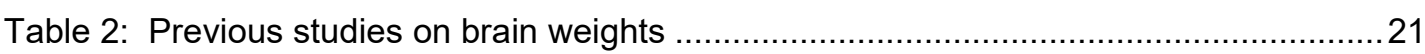

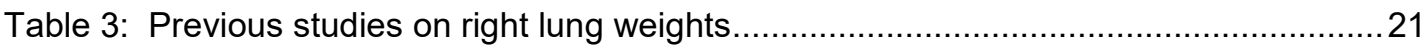

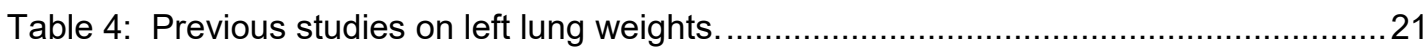

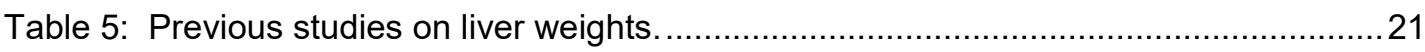

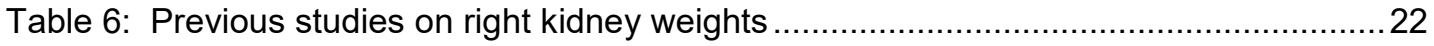

Table 7: Number of organ weights collected for each organ, per population subgroup ....... 45

Table 8: $R^{2}$ values for each predictor variable, per organ ..................................................46

Table 9: Multiple linear regression model for brain weight ............................................ 47

Table 10: Multiple linear regression model for heart weight ................................................ 48

Table 11: Multiple linear regression model for right lung weight......................................49

Table 12: Multiple linear regression model for left lung weight ............................................50

Table 13: Multiple linear regression model for liver weight ................................................... 51

Table 14: Multiple linear regression model for right kidney weight .................................... 52

Table 15: Multiple linear regression model for right kidney weight ......................................53

Table 16: Multiple linear regression model for right kidney weight .......................................54

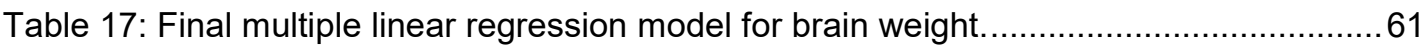

Table 18: Final multiple linear regression model for heart weight ........................................ 61

Table 19: Final multiple linear regression model for right lung weight.................................62

Table 20: Final multiple linear regression model for left lung weight ...................................63

Table 21: Final multiple linear regression model for liver weight ........................................ 64

Table 22: Final multiple linear regression model for spleen weight ....................................64

Table 23: Final multiple linear regression model for right kidney weight .................................65

Table 24: Final multiple linear regression model for left kidney weight ...............................65

Table 25: Organ weight reference ranges taken from 'The Forensic ABC in Medical Practice'

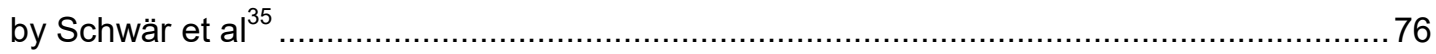

Table 26: Comparison of organ weight statistics for men aged 18-35 years with normal BMI indices

Table 27: Comparison of organ weight statistics for women aged 18-35 years with normal $\mathrm{BMI}$ indices

Table 28: Proposed post-mortem ideal organ weight reference ranges for South African Mortuaries. 


\section{LIST OF FIGURES}

Figure 1: Numbers of patients of each sample subgroup included in the study ....................35

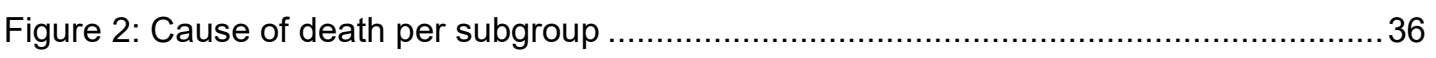

Figure 3: Causes of blunt force trauma per subgroup .................................................. 36

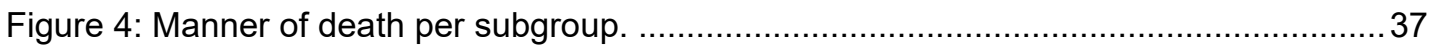

Figure 5: Organ weight exclusions in African Males aged 18-49 years...............................38

Figure 6: Organ weight exclusions in African Females aged 18-49 years. ............................39

Figure 7: Organ weight exclusions in African Males aged 50 years and above................... 39

Figure 8: Organ weight exclusions for African Females aged 50 years and above. .............40 40

Figure 9: Organ weight exclusions for White Males aged 18-49 years ............................. 41

Figure 10: Organ weight exclusions for White Females aged 18-49 years. ..........................41

Figure 11: Organ weight exclusions for White Males aged 50 years and older. ...................42

Figure 12: Organ weight exclusions for White Females aged 50 years and older ................42

Figure 13: Organ weight exclusions for Coloured Males aged 18-49 years ........................ 43

Figure 14: Organ weight exclusions for Coloured Females aged 18-49 years......................43

Figure 15: Organ weight exclusions for Coloured Males aged 50 years and older ............... 44

Figure 16: Organ weight exclusions for Coloured Females aged 50 years and older ...........44

Figure 17: Brain weight according to sample subgroup............................................. 47

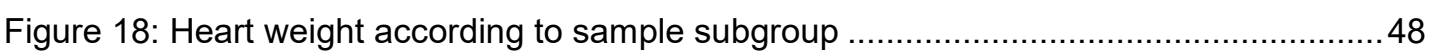

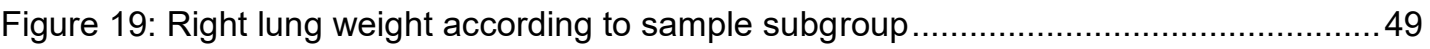

Figure 20: Left lung weight according to sample subgroup ..............................................50

Figure 21: Liver weight according to sample subgroup ......................................................

Figure 22: Right kidney weight according to sample subgroup ......................................... 52

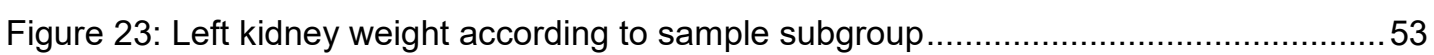

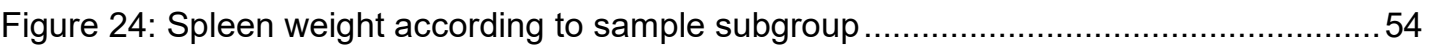

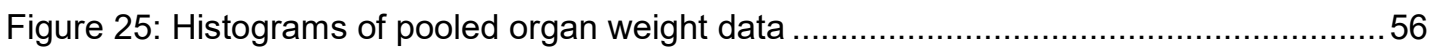

Figure 26: Log-transformations of selected pooled organ weight data .................................57 


\section{LIST OF DEFINITIONS AND ABBREVIATIONS}

\begin{tabular}{|c|c|}
\hline Adjusted $\mathrm{R}^{2}$ & $\begin{array}{l}\text { A modified version of } \mathrm{R}^{2} \text { that has been adjusted for the } \\
\text { number of predictors in the model. }\end{array}$ \\
\hline Alpha $(\alpha)$ & $\begin{array}{l}\text { The probability of rejecting the null hypothesis when it is } \\
\text { true; the significance level of the study. }\end{array}$ \\
\hline ANOVA & $\begin{array}{l}\text { The one-way analysis of variance test determines the } \\
\text { presence of statistically significant differences between the } \\
\text { means of two or more independent groups. }\end{array}$ \\
\hline $\mathrm{BMI}$ & $\sim$ Body mass index, expressed in $\mathrm{kg} / \mathrm{m}^{2}$ \\
\hline $\begin{array}{l}\beta \text {-weighted } \\
\text { coefficient }\end{array}$ & $\begin{array}{l}\text { The coefficient of a standardized variable, allowing direct } \\
\text { comparison of variables. }\end{array}$ \\
\hline Coefficient & $\begin{array}{l}\text { These are multiplied by the independent variables in the } \\
\text { regression equation for predicting the dependent variable. }\end{array}$ \\
\hline Collinearity & $\begin{array}{l}\text { This occurs when predictor variables are not independent } \\
\text { from each other. }\end{array}$ \\
\hline Coloured & $\begin{array}{l}\text { Mixed race; genetically predominantly Khoisan, Negroid } \\
\text { African, and Caucasian, with a smaller Asian contribution. }\end{array}$ \\
\hline $\begin{array}{l}\text { Degrees of } \\
\text { freedom }\end{array}$ & $\begin{array}{l}\sim \text { The number of values in the final calculation of a statistic } \\
\text { that are free to vary. }\end{array}$ \\
\hline $\begin{array}{l}\text { Difference } \\
\text { detection level }\end{array}$ & $\begin{array}{l}\text { The magnitude of the effect of interest to be detected by a } \\
\text { test with a specified power. Ensures that clinical } \\
\text { differences, not just statistical differences, are detected. }\end{array}$ \\
\hline Ethnicity & $\begin{array}{l}\text { See 'Race'. These terms are used interchangeably in this } \\
\text { paper. }\end{array}$ \\
\hline F-statistic & $\begin{array}{l}\text { The mean square value of the model divided by the mean } \\
\text { square value of the residual; numbers in brackets are the } \\
\text { model and residual degrees of freedom. It indicates whether } \\
\text { a group of variables are jointly significant, when compared } \\
\text { to a p-value. }\end{array}$ \\
\hline Healthy & $\sim$ Free from disease. \\
\hline Height & $\begin{array}{l}\text { The length of the deceased's body, measured from heel to } \\
\text { crown of head. }\end{array}$ \\
\hline Homoscedasticity & $\begin{array}{l}\text { The variance around the regression line is the same for all } \\
\text { values of the predictor variables. }\end{array}$ \\
\hline HREC & $\sim$ Human Research Ethics Committee. \\
\hline Lowess & $\sim$ Locally Weighted Scatterplot Smoothing. A lowess line fits \\
\hline
\end{tabular}




\begin{tabular}{|c|c|}
\hline & $\begin{array}{l}\text { a smooth line through a scatterplot; it does not have to be } \\
\text { linear. }\end{array}$ \\
\hline $\mathrm{LVH}$ & Left ventricular hypertrophy. \\
\hline Mean squares & $\begin{array}{l}\sim \text { The Sum of Squares divided by their respective degrees of } \\
\text { freedom. }\end{array}$ \\
\hline MRI & Magnetic Resonance Imaging. \\
\hline Normal & $\begin{array}{l}\text { Normal observations are drawn from a population which has } \\
\text { a normal distribution of those data, which can be shown } \\
\text { graphically as a symmetrical bell-shaped curve shaped by } \\
\text { its standard deviation, with most data points clustered about } \\
\text { the mean. }\end{array}$ \\
\hline Pathologist & Forensic Pathology consultant, registrar, or medical officer. \\
\hline $\begin{array}{l}\text { Partial residual } \\
\text { plots }\end{array}$ & $\begin{array}{l}\text { These graphs show a relationship between an independent } \\
\text { variable and the response variable controlling for } \\
\text { independent variables that are also in the model. }\end{array}$ \\
\hline $\begin{array}{l}\text { Post-mortem } \\
\text { interval }\end{array}$ & $\begin{array}{l}\text { The time between declaration of death and autopsy } \\
\text { examination. }\end{array}$ \\
\hline Power & $\begin{array}{l}\text { The probability of correctly rejecting the null hypothesis } \\
\text { when the alternative hypothesis is true; the sensitivity level } \\
\text { of the study. }\end{array}$ \\
\hline p-value & $\begin{array}{l}\text { The probability that a statistical estimate would be the same } \\
\text { as or more extreme than the observed results, when the } \\
\text { null hypothesis is actually true. The smallest level of } \\
\text { significance at which the null hypothesis is rejected. }\end{array}$ \\
\hline $\mathrm{R}^{2}$ & $\begin{array}{l}\text { Coefficient of determination. The proportion of the of the } \\
\text { variance in the dependent variable that is predicted by the } \\
\text { independent variables. }\end{array}$ \\
\hline Race & $\begin{array}{l}\text { Groups of people sharing physical traits, ancestry, genetics } \\
\text { and social relations. }\end{array}$ \\
\hline Range & $\sim$ Maximum and minimum data points in the sample. \\
\hline Report & $\begin{array}{l}\text { Unless otherwise stated, this refers to the medico-legal } \\
\text { post-mortem report compiled by the responsible Forensic } \\
\text { Pathologist. }\end{array}$ \\
\hline Residual & $\begin{array}{l}\text { The difference between the observed value of the } \\
\text { dependent variable and its predicted value. }\end{array}$ \\
\hline Root MSE (Mean & $\sim$ The square root of the mean square error is the standard \\
\hline
\end{tabular}




\begin{tabular}{|c|c|}
\hline Square Error) & deviation of the residuals. \\
\hline $\begin{array}{l}\text { Standard } \\
\text { deviation }\end{array}$ & $\begin{array}{l}\text { This quantifies the amount of variation or dispersion in a set } \\
\text { of data values. }\end{array}$ \\
\hline $\begin{array}{l}\text { Standard error } \\
\text { (of the mean) }\end{array}$ & $\begin{array}{l}\sim \text { The dispersion of sample means around the true population } \\
\text { mean. }\end{array}$ \\
\hline $\begin{array}{l}\text { Standardized } \\
\text { variable }\end{array}$ & $\sim$ Variable transformed so that it has a standard deviation of 1 \\
\hline Sum of squares & $\begin{array}{l}\text { The sum of the squared differences of each observation } \\
\text { from: the overall mean (total sum of squares - measures } \\
\text { overall data variance); the predicted values (residual sum of } \\
\text { squares - measures discrepancy between the data and } \\
\text { estimation model). The model sum of squares = the total - } \\
\text { residual sum of squares. }\end{array}$ \\
\hline t-statistic & $\begin{array}{l}\text { This is compared to a level of significance }(0.05) \text { to infer } \\
\text { whether regression coefficients, and their associated } \\
\text { variables, are significant. }\end{array}$ \\
\hline t-test & $\begin{array}{l}\sim \text { A hypothesis test to determine whether the means from two } \\
\text { sets of data are significantly different from one other. }\end{array}$ \\
\hline Q-Q plot & $\begin{array}{l}\text { A scatterplot of quantiles (percentiles) from the model } \\
\text { against quantiles of a normal distribution. If the model } \\
\text { quantiles are also normally distributed, the points form a } \\
\text { roughly straight line. }\end{array}$ \\
\hline UCT & University of Cape Town. \\
\hline $\begin{array}{l}\text { Variance inflation } \\
\text { factor }\end{array}$ & $\begin{array}{l}\text { This measures how much the variance of the model's } \\
\text { estimated coefficients are inflated compared to when the } \\
\text { predictor variables are not linearly related. }\end{array}$ \\
\hline Weight & mass in grams or kilograms. \\
\hline
\end{tabular}




\section{Introduction}

\subsection{Background with Research Motivation}

Measuring organ weights is a necessary part of every autopsy, as laid out in the Harmonisation of Medico-Legal Autopsy Rules. ${ }^{1}$ Weights are then compared to standard reference tables to determine whether they fall within or without defined limits. This information is used, together with macroscopic and microscopic observations, to make a judgement on the presence and type of any pathology. On occasion, the organ weight alone is significant: for example, increased heart weight is an independent risk factor for sudden death. ${ }^{2-4}$ In South Africa, due to caseloads and resource constraints, histology may not be taken in forensic autopsies of traumatic deaths. Organ weights, compared to a valid reference range, are then especially important as corroborating evidence of macroscopically observed pathology.

There have been several studies on post-mortem organ weights conducted on ethnically homogeneous populations from various areas. These include Iran, 5,6 Thailand, ${ }^{7}$ Japan, ${ }^{8}$ India, ${ }^{9}$ France,${ }^{10}$ and Denmark, ${ }^{11}$ as well as from heterogeneous populations in the United States of America (USA) ${ }^{12}$ and Jamaica, ${ }^{13}$ but no studies from African populations living in Africa. The single study found was from 1988 in South Africa, ${ }^{14}$ but this only addressed renal weights in Bantu-speaking Africans.

South Africa's population is comprised of diverse ethnic groups. The majority of decedents presenting to the Salt River Mortuary in Cape Town, South Africa, are ethnically African, Coloured, or White. 'Coloured' is a uniquely South African term for a mixed-race group that are genetically predominantly Khoisan (32-43\%), Bantuspeaking Africans (20-36\%), and European (21-28\%), with a smaller Asian contribution (9-11\%). ${ }^{15}$ In addition to potential genetic influences, South Africa has a recent history of apartheid laws resulting in very different living standards and nutrition for ethnically different groups of people ${ }^{16}$. It is possible that the legacy of this may also affect organ weights. 
Organ weight reference ranges must be accurately and regularly defined. ${ }^{10}$ This is because these 'normal values' are applicable to a stated time and place, and influenced by the biological and socioeconomic conditions of that period. A current reference range for use in South Africa, which could potentially be affected by ethnicity and nutrition, is urgently needed.

\subsection{Aims and Outcomes}

The primary aim of this study was the generation of post mortem organ weight reference ranges for use in South African mortuaries. Secondary aims were analysis of the data to determine which factors influence organ weights, and comparison of South African data to that from international populations in selected studies.

It is envisioned that this research will be published, thus allowing dissemination of the information and promotion of its use in daily forensic and anatomical pathology practice. A smartphone application has also been developed, allowing clinicians to conveniently enter variables and receive the predicted weight ranges specific to their patient, in order to better evaluate possible pathological changes in organs at autopsy.

\subsection{Brief Chapter Overview}

A literature review follows in Chapter 2, covering the theory base of post-mortem organ weight research. This includes the importance of valid reference ranges, and the types of cases usually included in studies to establish them. A synopsis of previous research begins with that cited in standard Forensic Pathology textbooks. It then discusses a collection of papers selected from modern research, chosen as a benchmark with which to compare our data. To put our study into perspective, tables on the organ weight statistics reported in some of the international literature on ethnically diverse populations are included. Comments on the methods used are provided for clarification, and to illustrate the difficulties in direct comparison with these studies' outcomes. The factors that have been found to impact on postmortem organ weights are then described: specifically, sex, age, weight, height, and ethnicity. This is proceeded by a limited discussion on selected confounding 
variables which may be used to inform exclusion criteria within a deceased population.

Chapter 3 deals with the methods employed in this investigation. After defining the study population and type of research, the sampling strategy and sample size calculations are discussed. This is followed by an outline of the practicalities of data flow, with a list of the exclusion criteria accompanied by brief explanations. Methods of data cleaning and statistical analysis are described, after which there is a short note on technical issues. Finally, ethics is covered, with a specific discussion on racial classification and its use in this context.

Next, chapter 4 is used to present the results of this investigation into post-mortem organ weights obtained at Salt River Mortuary. It begins with a demographic description of the sampled cases, including cause and manner of death. The reasons for organ exclusions in the various sample subgroups are presented graphically, thus accounting for all data, and a table summarizes the numbers of organ weights ultimately recorded for use. The chapter continues with descriptive and basic inferential statistics for each subsample, where attention is drawn to the influence of sex and race. After assumption testing, the final multiple linear regression models for each organ are presented and discussed.

In chapter 5 the effects of the independent variables on organ weight are analysed. The findings are then compared to those of other studies, allowing for differences in research designs. Study limitations and problems encountered in the performance of the study are then explored.

The outcomes of this research are presented in ideal organ weight reference ranges in Chapter 6. A smartphone application, developed by the author, is also introduced, which allows access to individualized prediction intervals.

Chapter 7 is the final chapter, which deals with recommendations and future research that may be undertaken using this study as a starting point, before the concluding remarks are given. 


\section{Literature review}

\subsection{Broad Theory Base}

The establishment of a reference range for the anatomical normal constitutes the first step in the recognition and study of the abnormal. There is a long tradition of using a population dying sudden, violent deaths as a data source for compiling these normal organ weight reference ranges. This is in order to minimize the possible effect of disease on organ masses obtained. ${ }^{11,17-19}$ Modern studies have additionally used exclusion criteria based on clinical records or family questionnaires to determine a history of illness, ${ }^{11}$ macroscopic evidence at autopsy, ${ }^{12}$ or histological examination to detect microscopic disease. ${ }^{10,17,20}$ It should be recognised that there have been no studies investigating whether diseased organs that do not yet show macroscopically visible pathological changes indeed have altered weights.

It is notable that until recently the well-known textbook, 'Knight's Forensic Pathology', has cited organ weight reference papers that are outdated and inconsistent in their application of these exclusion criteria. ${ }^{21}$ The latest edition of 'Knight's' does not supply organ weight reference tables at all, possibly because of the difficulty in defining them. ${ }^{22}$

Previous studies addressing the factors affecting organ weights have dealt with relatively small sample sizes, thus not allowing for extensive subgroup analysis. $^{12,17,20}$ Very few have directly investigated racial differences. ${ }^{12,23-25}$ Most papers have however examined the link between organ weights and sex, ${ }^{10,11,20,26}$ age, ${ }^{10,26,27}$ body weight/body mass index (BMI)/body surface area, ${ }^{10,11}$ and height. ${ }^{10,17,20,27}$ 


\subsection{Previous Research}

\subsubsection{Organ Weights in Standard Textbooks}

The $1^{\text {st }}$ to $3^{\text {rd }}$ editions of 'Knight's Forensic Pathology', a standard basic text in this field, provide organ weight reference ranges in an appendix. ${ }^{21}$

Two approaches to assessing heart weight are offered. The 1928 study by Smith provides tables of normal heart weight according to body weight. ${ }^{28}$ These tables were based on 1000 cases that included hospital deaths due to pneumonia, sepsis, and malignancies. He excluded patients known to have diseases that could affect heart weight, for example hypertension, as well as those with undefined 'microscopic cardiac lesions'. It was found that the weight of the heart does not increase with age, and is a consistent percentage of the total body weight, although this is less accurate at body mass extremes.

The heart weight tables produced by Zeek are also included in 'Knight's'. ${ }^{23}$ These were developed from a USA population in 1942 and attempted to associate heart weight with height rather than body weight, arguing that this is unstable in disease. He indeed showed good correlation in the 933 hospital autopsy cases used, of hearts that were 'relatively normal' without gross or microscopic abnormalities.

The only table in 'Knight's' that provides values for all the organs, lists these according to age in 1 year intervals, from birth to 21 years. This table is taken from a book, referencing a 1952 publication for medical students. ${ }^{29,30}$ The original data source for this could not be traced, however it is remarkable in that it uses very few subjects, often less than 10 individuals in each year group.

Another book, 'Normal Values in Clinical Medicine' by Sunderman and Boerner, is used to provide the adult brain and all paediatric organ weight references used in 'Knight's'. ${ }^{31}$ This same source is modified for use in Ludwig's well known textbook, 'Handbook for Autopsy Practice'. ${ }^{32}$ In tracing this book's own references, it becomes apparent that these are texts from the late 1800's in Germany. ${ }^{33,34}$ In these references, populations are not defined, sample sizes are not stated, and standard deviations are not given. It is also not clear what methods or criteria were used. 
The textbook most commonly cited for organ weight reference ranges in the Division of Forensic Medicine at UCT is 'The Forensic ABC in Medical Practice' by Schwär et al. ${ }^{35}$ The table of organ weights is not referenced, and despite personal communication with one of the authors the source could not be traced. The other problem with this reference is that no range is given for the kidneys, merely a single value.

\subsubsection{Best Research Practice}

In 2011 and 2015, 4 papers on post-mortem organ weights were published in the American Journal of Forensic Medicine and Pathology. ${ }^{17,20,36,37}$ They were authored by well-known forensic practitioners and researchers, Molina and DiMaio, and were particularly well designed.

These papers reported prospective studies on a population of adults aged 18-35 years in the USA who died sudden traumatic deaths. The accepted post-mortem interval was $<24$ hours with $<2$ hours between injury and death. Their exclusion criteria were medical illness including illicit drug use (on history or toxicological testing), surgical procedures performed, significant organ injury involving parenchymal loss or intraparenchymal haemorrhage, and gross or histological evidence of illness. Histological evidence of systemic disease in a particular organ resulted in the entire case being disqualified. It is notable that 'traumatic' causes of death included drowning and hanging, and that congested and pale organs were not excluded. Methodologically, bodies were weighed unclothed and livers were weighed with the gallbladders intact.

These studies' strict inclusion conditions meant that only 232 male and 102 female decedents were considered, with still fewer individual organs meeting the criteria for analysis. Positive correlations between organ weights and body length and weight/BMl were found, however these were inadequate to enable prediction of organ weight on an individual basis. The authors therefore proposed reference ranges for men and women using the organ masses from decedents with normal BMI indices. These cases were therefore as free of confounding variables as possible, and may be taken to represent healthy organ weights in this limited population. 


\subsubsection{Research on Ethnically Diverse Populations}

There are a multitude of studies available which attempt to describe normal organ weights in their populations of interest. Each uses slightly different methods and has a different sample size, making direct comparison difficult.

Much of the English language literature focusses on Caucasian decedents, such as the often quoted study by de la Grandmaison that reported on organ weights of French Caucasians. ${ }^{10}$ These were drawn from 'forensic cases', presumably including overdoses, hangings, and sudden unexpected deaths. They excluded macroscopic or histological abnormalities, however a note is made that the wide variation in lung weights could be due to oedema or congestion, implying that these findings were in fact not excluded. Broad ranges were similarly given for the other organ weights, which might suggest that further pathologies were inadvertently included in the sample.

In contrast to this sample selection method, another well-known study on a Danish Caucasian population by Garby only considered antemortem health records and family opinion of the presence of disease when excluding decedents. ${ }^{11}$ On the basis of this, cases were included if they were "healthy and apparently healthy". The only additional exclusion criteria were organ laceration or loss of substance; grossly diseased organs found at autopsy were not mentioned and presumably included. Garby's results for Danish lung, kidney and spleen weights could not be incorporated into the tables below for comparison. This is because they measured only combined kidney weight, did not study lung weights, and presented median spleen values for this right skewed distribution.

Several studies of varying quality have been conducted on organ weights in Asian populations. The Korean study included in the tables below considered only decedents without any diseases that could affect organ weights, without specifically defining these. ${ }^{26}$ Additionally, histology was used to exclude pathology. The other Asian population study included here is from Thailand. ${ }^{7}$ This study population comprised patients older than 15 years dying of injury, without macroscopic or histological abnormalities. Lung and kidney weights from this study are not included as they measured only the combined organ weights. 
Two studies have been chosen from the literature on organ weights in Middle Eastern populations. The study on Iranian brain weights considered all types of unnatural deaths in adults (defined as $>15$ years old). ${ }^{6}$ They did not include histology, or seemingly clinical pathological changes as exclusion criteria. The other study from Iran included in the tables below is by Sheikhazadi. ${ }^{5}$ It also considered deaths due to 'various medico-legal causes', excluding those with macroscopic or histological abnormalities. This notwithstanding, they appear to have included all organs of all the decedents in the study.

The only published study on Sub-Saharan African organ weights, by Moar, focusses on kidney weights. ${ }^{14}$ They included natural and unnatural causes of death but excluded macroscopically and histologically abnormal organs. The results are subdivided based on tribal affiliation of the deceased, as well as cause of death. Detailed statistical analysis is not performed and the combined renal weight is used.

\subsubsection{Results of Previous Studies}

Tabulated below are the results of the papers discussed in the preceding sections. There is an assortment of findings from these different studies in different populations and useful direct comparisons are impossible due to differences in study methodologies and insufficient numbers. Nevertheless, they provide an overview of the mean organ weight values and standard deviations that may be expected.

\begin{tabular}{|c|c|c|}
\hline Population and author & Men: $m \pm \sigma(n)$ & Women: $m \pm \sigma(n)$ \\
\hline French (de la Grandmaison ${ }^{10}$ ) & $365 \pm 71 \mathrm{~g}(355)$ & $312 \pm 78 g(329)$ \\
\hline Iranian $\left(\right.$ Sheikhazadi $\left.{ }^{5}\right)$ & $359 \pm 76(914)$ & $319 \pm 86(308)$ \\
\hline Danish $\left(\right.$ Garby $\left.^{11}\right)$ & $412 \pm 86 g(1080)$ & $313 \pm 67 g(510)$ \\
\hline Korean $\left(\mathrm{Kim}^{26}\right)$ & $346.8 \pm 57.9 \mathrm{~g}(266)$ & $298.8 \pm 62.6 \mathrm{~g}(140)$ \\
\hline Thai (Mathuramon ${ }^{7}$ ) & $302 \pm 54 g(459)$ & $360 \pm 60 \mathrm{~g}(100)$ \\
\hline USA (Molina ${ }^{17,36}$ ) & $331 \pm 56.7 g(232)$ & $245 \pm 52 g(102)$ \\
\hline USA $\left(\right.$ Smith $\left.^{28}\right)$ & $294 g^{*}(534)$ & $250 g^{*}(328)$ \\
\hline
\end{tabular}




\begin{tabular}{|c|c|c|}
\hline Study & Men: $m \pm \sigma(n)$ & Women: $\mathrm{m} \pm \sigma(\mathrm{n})$ \\
\hline Korean $\left(\mathrm{Kim}^{26}\right)$ & $1423.4 \pm 117.4 \mathrm{~g}(315)$ & $1294.3 \pm 105.8 \mathrm{~g}(121)$ \\
\hline Thai (Mathuramon ${ }^{7}$ ) & $1330 \pm 127 g(447)$ & $1209 \pm 131 \mathrm{~g}(93)$ \\
\hline Danish (Garby ${ }^{11}$ ) & $1499 \pm 130 \mathrm{~g}(1001)$ & $1321 \pm 112 g(488)$ \\
\hline USA (Molina ${ }^{20,37}$ ) & $1407 \pm 123.5 g(171)$ & $1233 \pm 115 g(74)$ \\
\hline Iranian (Mehrpour ${ }^{6}$ ) & $1323 \pm 117 g(856)$ & $1219 \pm 128 g(287)$ \\
\hline Iranian (Sheikhazadi ${ }^{5}$ ) & $1322 \pm 117 g(914)$ & $1209 \pm 131 \mathrm{~g}(308)$ \\
\hline
\end{tabular}

Table 2: Previous studies on brain weights. Notation as for Table 1.

\begin{tabular}{|c|c|c|}
\hline Study & Men: $m \pm \sigma(n)$ & Women: $\mathrm{m} \pm \sigma(\mathrm{n})$ \\
\hline French (de la Grandmaison ${ }^{10}$ ) & $663 \pm 239 g(355)$ & $546 \pm 207 g(329)$ \\
\hline Korean $\left(\mathrm{Kim}^{26}\right)$ & $645.6 \pm 170.2 \mathrm{~g} \mathrm{(324)}$ & $485 \pm 153.5 g(140)$ \\
\hline USA (Molina ${ }^{20,37}$ ) & $445 \pm 159 g(229)$ & $340 \pm 123 g(102)$ \\
\hline Iranian (Sheikhazadi ${ }^{5}$ ) & $567 \pm 175 g(914)$ & $442 \pm 118 g(308)$ \\
\hline
\end{tabular}

Table 3: Previous studies on right lung weights. Notation as for Table 1.

\begin{tabular}{|c|c|c|}
\hline Study & Men: $m \pm \sigma(n)$ & Women: $m \pm \sigma(n)$ \\
\hline French (de la Grandmaison ${ }^{10}$ ) & $583 \pm 216(355)$ & $467 \pm 174(329)$ \\
\hline Korean $\left(\operatorname{Kim}^{26}\right)$ & $559 \pm 150.5 \mathrm{~g}(327)$ & $417.6 \pm 129.9 g(129)$ \\
\hline USA (Molina ${ }^{20,37}$ ) & $395 \pm 147 g(230)$ & $299 \pm 117 g(102)$ \\
\hline Iranian (Sheikhazadi ${ }^{5}$ ) & $533 \pm 197 g(914)$ & $442 \pm 118 \mathrm{~g}(308)$ \\
\hline
\end{tabular}

Table 4: Previous studies on left lung weights. Notation as for Table 1.

\begin{tabular}{|c|c|c|}
\hline Study & Men: $m \pm \sigma(n)$ & Women: $m \pm \sigma(n)$ \\
\hline French (de la Grandmaison ${ }^{10}$ ) & $1677 \pm 396 \mathrm{~g}(355)$ & $1475 \pm 362(329)$ \\
\hline Korean $\left(\mathrm{Kim}^{26}\right)$ & $1650.4 \pm 333 g(344)$ & $1344 \pm 286 g(151)$ \\
\hline Thai (Mathuramon ${ }^{7}$ ) & $1391 \pm 283 g(460)$ & $1211 \pm 270 \mathrm{~g}(99)$ \\
\hline Danish $\left(\right.$ Garby ${ }^{11}$ ) & $1807 \pm 422 g(993)$ & $1542 \pm 409 g(462)$ \\
\hline USA (Molina ${ }^{20,37}$ ) & $1561 \pm 317 g(225)$ & $1288 \pm 330 \mathrm{~g}(99)$ \\
\hline Iranian (Sheikhazadi ${ }^{5}$ ) & $1501 \pm 298 g(914)$ & $1372 \pm 297 g(308)$ \\
\hline
\end{tabular}

Table 5: Previous studies on liver weights. Notation as for Table 1.

\begin{tabular}{|l|l|l|}
\hline Study & Men: $\mathrm{m} \pm \sigma(\mathrm{n})$ & Women: $\mathrm{m} \pm \sigma(\mathrm{n})$ \\
\hline French $\left(\right.$ de la Grandmaison $\left.^{10}\right)$ & $162 \pm 39 \mathrm{~g}(355)$ & $135 \pm 39 \mathrm{~g}(329)$ \\
\hline Korean $\left(\mathrm{Kim}^{26}\right)$ & $155 \pm 30.8 \mathrm{~g}(334)$ & $126 \pm 27.4 \mathrm{~g}(141)$ \\
\hline USA (Molina & \\
\hline
\end{tabular}




\begin{tabular}{|c|c|c|}
\hline Iranian (Sheikhazadi ${ }^{5}$ ) & $147 \pm 48 g(914)$ & $131 \pm 26 \mathrm{~g} \mathrm{(308)}$ \\
\hline Study & Men: $m \pm \sigma(n)$ & Women: $\mathrm{m} \pm \sigma(\mathrm{n})$ \\
\hline French (de la Grandmaison ${ }^{10}$ ) & $160 \pm 41 \mathrm{~g}(355)$ & $136 \pm 37 g(329)$ \\
\hline Korean $\left(\mathrm{Kim}^{26}\right)$ & $161 \pm 33 g(336)$ & $133 \pm 28 g(142)$ \\
\hline USA (Molina ${ }^{20,37}$ ) & $137 \pm 28 g(227)$ & $116 \pm 32 g(102)$ \\
\hline Iranian (Sheikhazadi ${ }^{5}$ ) & $150 \pm 52 g(914)$ & $135 \pm 36 g(308)$ \\
\hline
\end{tabular}

Table 7: Previous studies on left kidney weights. . Notation as for Table 1

\begin{tabular}{|c|c|c|}
\hline Study & Men: $m \pm \sigma(n)$ & Women: $m \pm \sigma(n)$ \\
\hline French (de la Grandmaison ${ }^{10}$ ) & $156 \pm 87 g(355)$ & $140 \pm 78 g(329)$ \\
\hline Korean $\left(\mathrm{Kim}^{26}\right)$ & $115.3 \pm 42.9 \mathrm{~g}(322)$ & $99.5 \pm 43 g(145)$ \\
\hline Thai (Mathuramon ${ }^{7}$ ) & $96 \pm 37 g(453)$ & $82 \pm 36 g(98)$ \\
\hline USA (Molina ${ }^{20,37}$ ) & $139 \pm 58 g(227)$ & $115 \pm 51 \mathrm{~g}(101)$ \\
\hline Iranian (Sheikhazadi ${ }^{5}$ ) & $172 \pm 69 g(914)$ & $167 \pm 68 g(308)$ \\
\hline
\end{tabular}

Table 8: Previous studies on spleen weights. Notation as for Table 1.

\subsection{Factors Influencing Organ Weights}

\subsubsection{Sex}

Organ weights have generally been found to be bigger in males than females, however this is not always the case. ${ }^{10,11,17,20,26}$ Kim's work suggested that heart and spleen weights between the sexes were similar if decedents were matched for age, height, and weight. ${ }^{26}$ This agreed with another study from Jamaica where lung weights between the sexes were similar when matched for height. ${ }^{13}$ Yet another paper reported that after the influence of body surface area was accounted for, sex did not have an additional impact on renal weights. ${ }^{24}$

\subsubsection{Age}

In vivo studies of organ weights in living subjects have been done, using known organ densities and Magnetic Resonance Imaging (MRI) to determine organ volumes. One such study showed significant negative relationships between organ mass and age for the brain, kidneys, liver, and spleen, which are thought to correlate with the functional decline in metabolically active tissue with age. A 
positive relationship for the weight of the heart was found, however this may represent the increased prevalence of cardiac pathology with age. ${ }^{38}$

Post mortem studies concentrating on aged populations confirm the age related decrease in the mass of most organs. ${ }^{10,39}$ Importantly, the authors of the Japanese paper note that organ changes due to geriatric disorders are difficult to distinguish from those due to ordinary physiological changes, making constructing a reference range for the elderly problematic.

The above consideration is especially significant when evaluating heart weights. Most studies involving a range of patient ages have found a decrease in the weight of all organs with age, except for that of the heart, which increases with age. ${ }^{10,26}$ On the other hand, Zeek's research on cardiac weights showed that provided disease is carefully excluded, age does not affect heart weight before 69 years in men and 49 years in women. ${ }^{23}$

The other organ well known to vary with age is the brain. The Iranian study mentioned above, which focussed specifically on brain weights, found a significant negative correlation between age and brain weight in both sexes. ${ }^{6}$ Likewise, the study from Korea showed that of all the organs considered, only the brain showed a statistically significant negative correlation with increasing age. ${ }^{26}$

\subsubsection{Body Weight}

Several studies have found that body weight positively corresponds to organ weight, in particular to that of the heart. ${ }^{10,17,26,27,40}$ For example, Molina found a strong correlation of heart weight to body weight with $\mathrm{R}^{2}$ values of 0.53 and 0.66 for men and women respectively. ${ }^{17,36}$

With respect to the other organs, Molina found that the strongest associations with body weight were for the liver, with $R^{2}$ values of 0.41 and 0.48 , and the combined kidney weights, with $R^{2}$ values of 0.23 and 0.25 for men and women respectively. The other organs showed only weak correlations with body weight, with coefficients of determination of 0.16 and 0.03 for the brain, 0.03 and 0.12 for the spleen, and 0.01 and 0.04 for the combined lung weights, for men and women respectively. ${ }^{20,37}$ 
These echoed de la Grandmaison's findings which reported significant associations of heart, liver, and kidney weights with body weight in both sexes. ${ }^{10}$

\subsubsection{Height}

Many studies show a positive association between heart weight and height. ${ }^{10,17,27}$ Zeek's study showed a definite association, with correlation coefficients of 0.33 and 0.29 for men and women respectively. ${ }^{23}$ On the other hand, Molina's studies could only show a weakly positive correlation with an $\mathrm{R}^{2}=0.13$ for both sexes. ${ }^{17,36}$

Results are likewise mixed for the liver and spleen. de la Grandmaison found that in men, these organ weights were strongly positively correlated with height, whereas Molina found poor positive correlations with $R^{2}$ values of 0.06 and 0.2 for the liver, and 0.07 and 0.11 for the spleen in men and women respectively. ${ }^{10,20,37}$

de la Grandmaison as well as Kim found that the correlation with height was weak or not significant for other organs. ${ }^{10,26}$ These findings agree with Molina who found uniformly weak correlations with height for the brain $\left(R^{2}=0.02\right.$ and 0.09$)$, combined lungs $\left(R^{2}=0.07\right.$ and 0.008$)$ and kidneys $\left(R^{2}=0.06\right.$ and 0.25$)$ for men and women respectively. ${ }^{20,37}$ Once more, in direct contrast to these findings, a study directed at lung weights in Jamaicans found strong correlation coefficients with height of 0.24 and 0.28 for men and women respectively. ${ }^{13}$

\subsubsection{Ethnicity}

The vast majority of studies determining organ weight reference ranges have been based on ethnically homogeneous overseas populations. ${ }^{9,10,20,39}$ All these result in different weight ranges, and no formal meta-analysis of the available research has been published enabling a direct comparison of data from different population groups.

In view of the potential influence of race on organ weights, attention may be drawn to an MRI study which was conducted on living patients in order to investigate known racial differences in resting energy expenditure. ${ }^{41}$ It found that there was a significant racial difference in the mean summed weights of high-metabolic rate organs (liver, heart, spleen, kidneys, and brain). The mean total weight was $3.4 \mathrm{~kg}$ in Caucasians compared to $3.1 \mathrm{~kg}$ in African Americans. 
Other studies in living patients report different results. An in vivo MRI study of organ weights compared Caucasian and African-American subjects and found no significant differences, although it must be noted that they had a sample size of only 75 people. $^{38}$ A study primarily investigating organ growth algorithms for use in pharmacokinetic modelling found no substantial racial differences between AfricanAmerican and Caucasian subjects. ${ }^{12}$ Furthermore, guidelines used in radiological protection indicate minimal variability in organ weights in different ethnic populations. $^{42}$

Turning to post-mortem research, a small study in the USA compared 'Black and White' organ weights, and did not find significant differences. ${ }^{12}$ In line with this, several other studies of particular organ weights have failed to show racial differences. A 1985 study in the USA on kidney weights in 357 individuals found that race had no additional impact on renal weight once body build was taken into account. $^{24}$ The study population here was $76 \%$ White, $21 \%$ Black, and $3 \%$ Native American. Zeek's study on heart weights compared similar numbers of hearts from White and Negroid decedents and found no differences after controlling for height and age. ${ }^{23}$ In another setting, research on post-mortem lung weights in Jamaicans of African extraction was later compared by the same authors to lung weights of a White population in London. ${ }^{13,25}$ Similar clinical and histological exclusion criteria were used and the mean lung weights found were similar, although those from the African population were consistently slightly less.

The single published study on organ weights from a population of Sub-Saharan African decedents dealt only with renal weights in Negroid Africans, consequently not allowing ethnic comparisons to be made. ${ }^{14}$

Accordingly, to date studies investigating racial differences in organ weights are scarce, small, not representative of the local South African population, and may not even have been conducted on post mortem organs. 


\subsection{Confounding Variables}

\subsubsection{Autolysis and Decomposition}

Autolytic changes associated with a delay in autopsy could logically affect organ weight due to fluid shifts in the body. Experiments in rats have shown that increases in the weights of the lungs, heart, cerebellum, and kidneys occur as early as 3 hours after death. ${ }^{43}$ In humans, one large study on infant organ weights found that only the right lung weight is affected by a prolonged post-mortem interval. ${ }^{44}$ Previous investigators in the studies reviewed have used a variety of post-mortem intervals, all apparently arbitrarily selected. . $10,17,20$

\subsubsection{Effect of Blood Volume}

It is reasonable that organs congested with blood would weigh more, while those in a case of exsanguination would weigh less. This may be particularly so in the case of the spleen, which stores a pool of red cells, releasing up to $50 \mathrm{ml}$ in times of stress. ${ }^{45}$ However, varied results have been found in empirical research. An old study from 1933 found that patients dying of massive haemorrhage had lower liver and spleen weights, ${ }^{19}$ while another paper from 1974 reported no effect of exsanguination on their liver or spleen weights ${ }^{46}$.

More recently, Molina's work has shown results that vary with sex and the organ in question. ${ }^{17,20,36,37}$ They described that in men, congestion only increases the weights of the spleen, kidneys, and lungs; the brain, heart, and liver are unaffected. In women, congestion was found to increase the weights of the kidneys and lungs only. Male patients who experienced exsanguination (defined as $>1 \mathrm{~L}$ blood loss) had significantly decreased weights of their lungs, liver, and spleen; the brain, heart, and kidneys were unaffected. ${ }^{17}$ In women, exsanguination decreased the weights of the lungs only.

\subsubsection{Substance Misuse}

Abuse of illegal drugs is common in the Western Cape, and is related to violent death. ${ }^{47}$ A recent study at Salt River Mortuary found that of 104 violent deaths, $60.6 \%$ were positive for substances including methamphetamine, methaqualone, cannabis, heroin, and cocaine. ${ }^{47}$ Methamphetamine use is related to heavy hearts at autopsy, cardiomyopathy, and premature coronary artery disease. ${ }^{48}$ Cocaine is 
another substance with a well-known association with cardiovascular pathology. ${ }^{49}$ Heavy alcohol use is also related to various cardiac changes, including hypertrophy, dilation, and fibrosis. It may also lead to hypertension, which can in turn cause enlargement of the heart. ${ }^{50}$

A study addressing organ weight disparities in chronic drug and alcohol users at forensic autopsy found that alcoholism positively correlated with heart and liver enlargement, as well as spleen enlargement in females. ${ }^{51}$ Chronic drug use was associated with splenomegaly in men. However, they do not comment on whether these organs appeared macroscopically abnormal at autopsy, for example if the heart appeared dilated and floppy, and the liver fatty.

\subsubsection{Disease and Agonall Pathological Changes}

Gross organ pathologies may be incidental and chronic, for instance left ventricular hypertrophy, fatty liver disease, or benign nephrosclerosis.

Alternatively, pathological conditions that could affect organ weight can occur as terminal medical consequences in an injured patient during prolonged survival in hospital. Examples are pneumonia after a fall in an elderly person, Adult Respiratory Distress Syndrome in a polytrauma patient, and cerebral oedema after a head injury. ${ }^{52}$

Causes of unnatural death other than sudden traumatic injuries, such as poisoning, strangulation and hanging, are often associated with organ infiltrates, congestion, hypertrophy, or necrosis, which logically could affect organ weight. ${ }^{53}$

Finally, a degree of cardiac decompensation with its associated decreased venous return and passive organ congestion, is almost ubiquitous in every death. ${ }^{53,54}$ These too may affect organ weight. 


\section{Methods}

\subsection{Research Procedure}

\subsubsection{Study Design and Population}

This study involved a retrospective review of autopsy reports. The population considered was adults dying of traumatic causes at the scenes of incident, without macroscopic organ pathology or extensive organ injury. These cases were drawn from the Salt River medico-legal mortuary records, located at the University of Cape Town (UCT) Faculty of Health Sciences, from 11/02/2013 to 11/08/2016.

\subsubsection{Sampling}

Within the study population there are 12 subgroups formed by the combinations of sex (male; female), race (African; Coloured; White) and age (18-49; $\geq 50$ years). Disproportionate randomized stratified sampling was used in an attempt to ensure sufficient data points to adequately represent each subgroup. This was necessary given the overwhelming majority of traumatic deaths in young African and Coloured males.

The statistical package STATA ${ }^{\circledR}-13$ (StataCorp, USA) was utilized for power calculations. Computations yielded the sample sizes needed to detect a difference in the mean organ weights in our study compared to those reported in the reference statistics, chosen from Molina's recent papers. ${ }^{17,20,36,37}$ The mean organ weights and standard deviations obtained by them for each organ were used; additional criteria were setting $\alpha=0.05$; Power $=0.9$, and a $10 \%$ difference detection level for all organs except the spleen. The spleen was set at $15 \%$ due to its marked interindividual variability. This yielded required sample sizes of 33 and 50 cases (heart), 56 and 12 (brain), 46 and 71 (liver), 83 and 94 (spleen), 137 and 140 (right lung), 148 and 163 (left lung), 45 and 68 (right kidney), and 46 and 82 (left kidney) for men and women respectively. 
Due to our excellent source of data, and in order to improve precision, it was decided to exceed these minimum required sample sizes. It was attempted to collect data from up to 200 patients from each of the 12 subgroups.

\subsubsection{Case Selection}

The UCT Division of Forensic Medicine and Toxicology's computerized record database was searched for potentially suitable cases, with certain exclusion criteria able to be screened for at this stage. Thereafter, a random number generator was used to select the cases used in the study. The associated autopsy reports were then drawn, either through physically retrieving the contemporaneous autopsy notes which are archived within the Division, or via the online Forensic Pathology Service record system. The cases thus obtained were then individually reviewed for exclusion criteria. This process was repeated after exclusions until the required sample size was met, or until no more suitable cases could be found. Following this, a data capture tool developed on Microsoft Excel was employed by the investigator to capture and store the data.

\subsubsection{Exclusion Criteria}

A critical sampling objective was to obtain cases consistent with our study population definition, and this reflects in the exclusion criteria. Before presenting the list, a few of these are discussed for clarity.

In addressing potential confounding factors, a first step was to ensure that all pathologists follow the same procedure at autopsy regarding prosection technique, method of organ trimming, and timing of dissection (before or after organ weighing). A standardized method, attached as Appendix A, was communicated by email to ascertain this with the doctors involved, prior to case selection. This was important to minimize inter-observer variability, with the single-site nature of the study further minimising procedural inconsistencies.

In terms of race, by design the sample subgroups only made provision for African, White, and Coloured decedents. Very few cases at Salt River Mortuary are identified as 'Indian' or 'Asian' and it was thought that not enough would have been collected from this subgroup to enable valid comparisons to be made. Thus, this population was ignored for the purposes of this study. 
When considering post-mortem interval, we recognise that grossly visible autolysis and decomposition could affect organ weight. However, the issues around tissue degradation notwithstanding, the majority of autopsies at our centre occur approximately 3 days after death certification. This is therefore a valid interval during which to establish organ weights useful to our setting.

Pathologist opinion of the macroscopic organ appearance was relied on to differentiate healthy from diseased organs. Additionally, we forestalled a possible source of this confounder by excluding natural deaths, hangings, and poisoning deaths. Deaths at a medical centre were also disregarded, where there may have been time for the development of medical consequences of trauma that could affect organ weights. Likewise, in the lungs, the degree of terminal pulmonary oedema or congestion is logically affected by the survival period after the fatal injury.

On the other hand, it could be argued that the common autopsy findings of mild 'congestion' or 'oedema' are part of the normal post mortem organ state, representing terminal cardiac failure or post-mortem lividity. In this study, weights of lungs were still accepted for which a comment in the autopsy report indicated that they showed posterior congestion.

The exclusion criteria applied in this study were:

'Unknown' decedents whose ages were not certain.

$\sim$ Deceased's age $<18$ years.

Autopsy performed by pathologist who does not routinely dissect and weigh organs according to the specified method (see Appendix A).

Deceased's race documented as 'Indian' or 'Asian'.

$\sim$ Signs of autolysis or decomposition of the organs.

$\sim$ Greater than 3 days between date of death certification and date of autopsy. 
Cause of death anything other than sharp force trauma, blunt force trauma, or gunshot wounds.

$\sim$ Death certified at a medical centre.

Macroscopic pathological organ changes due to incidental disease or congestion/oedema, except in the lungs where 'posterior congestion' was accepted.

$\sim$ Organ injury resulting in tissue loss or pulping/mincing of tissue.

If a specific organ was excluded, the rest of that deceased's organ weights were still screened for data collection. One pathologist does not routinely measure individual kidney weights, but rather enters a combined weight. In this case the kidney weights were excluded, however the other organ weights recorded were still considered for inclusion.

\subsubsection{Data Collection}

Organ weights collected for this study were those of the brain, heart, right and left lungs, spleen, liver and right and left kidneys. Individual weights of the paired organs were recorded.

Independent variables considered were: sex, age, race (African, Coloured, White), body weight (measured clothed if that is how the decedent presented), height, cause of death and manner of death, as judged at the time of autopsy.

In addition to any other incidental pathologies identified, data on the numbers of exclusions due to specific organ pathologies were collected. In this way, all individual organ weights allocated for collection were accounted for. These specific organ exclusions were: brain swelling, brain evisceration, cardiac dilation or left ventricular hypertrophy (defined here as left ventricular thickness of $>15 \mathrm{~mm}$, or a comment that the heart was 'enlarged' or 'hypertrophied'), liver congestion including 'nutmeg' liver, shattered liver, fatty liver, spleen congestion, wrinkled splenic capsule, diffluent spleen, kidney congestion, granular kidneys, congenital kidney abnormalities, pulmonary tuberculosis (TB), lung collapse, lung congestion, lung oedema, or blood aspiration. 


\subsection{Data Management}

\subsubsection{Data Cleaning}

Accuracy of transcription was tested by rechecking $5 \%$ of the cases. These cases were randomly selected for quality assurance which also included adherence to exclusion criteria. Furthermore, individual 'outlying' data points were reviewed for accurate transcription and adherence to exclusion criteria. Several instances of inconsistencies were found where the height and weight of the decedent were switched around, which may have been due to pathologists recording them in different orders. The entire data set was then screened for this mistake, which was easily detected by the implausible BMI values generated.

\subsubsection{Statistical Analysis}

Sample statistics were generated using STATA ${ }^{\circledR}-13$, which yielded descriptive and inferential output. Multiple linear regression models for each organ were built, after suitable transformation of skewed distributions and assumption checking. The veracity of predictions was tested and formulae for predicted ranges established. All statistical calculations and analyses were personally performed by the author.

\subsection{Technical Issues}

Bodies were stored in fridges at $4^{\circ} \mathrm{C}$ prior to autopsy. They were eviscerated using a modification of the en bloc Ghon method, and individual organs dissected as per Appendix A. $^{55}$

Cases prior to $11 / 02 / 2013$ could not be used as this was when the mortuary scales were replaced; before this various models were used and none was calibrated. The new bench instruments, used for weighing organs at autopsy, are Micro T7E scales, with a resolution of $1 \mathrm{~g}$. The new body instrument is a Sasco WP003 scale, with a resolution of $0.5 \mathrm{~kg}$. These scales were calibrated at the mortuary on purchase and installation, and recalibration was requested on 31/03/2016. Calibration certificates are attached as Appendix B. It was found that the bench scales are accurate with an uncertainty of measurement of $1-4 \mathrm{~g}$ ( $95 \%$ confidence interval) while the body 
scale is accurate with an uncertainty of measurement of $200 \mathrm{~g}$ (95\% confidence interval).

\subsection{Ethics}

The mortuary database is a registered research repository with UCT HREC (Human Research Ethics Committee) number R036/2014. Additionally, this study was independently granted HREC approval, with number 164/2016. The ethics approval letter is attached as Appendix C. In accordance with this, informed consent was not requested from the family members of the decedents in this retrospective survey of routinely gathered, non-sensitive data.

Privacy and confidentiality were important in the conduct of this study. Data were collected against the deceased's Salt River Mortuary reference number. This is in the form WC/11/0000/20YY. It is already abstracted from the deceased's name, which was not recorded at all. The data have not been published on an individual basis, but rather statistics presented for each patient subgroup considered. Research data were stored electronically in the file hosting service Dropbox, which is password protected, and backed up on an external hard drive which was securely stored off site.

\subsubsection{Racial Classification}

It is understood that race is used as a categorical variable, when in reality racially associated gene variations are continuously distributed, particularly within our ethnically heterogenous South African population. However, there are several examples in medicine of phenotypic differences that are associated with the arbitrary racial classification used in our autopsy reports. For example, anthropomorphic bone identification and response to particular anti-hypertensive medications. . $^{56-58}$

The racial classification of decedents in this study was taken from the pathologists' autopsy reports. It is based on personal observations as well as the racial group indicated on the forms provided by FPS. These forms are completed by the Forensic Pathology Officers who collect the bodies and assist family members with formal identification. An anonymised form is attached as Appendix D. 
Racial classification is used pragmatically as part of the general identifying features of the deceased, together with gender and age. This general description is valuable from a legal standpoint in helping to ensure that the correct body is autopsied. Along with other factors, it also contributes to establishing a presumptive identity before family members are requested to come to make a formal identification. Thus, racial classification is a combination of visual clues as to racial characteristics as well as the cultural and ethnic self-identity of the decedent's family. 


\section{Results}

\subsection{Decedents Sampled}

\subsubsection{Case inclusions}

In several of the subgroups fewer than 200 cases fulfilled our requirements after applying the exclusion criteria. This yielded a total sample size of 1262 decedents. Of these, $865(69 \%)$ were male and $397(31 \%)$ were female. The sample consisted of $516(41 \%)$ African, 500 (40\%) Coloured, and $246(19 \%)$ White individuals. 780 $(62 \%)$ were between the ages of 18 and 49 years, and $482(38 \%)$ were 50 years or older. The figure below gives a more detailed breakdown of the number of cases in each sample subgroup. Despite the disproportionate randomized stratified sampling technique used, this preponderance of males, younger age category, and African and Coloured decedents reflects the demographics of the source population at Salt River Mortuary. The numbers of older females that could be included was low because so many died in hospital; likewise, many younger White females were excluded due to hanging or overdose deaths.

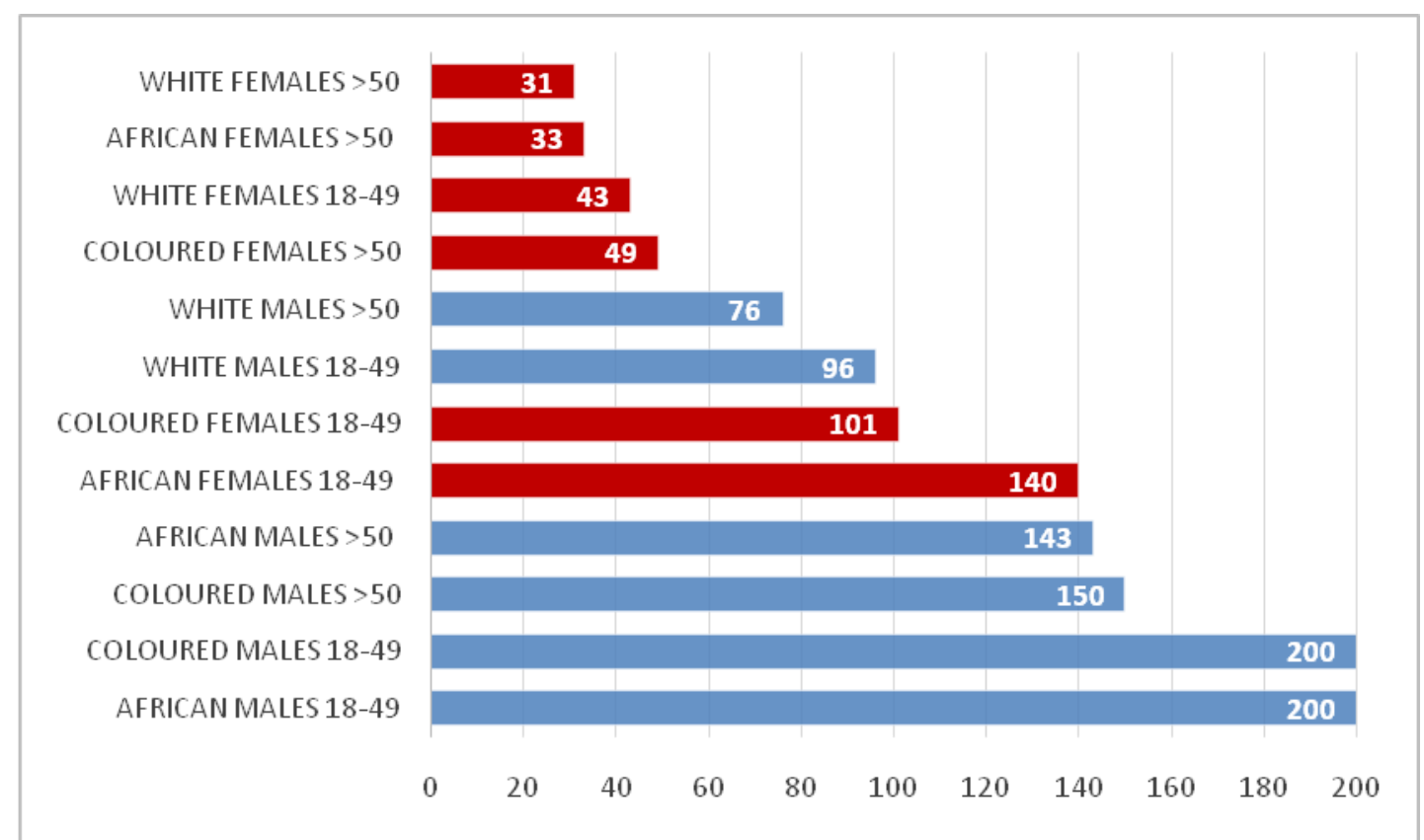

Figure 1: Number of patients of each sample subgroup included in the study. Age in years. Females in red; males in blue. 


\subsubsection{Causes of Death}

The absolute numbers and relative proportions of the various causes of death in the different sample subgroups are demonstrated in Figure 2. Figure 3 below further delineates the specific causes of blunt force trauma sustained by the decedents in this study.

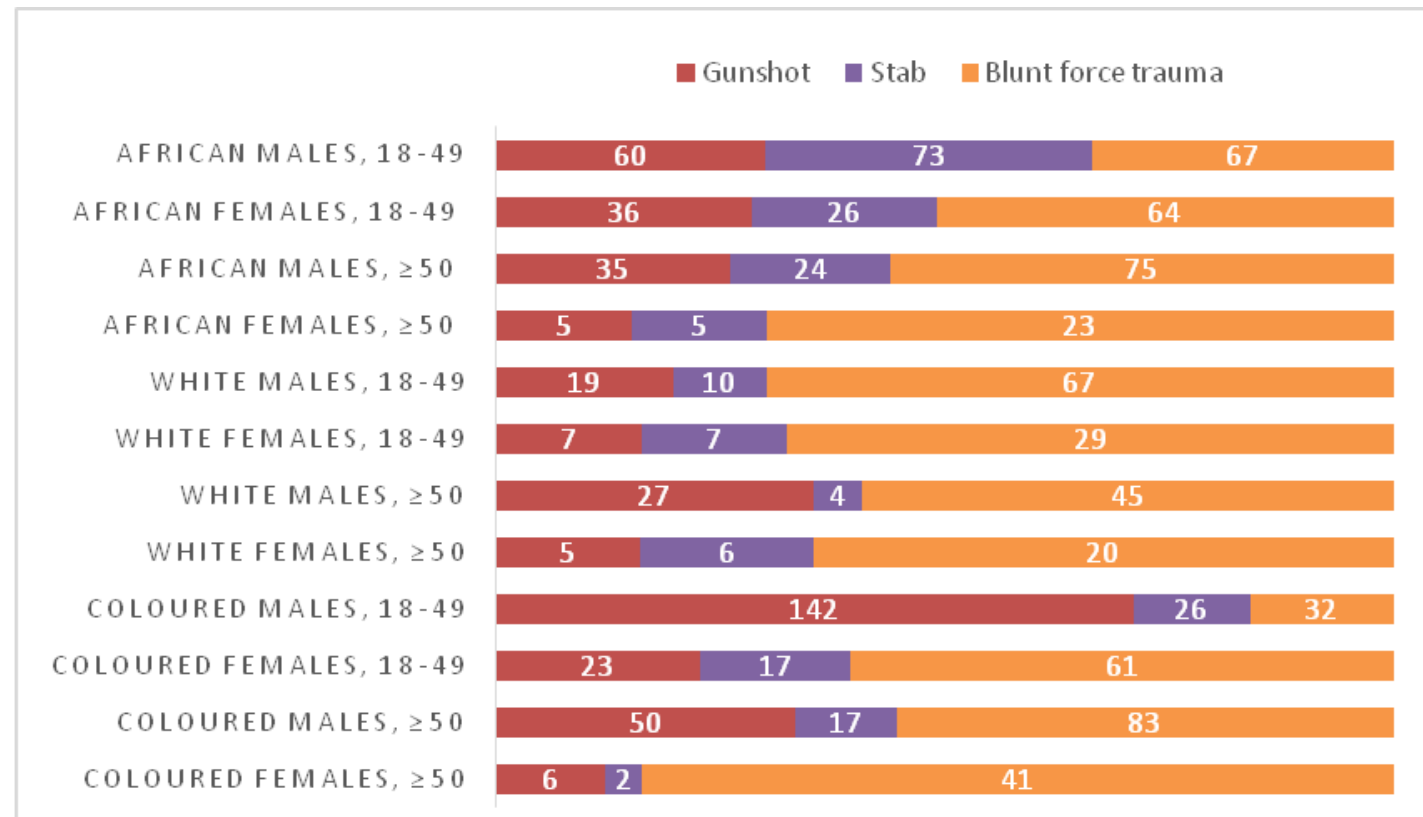

Figure 2: Cause of death per subgroup. Age in years. 'Stab' includes incised wounds.

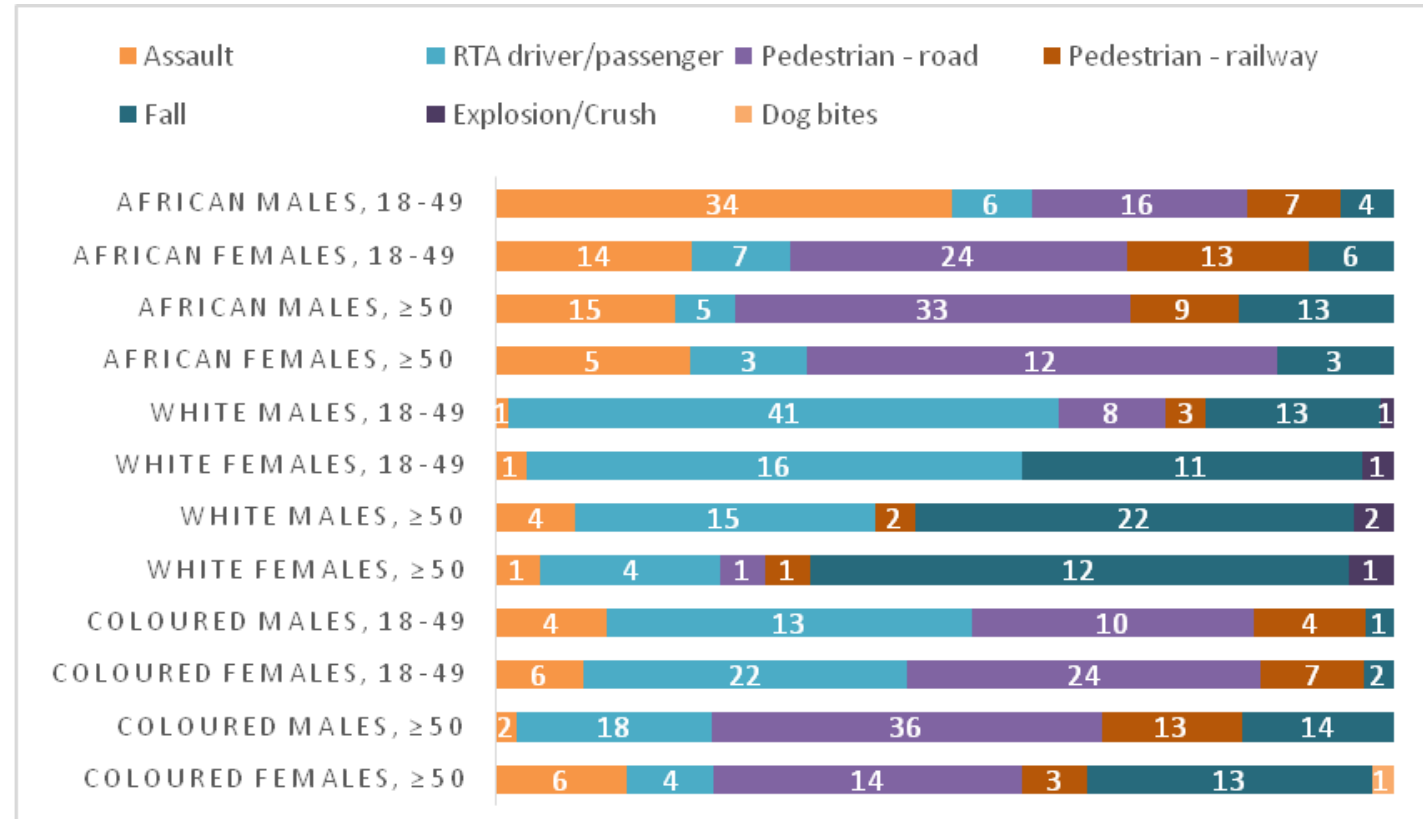

Figure 3: Type of blunt force trauma per subgroup. Age in years. RTA = Road traffic accident. ‘RTA - driver/passenger' includes bicyclists and motorcyclists; 'Fall’ includes jumps. 
The majority of deaths were due to blunt force trauma. Compared to other subgroups, this proportion is particularly high in older Coloured females, mostly due to pedestrian vehicle accidents and falls. Assaults are more common among all African decedents, especially the younger males. Motor vehicle accidents where the decedent was a driver or passenger stand out in younger White decedents while falls and jumps are more common in their older counterparts. On the other hand, there is a notable exception in younger Coloured males, most of whom incurred gunshot wounds.

\subsubsection{Manners of Death}

Figure 4 shows the presumed manners of death at the time of autopsy in the sample cases, according to population subgroup. The absolute number of cases is indicated and their relative proportions can be appreciated. It is important to note that this is not to be taken as representative of the distribution of manner of deaths at Salt River mortuary as a whole. In the cases studied many deaths were documented to be murders, especially among the African and Coloured decedents. This is particularly striking in the younger men where gang-related activity is common. Accidental deaths make up a larger proportion of deaths in women and older people. Suicides, in the form of jumping from a height and gunshots, occurred significantly more commonly in the White decedents.

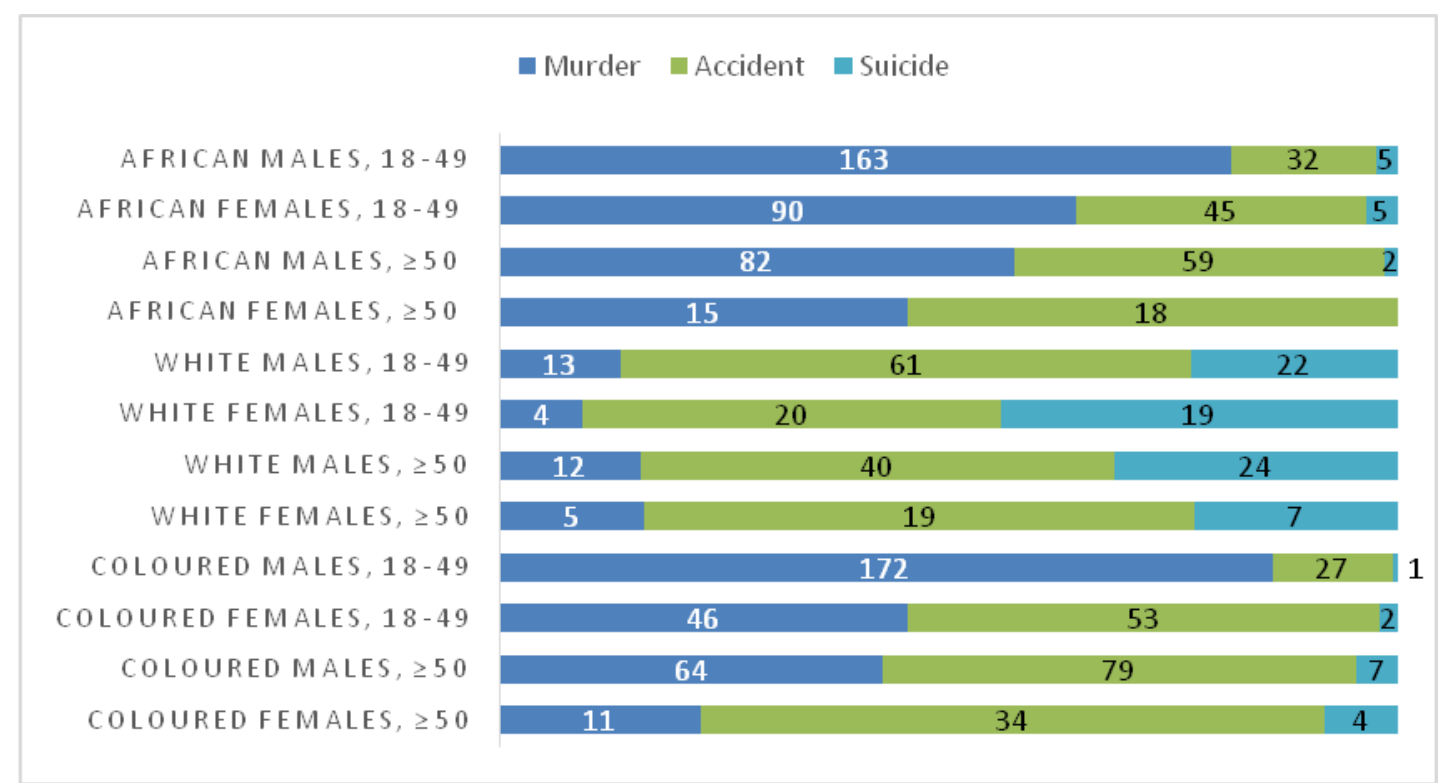

Figure 4: Manner of death per subgroup. Age in years. 


\subsection{Organs Sampled}

\subsubsection{Organ exclusions}

The charts below show the numbers, proportions, and reasons for individual organ exclusions within each sample subgroup. Cases where the combined kidney weight was reported are not included but have been recorded under each figure for completeness.

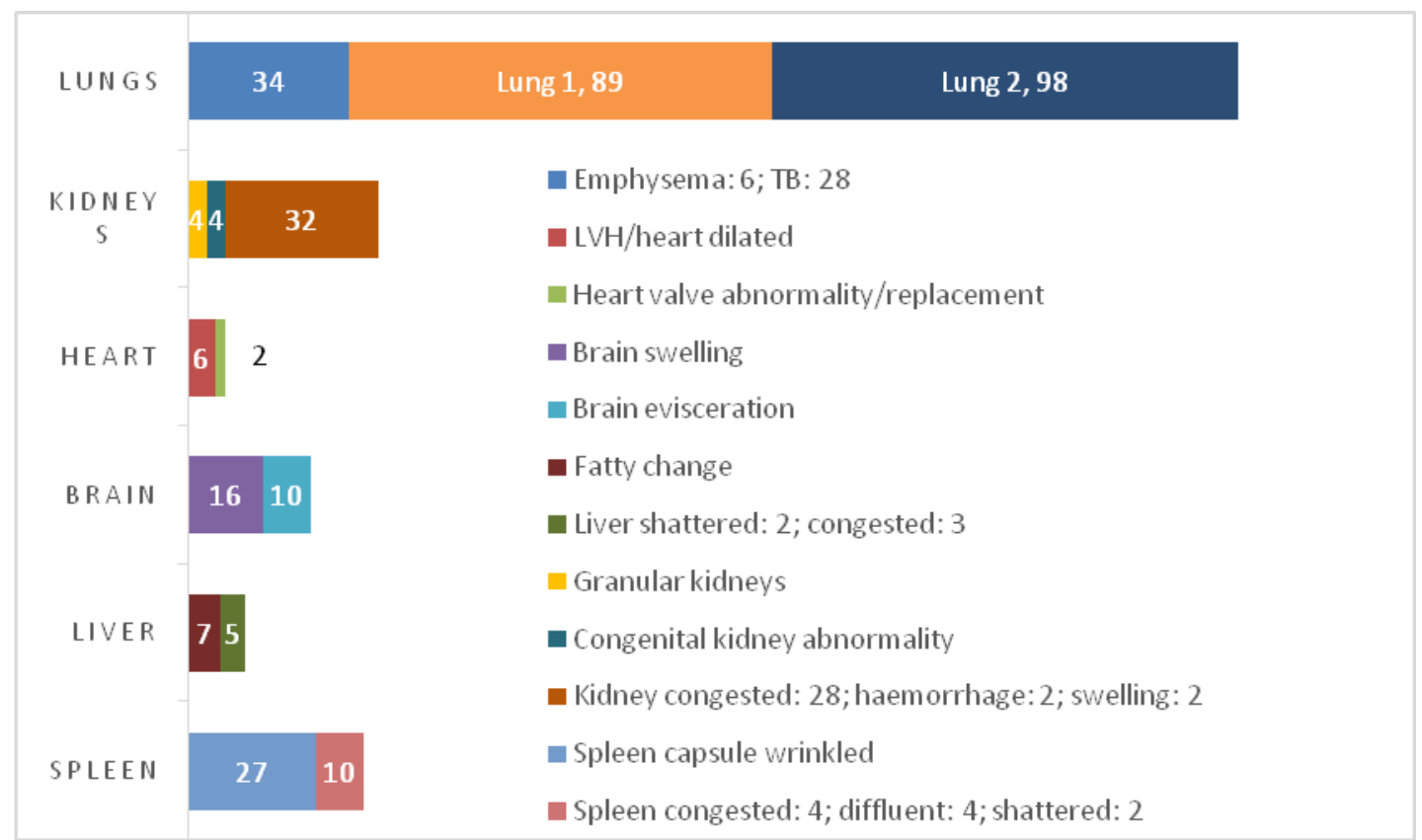

Figure 5: Organ weight exclusions in African males aged 18-49 years. Lung 1 = lung congestion, oedema, parenchymal haemorrhage or blood aspiration. Lung 2 = lung collapse. TB = pulmonary tuberculosis; LVH = left ventricular hypertrophy.

Cause and manner of death is reflected in the large number of lung weight exclusions, where stab wounds to the chest resulted in haemopneumothoraces, which collapsed the organ, as well as intraparenchymal haemorrhage around the stab wound tract. Lung congestion and oedema are commonly associated with terminal cardiac failure, and pulmonary tuberculosis is also frequent. The spleen weights excluded due to capsule wrinkling also reflect haemorrhagic shock. There are few cardiac exclusions and few kidney exclusions due to natural disease in this group. Additionally, 26 kidney weights from the African Males aged 18-49 years were excluded as only the combined weight was documented. 


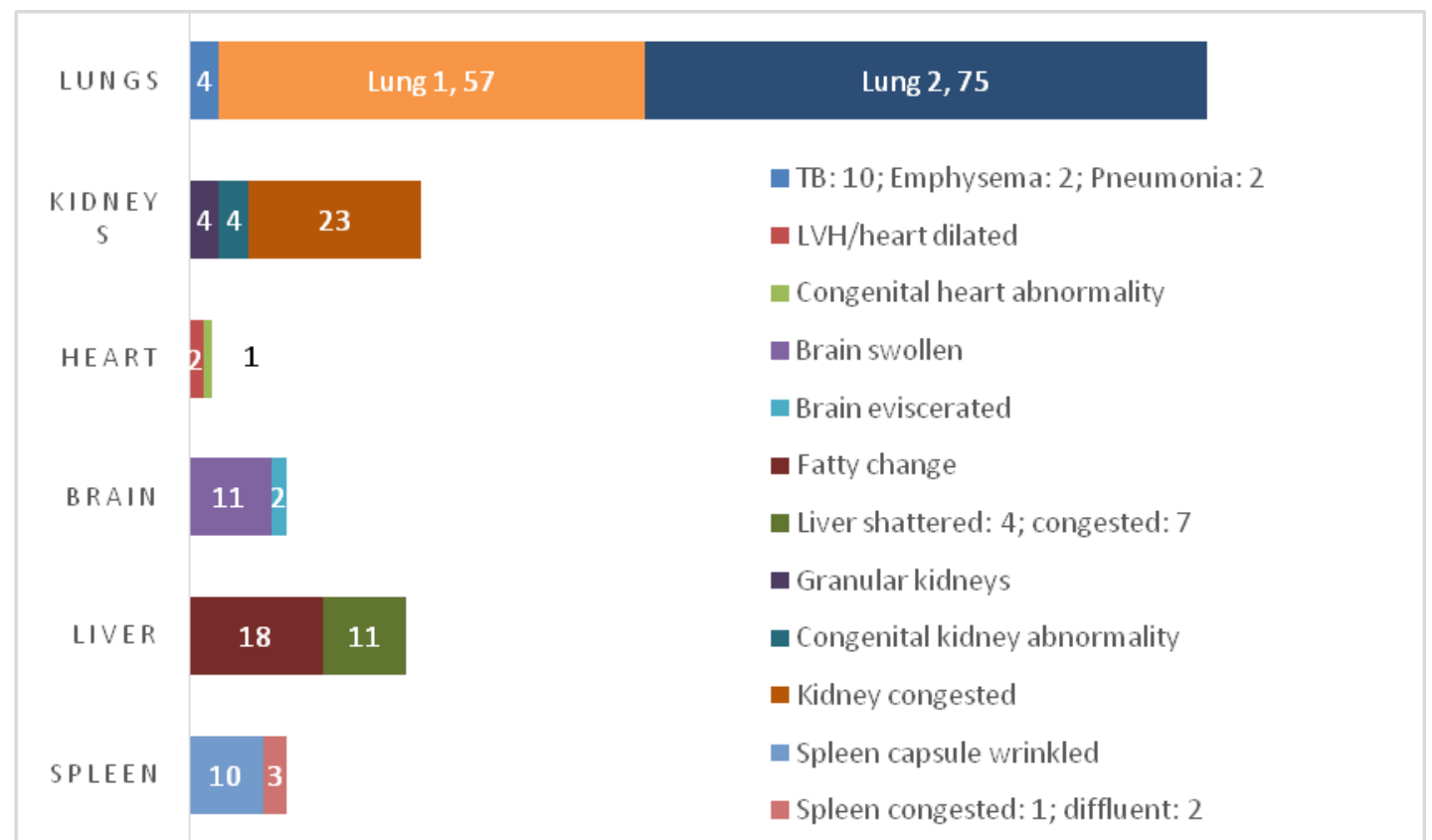

Figure 6: Organ weight exclusions in African females aged 18-49 years. Notation as for Figure 5.

The exclusion patterns in the African Females aged 18-49 years mirrors that of the younger African Males, except that there are more cases of fatty livers, possibly reflecting the higher average $\mathrm{BMI}$ in this group. There are also fewer reported cases of pulmonary tuberculosis. Additionally, the weights of 4 kidneys from this group were excluded as only their combined weights were documented.

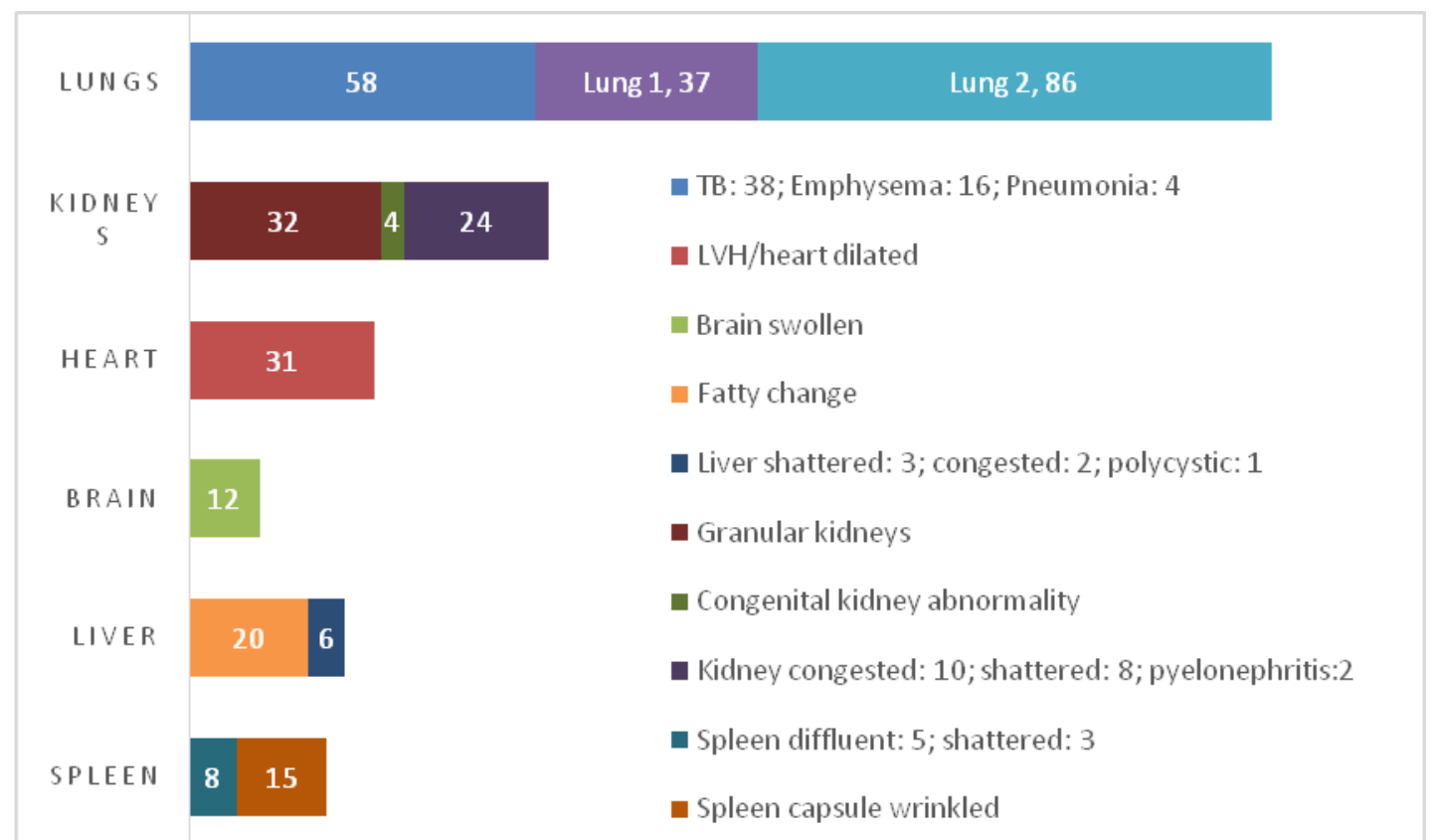

Figure 7: Organ weight exclusions in African males aged 50 years and above. Notation as for Figure 5. 
The organ weight exclusions of the African Males aged 50 years and older reveals the emergence of natural disease with age. Far more lungs were excluded due to tuberculosis and smoking related changes. Cardiac hypertrophy and granular kidneys, reflecting hypertensive changes, were also more common. There were an additional 8 kidneys from this group which were excluded as only the combined weights were documented.

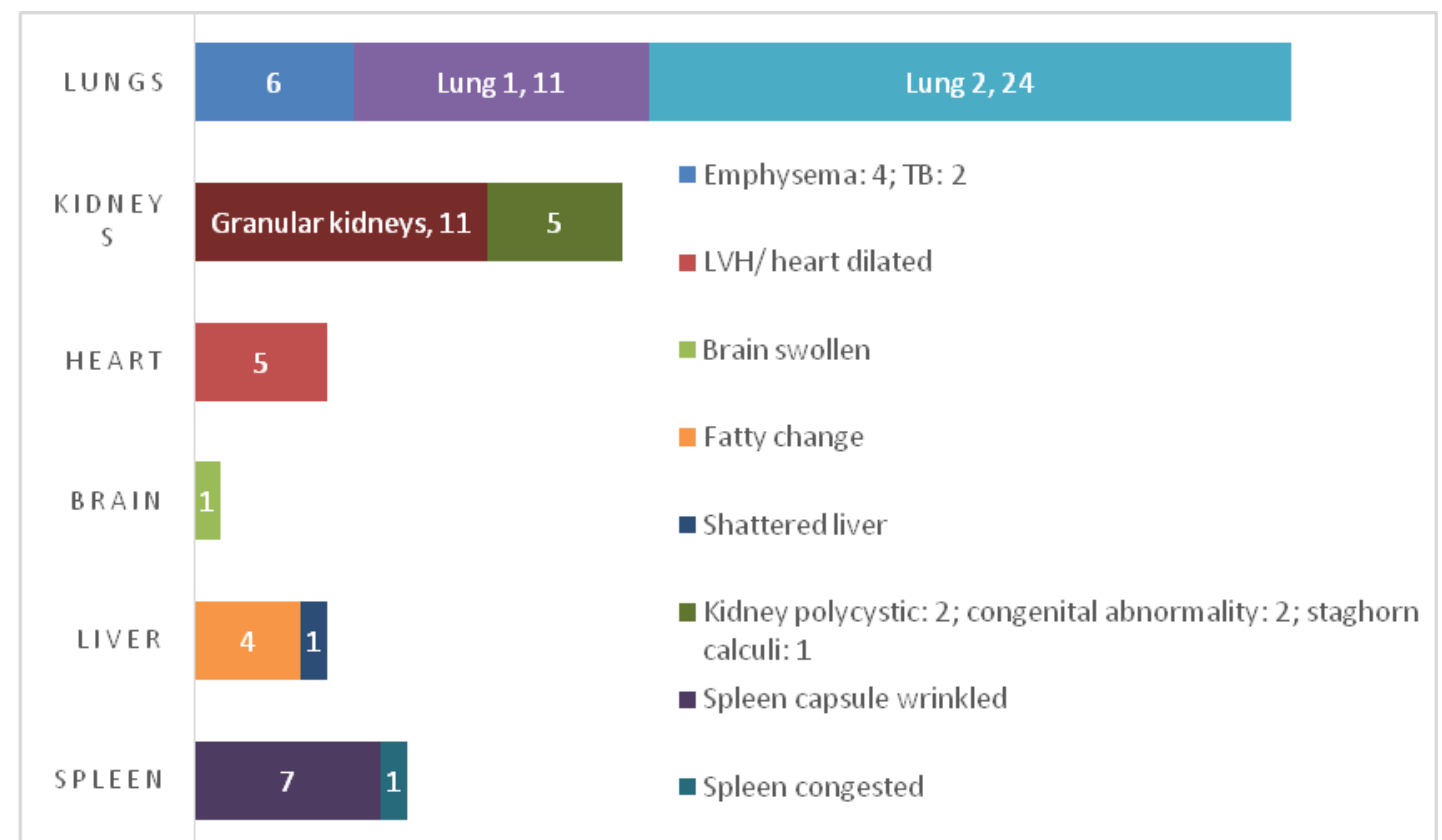

Figure 8: Organ weight exclusions for African females aged 50 years and above. Notation as for Figure 5.

This organ weight exclusion figure for the older African females also shows the rise of cardiac and renal disease with age, as well as an increased number of fatty livers.

Figure 9 below, detailing the organ exclusions in younger White males, shows more left ventricular hypertrophy and cardiac dilation with concomitant granular kidneys than their African counterparts in the same age group. More livers were also found to be fatty in this group.

No additional kidney exclusions were made in the subgroups of African Females aged 50 years and above or White Males aged 18-49 years. 


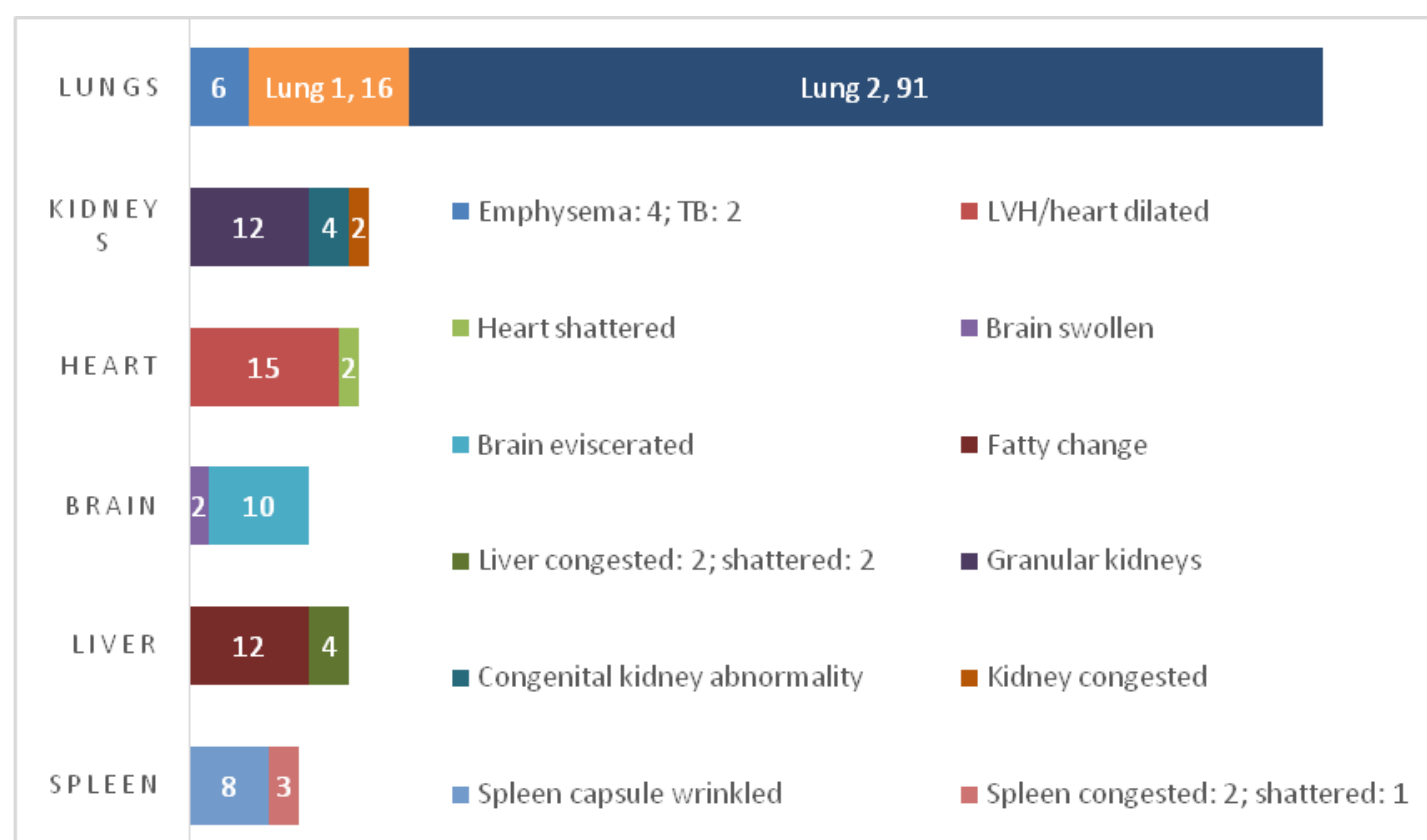

Figure 9: Organ weight exclusions for White males aged 18-49 years. Notation as for Figure 5.

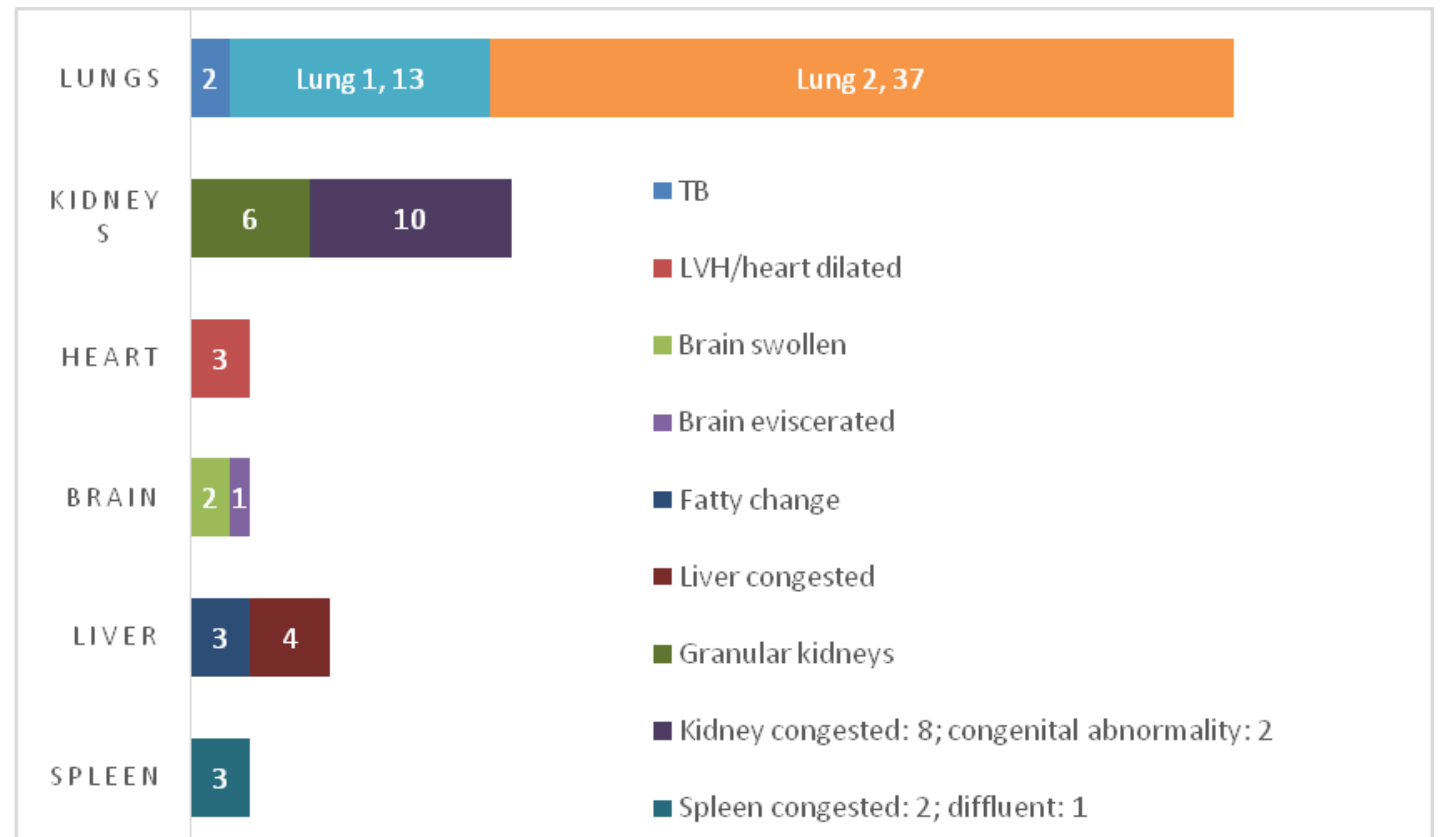

Figure 10: Organ weight exclusions for White females aged 18-49 years. Notation as for Figure 5.

Like the younger White male subgroup, there are more natural cardiac and renal pathologies identified in the White females aged 18-49 years sampled compared to their age and sex matched African counterparts. The weights of 4 kidneys were excluded from the recorded values as only their combined weights were documented. 


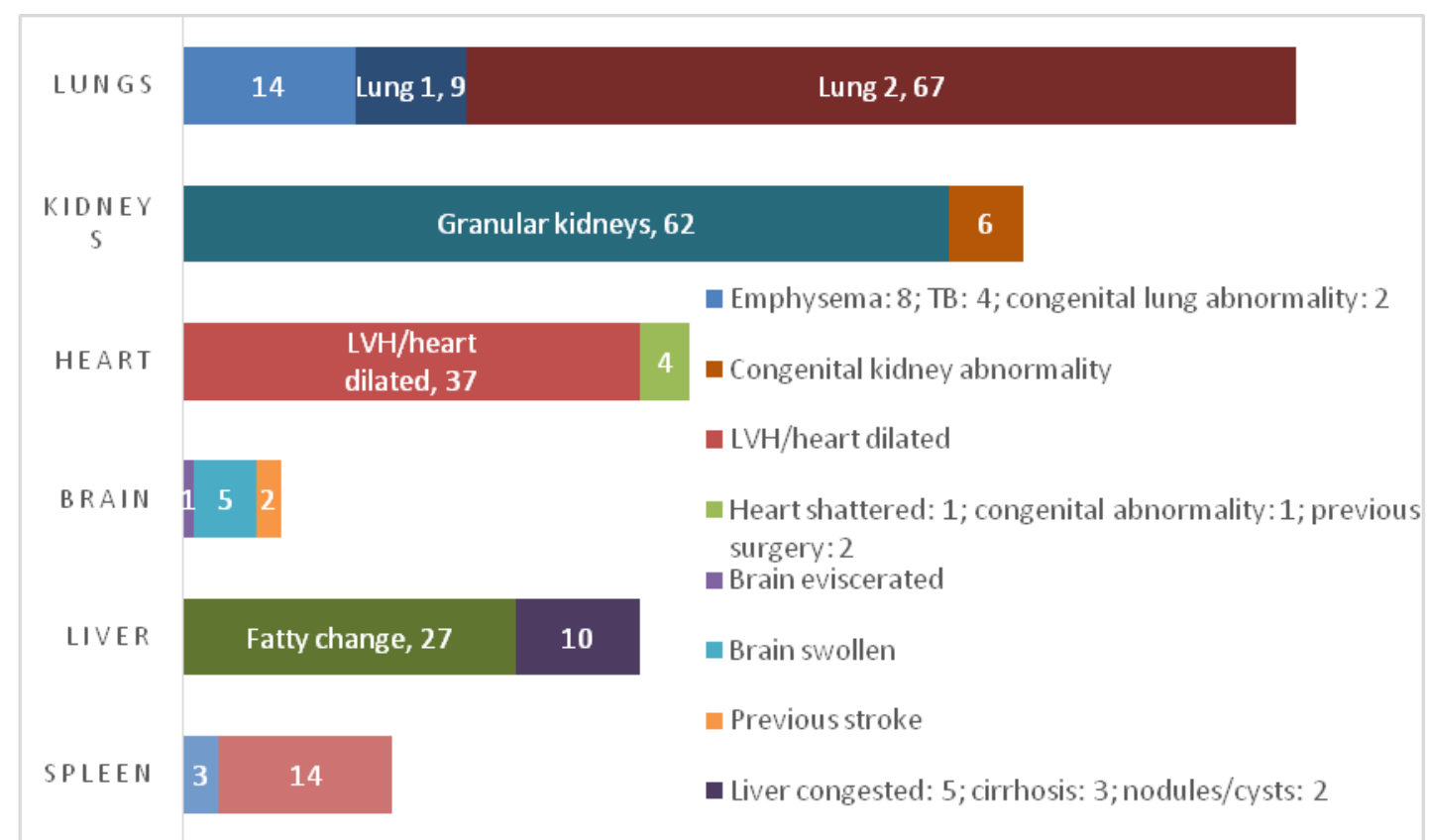

Figure 11: Organ weight exclusions for White males aged 50 years and older. Notation as for Figure 5.

Figures 11 and 12 show a relatively high prevalence of natural pathology involving the lungs, kidneys, heart, and liver in older White decedents. It also reflects in the previous cardiac surgery found in 2 of the male decedents. Additionally, 2 kidneys were excluded from each group as only their combined weight were documented.

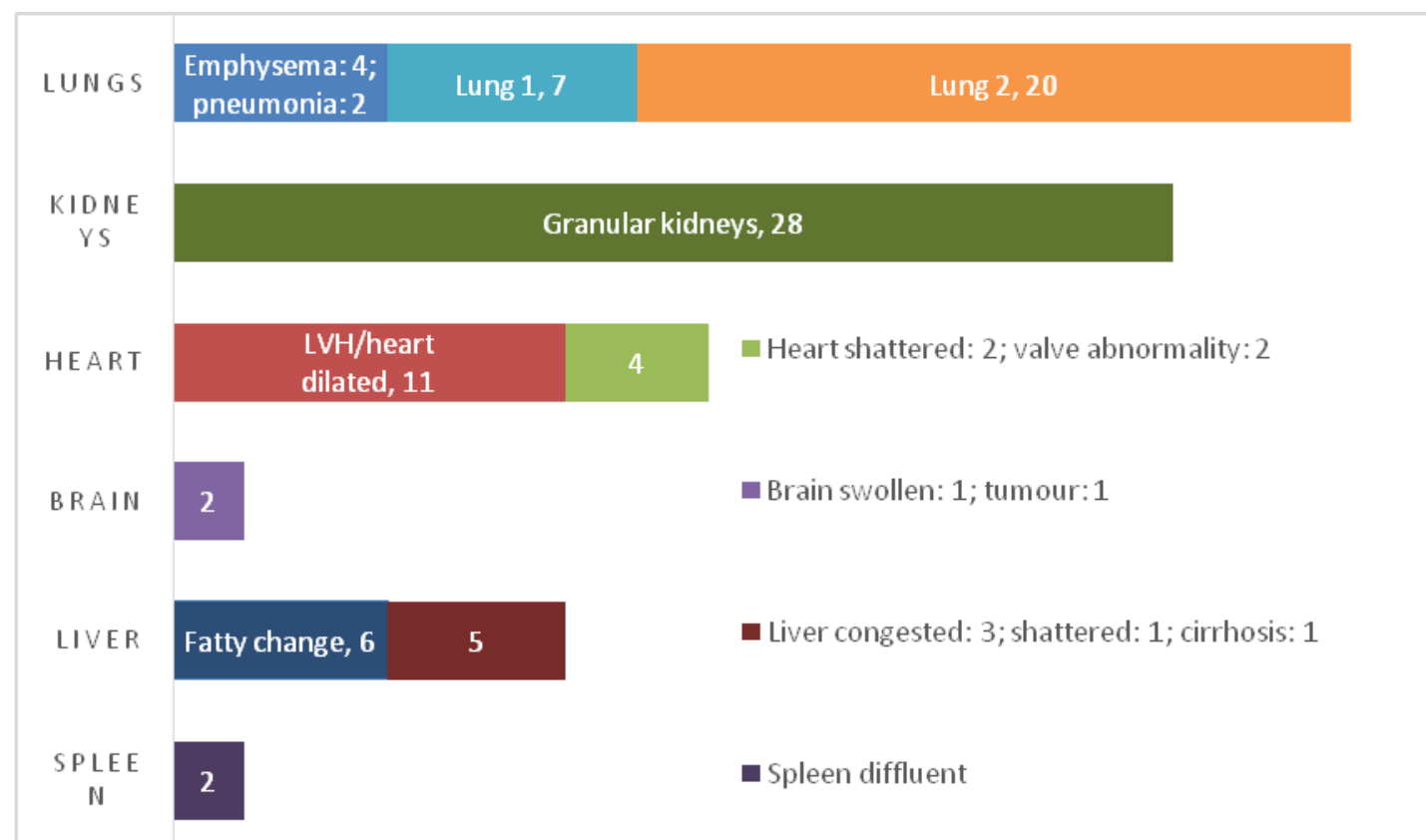

Figure 12: Organ weight exclusions for White females aged 50 years and older. Notation as for Figure 5. 


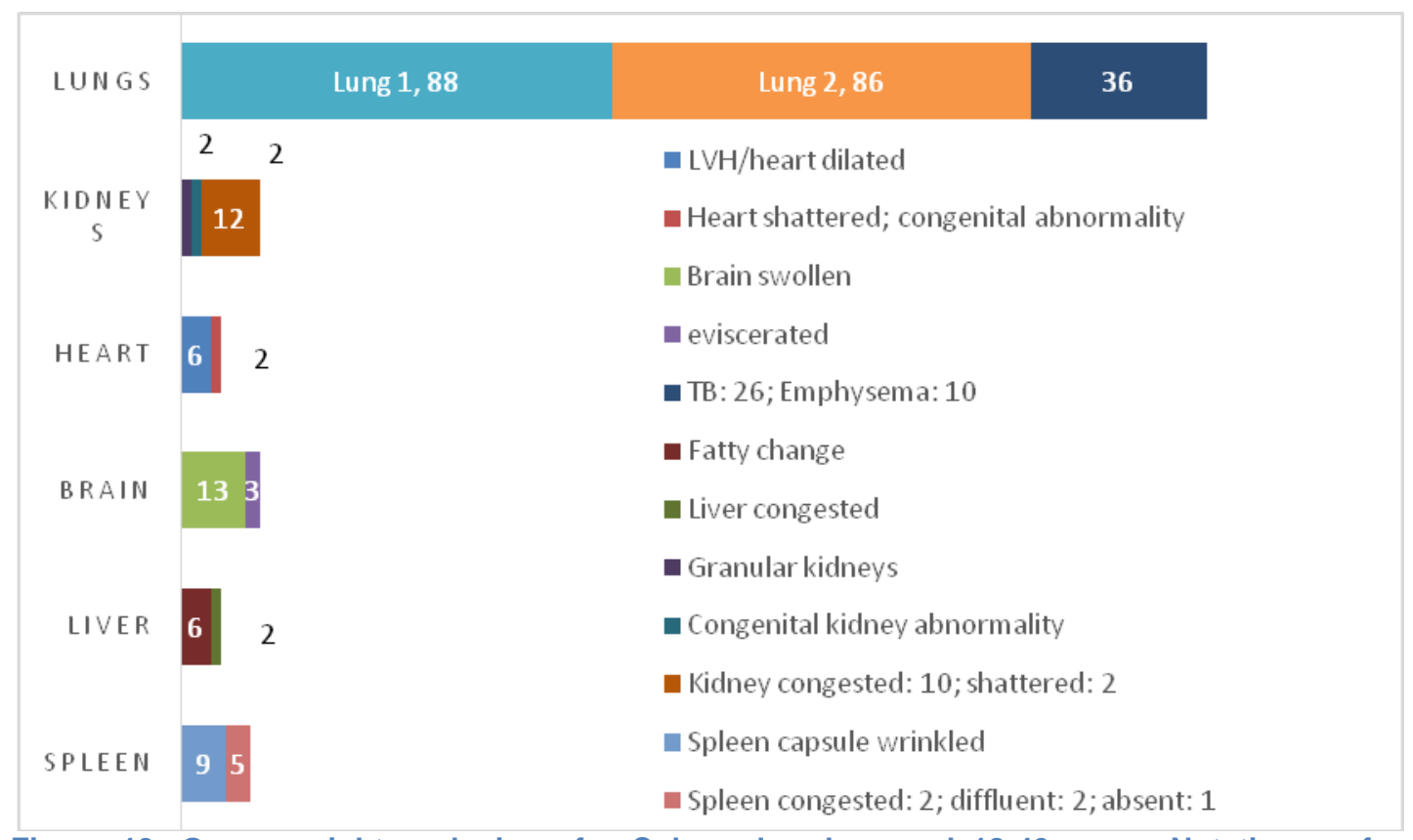

Figure 13: Organ weight exclusions for Coloured males aged 18-49 years. Notation as for Figure 5.

Younger Coloured males (Figure 13) and females (Figure 14) show few age-related diseases, but a significant prevalence of pulmonary tuberculosis. Additionally, the weights of 16 and 12 kidneys respectively were excluded as only combined kidney weights were documented.

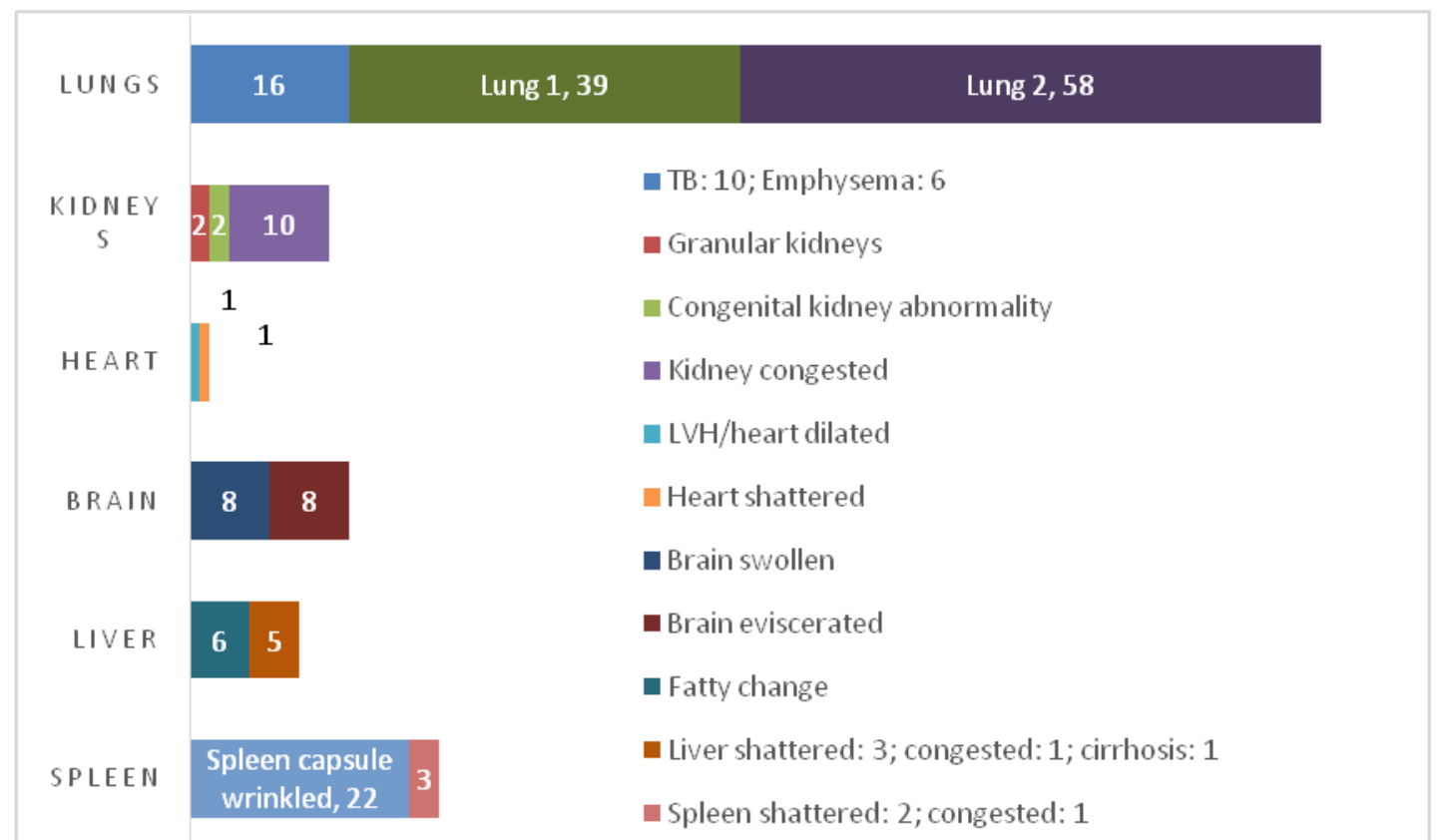

Figure 14: Organ weight exclusions for Coloured females aged 18-49 years. Notation as for Figure 5. 


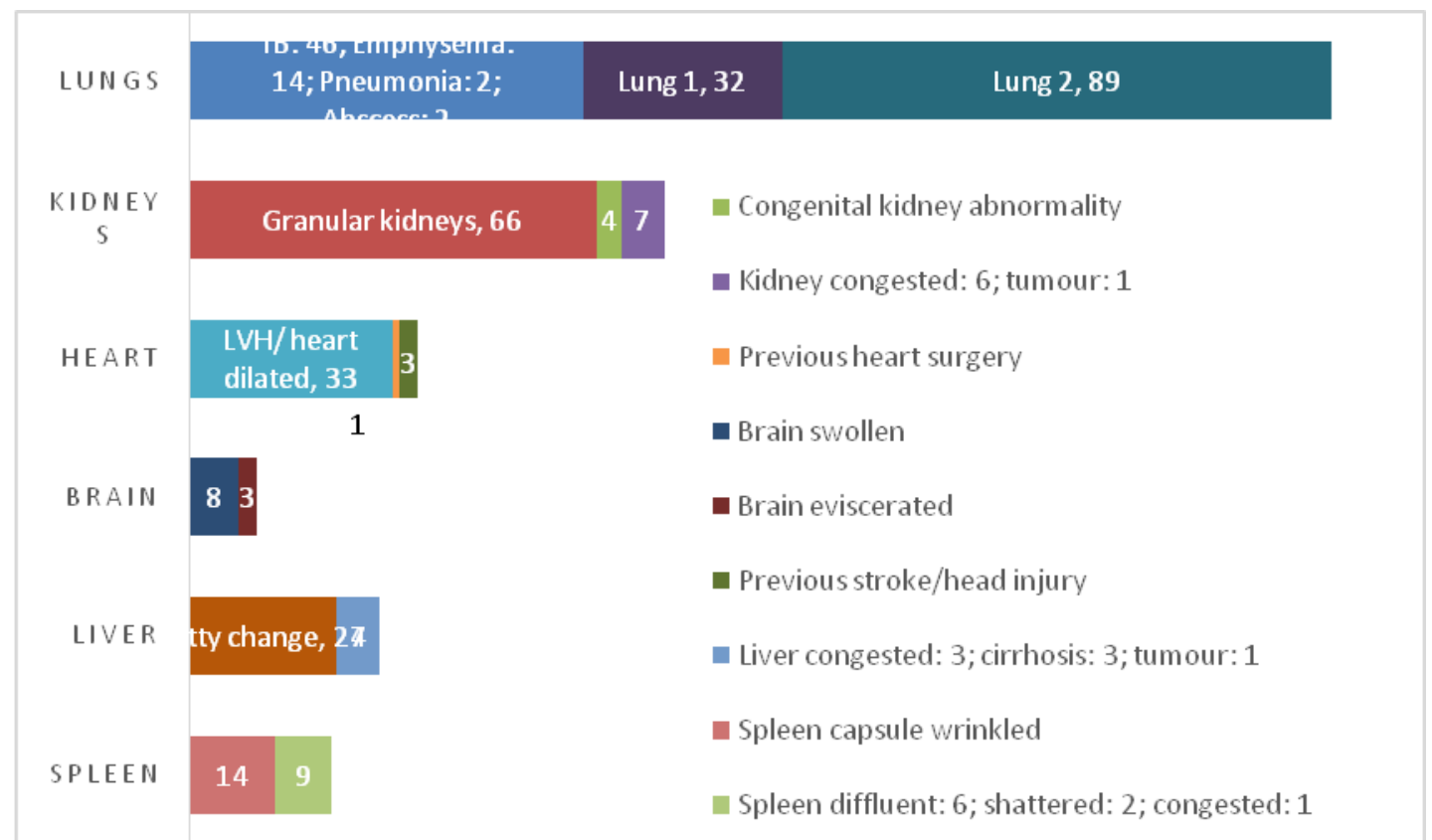

Figure 15: Organ weight exclusions for Coloured males aged 50 years and older. Notation as for Figure 5.

The subgroups of Coloured decedents aged 50 years and older, both male (Figure 15) and female (Figure 16), show an enormous burden of lung pathology, particularly tuberculosis. This in addition to the age-related cardiac and renal pathology expected. Another 22 and 4 kidneys respectively were excluded as only combined weights were given.

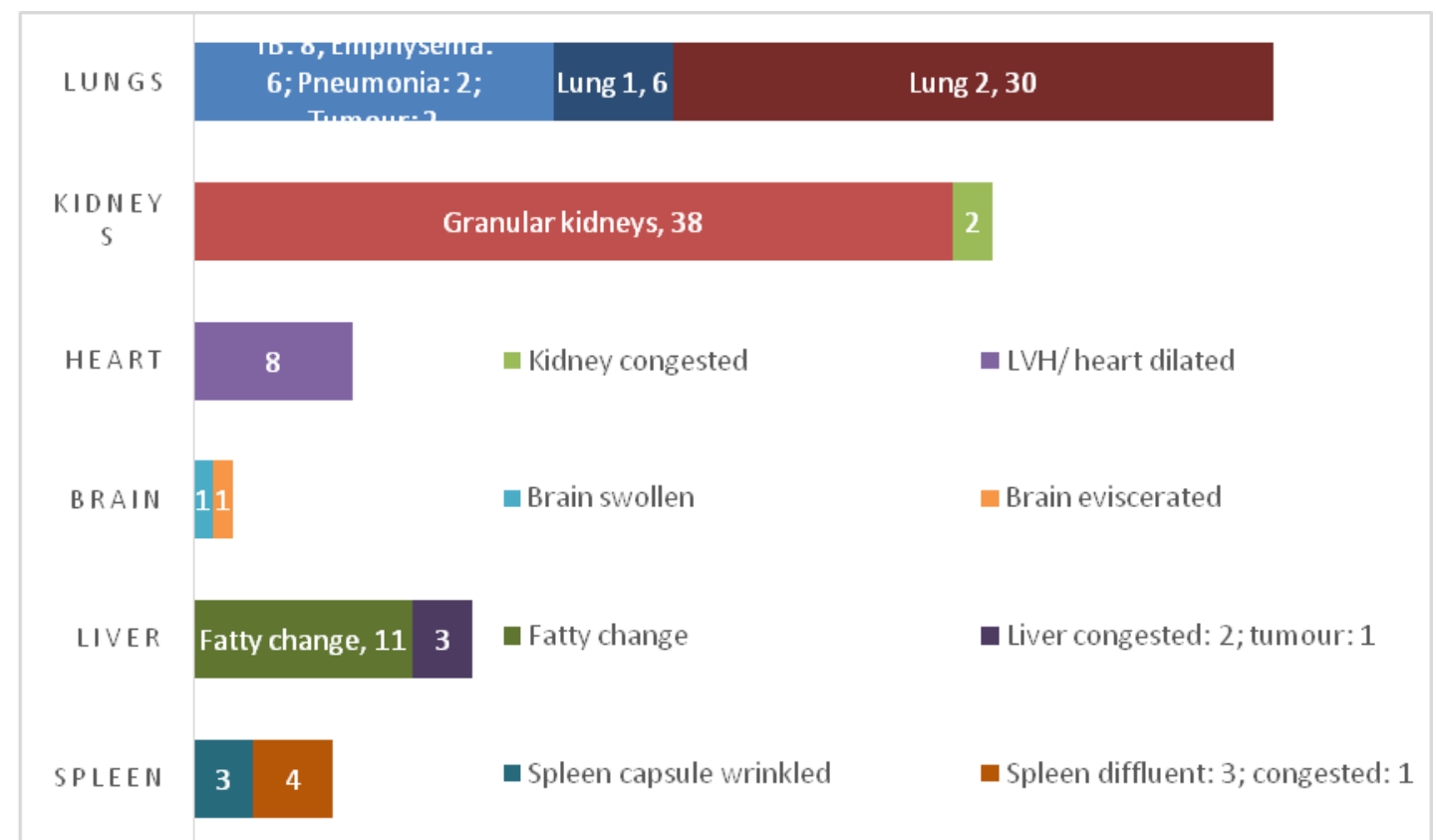

Figure 16: Organ weight exclusions for Coloured Females aged 50 years and older. Notation as for Figure 5. 


\subsubsection{Organ Inclusions}

The table below provides the number of each of the organs considered, after exclusions, that qualified for inclusion into the study.

\begin{tabular}{|l|c|c|c|c|c|c|c|c|c|}
\hline & Brain & $\begin{array}{l}\text { Right } \\
\text { Lung }\end{array}$ & $\begin{array}{l}\text { Left } \\
\text { Lung }\end{array}$ & Heart & Liver & Spleen & $\begin{array}{l}\text { Right } \\
\text { Kidney }\end{array}$ & $\begin{array}{l}\text { Keft } \\
\text { Kidney }\end{array}$ & $\begin{array}{l}\text { Total } \\
\text { Cases }\end{array}$ \\
\hline African Males 18-49 & 174 & 90 & 89 & 192 & 188 & 163 & 168 & 166 & $\mathbf{2 0 0}$ \\
\hline African Females 18-49 & 127 & 69 & 65 & 137 & 111 & 127 & 122 & 123 & $\mathbf{1 4 0}$ \\
\hline African Males $\geq 50$ & 131 & 55 & 50 & 112 & 117 & 120 & 109 & 109 & $\mathbf{1 4 3}$ \\
\hline African Females $\geq 50$ & 32 & 14 & 11 & 27 & 28 & 25 & 25 & 25 & $\mathbf{3 3}$ \\
\hline White Males 18-49 & 84 & 38 & 41 & 79 & 80 & 85 & 87 & 87 & 96 \\
\hline White Females 18-49 & 40 & 17 & 17 & 40 & 36 & 40 & 33 & 33 & $\mathbf{4 3}$ \\
\hline White Males $\geq 50$ & 68 & 32 & 30 & 35 & 39 & 59 & 41 & 41 & $\mathbf{7 6}$ \\
\hline White Females $\geq 50$ & 29 & 15 & 14 & 16 & 20 & 29 & 16 & 16 & $\mathbf{3 1}$ \\
\hline Coloured Males 18-49 & 184 & 103 & 87 & 192 & 192 & 186 & 184 & 184 & $\mathbf{2 0 0}$ \\
\hline Coloured Females 18-49 & 85 & 46 & 43 & 99 & 90 & 76 & 88 & 88 & $\mathbf{1 0 1}$ \\
\hline Coloured Males $\geq 50$ & 136 & 59 & 56 & 116 & 119 & 127 & 101 & 100 & $\mathbf{1 5 0}$ \\
\hline Coloured Females $\geq 50$ & 47 & 22 & 22 & 41 & 35 & 42 & 27 & 27 & $\mathbf{4 9}$ \\
\hline Total Organs & $\mathbf{1 1 3 7}$ & $\mathbf{5 6 0}$ & $\mathbf{5 2 5}$ & $\mathbf{1 0 8 6}$ & $\mathbf{1 0 5 5}$ & $\mathbf{1 0 7 9}$ & $\mathbf{1 0 0 1}$ & $\mathbf{9 9 9}$ & $\mathbf{1 2 6 2}$ \\
\hline
\end{tabular}

Table 7: Number of organ weights collected for each organ, per population subgroup. Age in years.

\subsection{Descriptive and Inferential Statistics}

Univariate analyses were conducted to determine the direction and magnitude of the effect of each independent variable on the various organ weights. This is a very misleading exercise, but is shown because many other papers present associations in this manner. The problem is that the effects of confounding variables are ignored. For example, when evaluating the effect of sex on brain weight, superficially it would seem highly significant that sex accounts for $17 \%$ of the variability in this organ's weight, as seen in Table 8 below. However, the confounders of weight and height differences between men and women are not considered, potentially overemphasising the importance of sex. Bearing this in 
mind, the independent variables studied are all poor predictors of lung weight, which may reflect the overarching effect of fluid shifts affecting this organ. Race appears to be a very small, albeit statistically significant, contributor to the weight variability of all organs, except the spleen.

\begin{tabular}{|l|c|c|c|c|c|c|c|c|}
\hline & Brain & Heart & $\begin{array}{l}\text { Right } \\
\text { Lung }\end{array}$ & $\begin{array}{l}\text { Left } \\
\text { Lung }\end{array}$ & Liver & Spleen & $\begin{array}{l}\text { Right } \\
\text { Kidney }\end{array}$ & $\begin{array}{l}\text { Left } \\
\text { Kidney }\end{array}$ \\
\hline Sex & 0.17 & 0.14 & 0.08 & 0.09 & 0.03 & $0.00^{*}$ & 0.04 & 0.05 \\
\hline Age & 0.03 & 0.12 & 0.03 & 0.02 & $0.00^{*}$ & $0.00^{*}$ & 0.03 & 0.03 \\
\hline Race & 0.04 & 0.05 & 0.02 & 0.03 & 0.04 & 0.10 & 0.06 & 0.06 \\
\hline Height & 0.14 & 0.18 & 0.06 & 0.11 & 0.13 & 0.09 & 0.14 & 0.16 \\
\hline Weight & 0.03 & 0.29 & 0.03 & 0.03 & 0.23 & 0.19 & 0.26 & 0.26 \\
\hline BMI & $0.00^{*}$ & 0.14 & $0.00^{*}$ & $0.00^{*}$ & 0.13 & 0.12 & 0.16 & 0.15 \\
\hline
\end{tabular}

Table 8: $R^{2}$ values for each predictor variable, per organ. Liver, spleen, and kidney weights used were the log transformation of the data. ${ }^{*}=p$ value $<0.05$; shaded cells highlight values $\geq 0.10$.

In Figures 17-24 descriptive organ weight data are presented in box-and-whisker plots with accompanying tables which provide the mean, standard deviation, and range of data points obtained for each subgroup. The t-test and ANOVA test were used to determine the presence of statistically significant differences in organ weights within the sex and race categories; this information is included beneath. A basic multiple linear regression analysis of each organ was then run on STATA. The main results of these are presented in Tables 9-16.

Multiple linear regression holds other independent variables constant when evaluating the effect each predictor variable, meaning that comparisons can be made free of the effect of confounders. The baseline decedent chosen was an African male, thus these race and sex categories do not appear in the model. The coefficients, given after the predictor variables, are interpreted as the amount of change (in grams) in the organ weight for each unit change in that variable. For example, in the brain weight model in Table 9 , for every $1 \mathrm{~cm}$ increase in height, we can expect the brain to be $2 \mathrm{~g}$ heavier. Thus, a $20 \mathrm{~cm}$ height difference between decedents equates to an expected $40 \mathrm{~g}$ difference in brain weight. When sex changes from male to female, the brain mass decreases by $110 \mathrm{~g}$. The constant is the baseline weight of the organ in question in an African male decedent, before adding to or subtracting from that weight the effects of their particular age, height, and body weight. 


\subsubsection{Brain Weights}

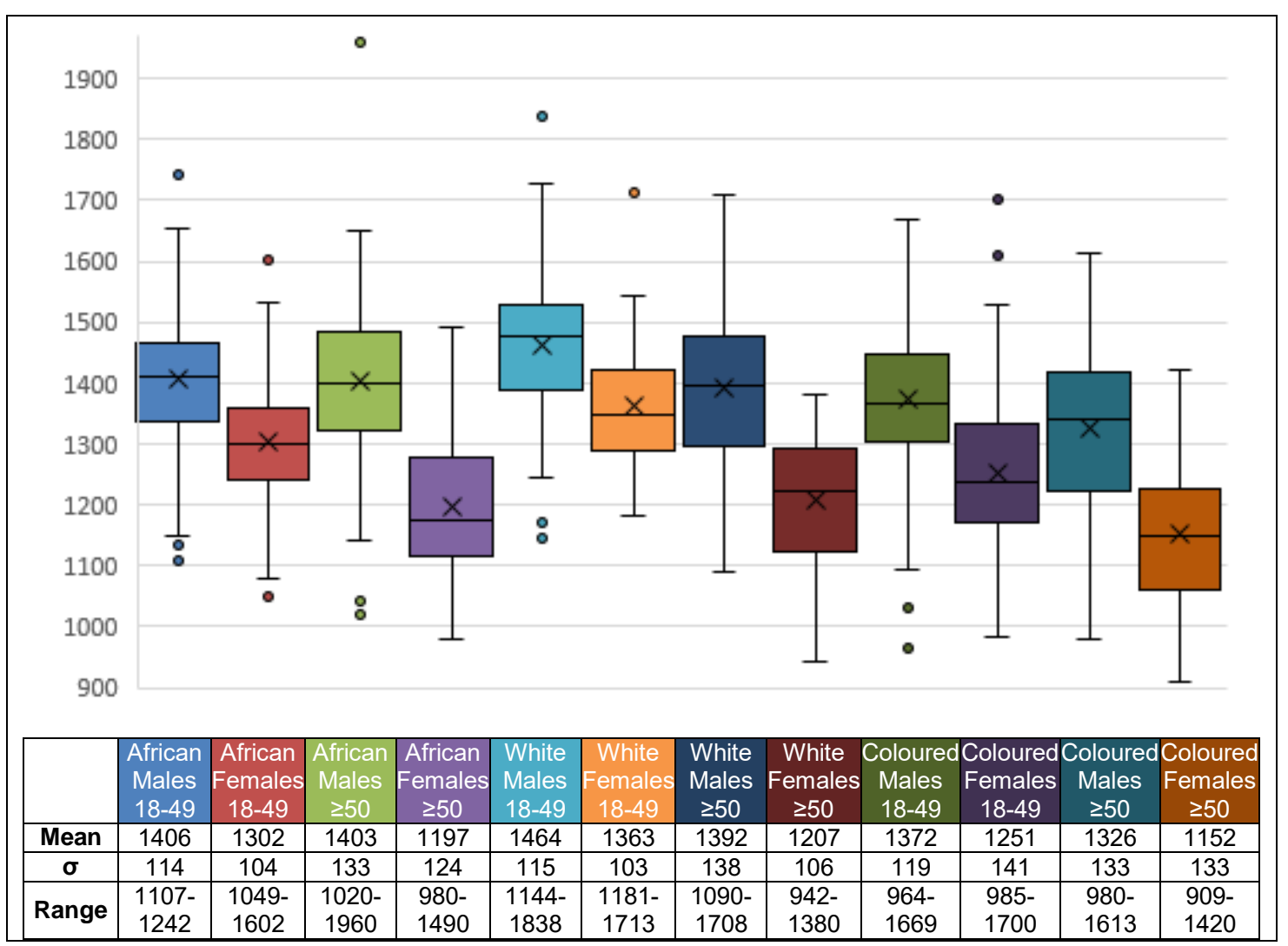

Figure 17: Brain weight per sample subgroup. Mass in grams; age in years; $\sigma=$ standard deviation.

The average male's brain was $1389 \mathrm{~g}$, with the average female's brain weighing $128 \mathrm{~g}$ less, which is significant $(p=0.00)$. The average African decedent's brain weighed 1363g; the average White decedent's brain weighed $27 \mathrm{~g}$ more, which is significant $(p=0.02)$. The mean brain weight in Coloured decedents was $50 \mathrm{~g}$ less than that of the African decedents: this is significant with $p=0.00$. There was also a significant difference between Coloured and White groups, with the mean brain weight in Coloured decedents $77 \mathrm{~g}$ less than that of the White group $(p=0.00)$.

\begin{tabular}{|lr|ll|}
\hline BRAIN WEIGHT PREDICTORS & \multicolumn{2}{|l|}{ MODEL DETAILS } \\
Female & $-110.3^{* * *}(9.124)$ & Constant & $1087^{* * *}(86.44)$ \\
Age & $-1.729^{* * *}(0.216)$ & Observations & 1137 \\
Height & $2.020^{\star * *}(0.534)$ & R-squared & 0.285 \\
Weight & $0.639^{* * *}(0.232)$ & & \\
White & $27.05^{\star * *}(10.45)$ & & \\
Coloured & $-45.00^{* * *}(8.255)$ & & \\
\hline
\end{tabular}

Table 9: Multiple linear regression model for brain weight. Beta values given with

corresponding $p$-values: ${ }^{\star \star \star} p<0.01,{ }^{* \star} p<0.05,{ }^{*} p<0.1$. Standard errors in parentheses.

Multiple linear regression shows all variables considered to be significant, with body weight having a smaller actual effect than the others. 


\subsubsection{Heart Weights}

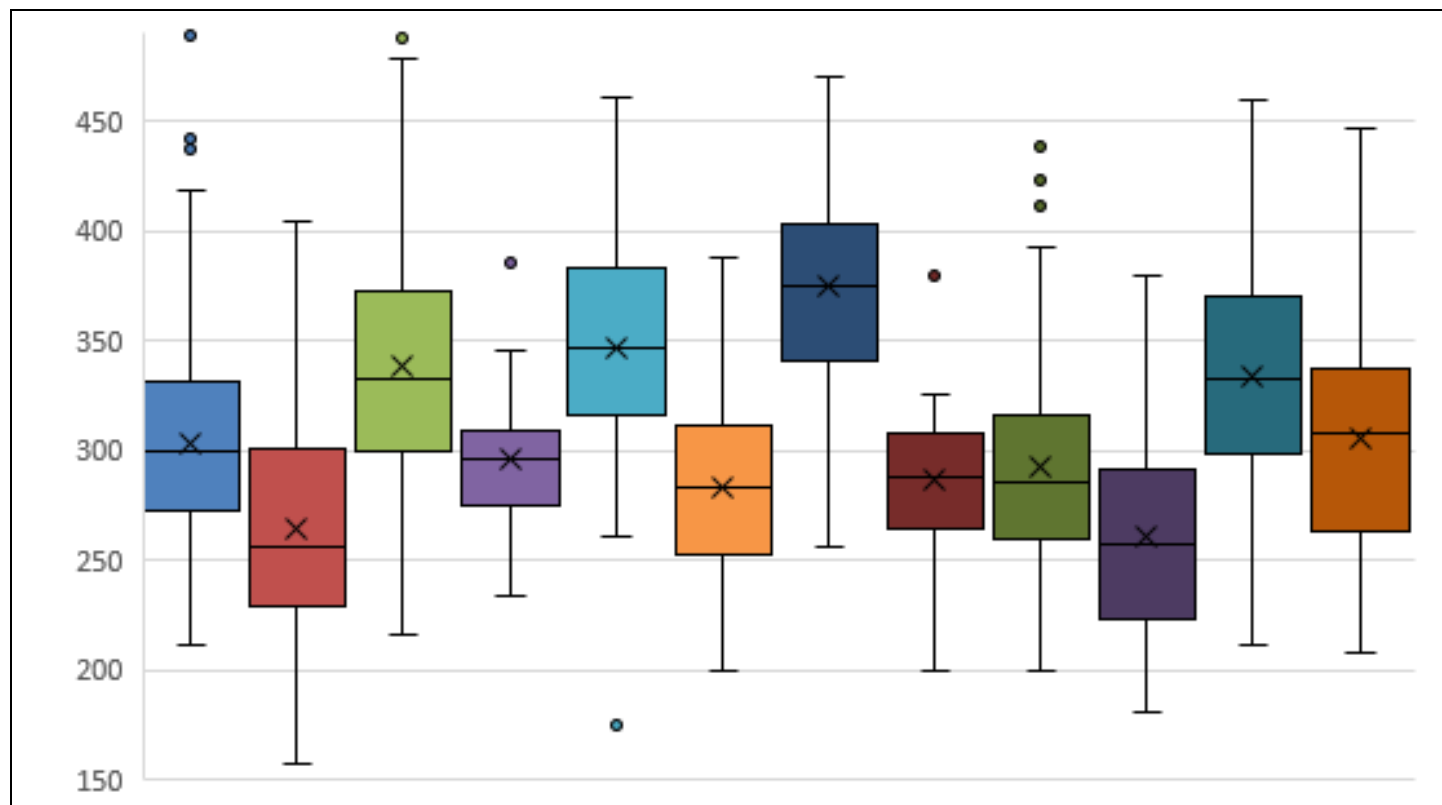

\begin{tabular}{|c|c|c|c|c|c|c|c|c|c|c|c|c|}
\hline & $\begin{array}{c}\text { African } \\
\text { Males } \\
18-49 \\
\end{array}$ & \begin{tabular}{|c|} 
African \\
Females \\
$18-49$ \\
\end{tabular} & $\begin{array}{c}\text { African } \\
\text { Males } \\
\geq 50 \\
\end{array}$ & \begin{tabular}{|c|} 
African \\
Females \\
$\geq 50$
\end{tabular} & $\begin{array}{l}\text { White } \\
\text { Males } \\
18-49 \\
\end{array}$ & \begin{tabular}{|c|} 
White \\
Females \\
$18-49$ \\
\end{tabular} & $\begin{array}{l}\text { White } \\
\text { Males } \\
\geq 50\end{array}$ & \begin{tabular}{|c|} 
White \\
Females \\
$\geq 50$
\end{tabular} & $\begin{array}{c}\text { Coloured } \\
\text { Males } \\
18-49 \\
\end{array}$ & \begin{tabular}{|c|} 
Coloured \\
Females \\
$18-49$
\end{tabular} & $\begin{array}{l}\text { Coloured } \\
\text { Males } \\
\geq 50 \\
\end{array}$ & $\begin{array}{c}\text { Coloured } \\
\text { Females } \\
\geq 50\end{array}$ \\
\hline Mean & 303 & 264 & 338 & 296 & 347 & 283 & 375 & 286 & 292 & 261 & 333 & 306 \\
\hline$\sigma$ & 48 & 50 & 54 & 31 & 49 & 46 & 53 & 41 & 45 & 45 & 53 & 54 \\
\hline Range & $211-489$ & $157-404$ & $216-488$ & $234-385$ & $175-514$ & 199-388 & $256-525$ & $200-380$ & $199-438$ & $181-380$ & $211-511$ & 208-447 \\
\hline
\end{tabular}

Figure 18: Heart weight per sample subgroup. Mass in grams; age in years; $\sigma=$ standard deviation.

The average male's heart was $319 \mathrm{~g}$, with the average female's heart weighing $45 \mathrm{~g}$ less, which is significant $(p=0.00)$. The average African decedent's heart weighed $300 \mathrm{~g}$; the average White decedent's heart weighed $32 \mathrm{~g}$ more, which is significant $(p=0.00)$. The mean heart weight in Coloured decedents was not significantly different to that of the African baseline $(p=0.5)$, but was significantly different to the White group ( $35 \mathrm{~g}$ less; $\mathrm{p}=0.00)$.

\begin{tabular}{|ll|ll|}
\hline HEART WEIGHT & PREDICTORS & MODEL DETAILS \\
\hline Female & $-38.62^{* * *}(2.976)$ & Constant & $70.10^{* *}(28.22)$ \\
Age & $1.086^{* * *}(0.0759)$ & Observations & 1086 \\
Height & $0.551^{* * *}(0.174)$ & $\mathbf{R}^{2}$ & 0.529 \\
Weight & $1.574^{* * *}(0.0808)$ & & \\
White & $14.65^{* * *}(3.614)$ & & \\
Coloured & $2.568(2.653)$ & & \\
\hline
\end{tabular}

Table 10: Multiple linear regression model for heart weight. Beta values given with corresponding $p$-values: ${ }^{* *} p<0.01,{ }^{* *} p<0.05,{ }^{*} p<0.1$. Standard errors in parentheses.

The regression model shows all variables to be significant: since the race category White is significantly different to the African baseline, Coloured must also be included although in itself it is not significant. Heart weight is particularly affected by body weight, sex, and race. 


\subsubsection{Right Lung Weights}

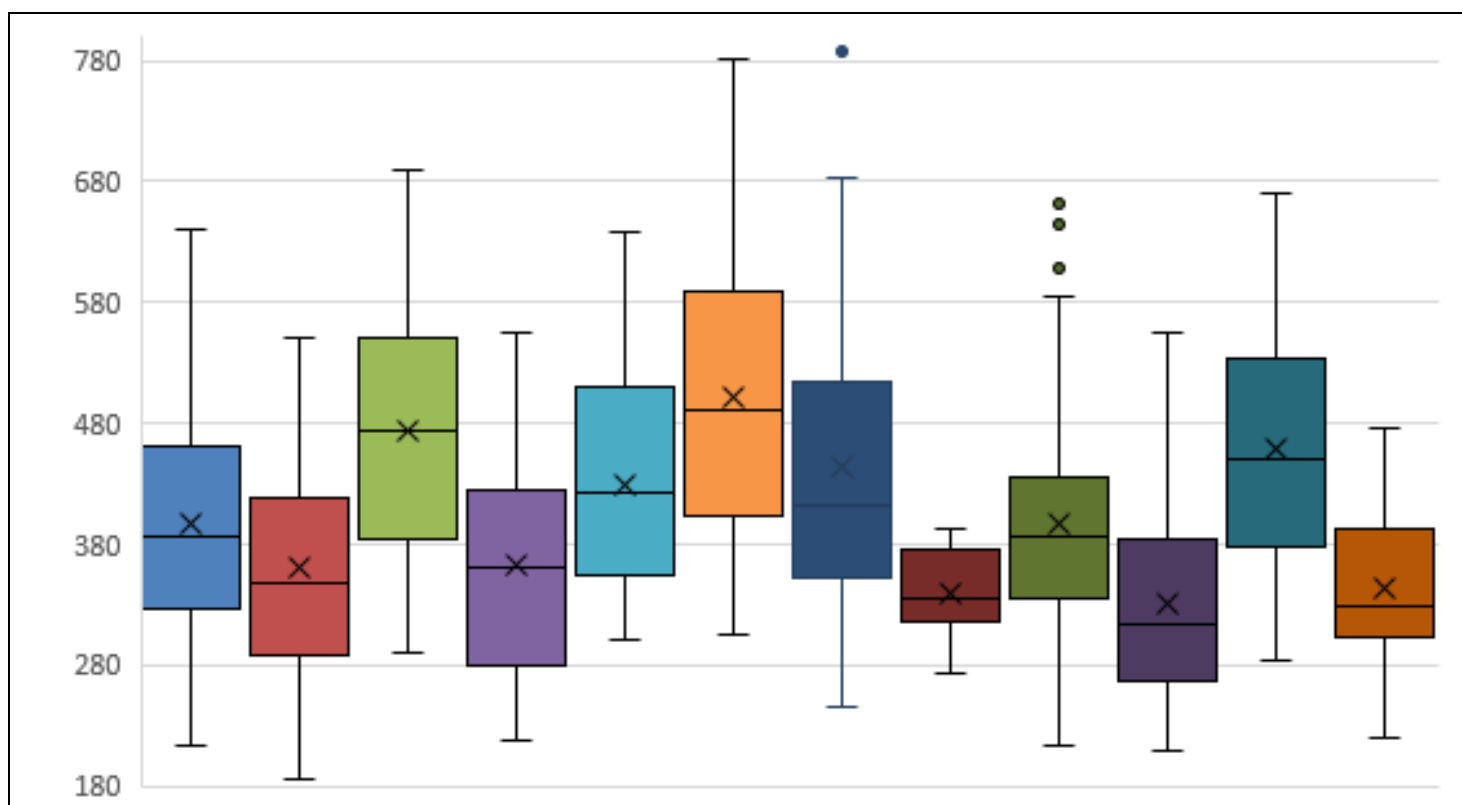

\begin{tabular}{|c|c|c|c|c|c|c|c|c|c|c|c|c|}
\hline & $\begin{array}{c}\text { African } \\
\text { Males } \\
18-49\end{array}$ & \begin{tabular}{|c|} 
African \\
Females \\
$18-49$
\end{tabular} & $\begin{array}{c}\text { African } \\
\text { Males } \\
\geq 50\end{array}$ & $\begin{array}{c}\text { African } \\
\text { Females } \\
\geq 50\end{array}$ & $\begin{array}{l}\text { White } \\
\text { Males } \\
18-49\end{array}$ & $\begin{array}{c}\text { White } \\
\text { Females } \\
18-49\end{array}$ & $\begin{array}{c}\text { White } \\
\text { Males } \\
\geq 50\end{array}$ & $\begin{array}{c}\text { White } \\
\text { Females } \\
\geq 50\end{array}$ & $\begin{array}{c}\text { Coloured } \\
\text { Males } \\
18-49\end{array}$ & \begin{tabular}{|} 
Coloured \\
Females \\
$18-49$
\end{tabular} & $\begin{array}{c}\text { Coloured } \\
\text { Males } \\
\geq 50\end{array}$ & $\begin{array}{c}\text { Coloured } \\
\text { Females } \\
\geq 50\end{array}$ \\
\hline Mean & 397 & 360 & 474 & 363 & 429 & 501 & 443 & 339 & 398 & 331 & 458 & 343 \\
\hline$\sigma$ & 97 & 94 & 117 & 85 & 88 & 118 & 127 & 35 & 87 & 85 & 95 & 69 \\
\hline Range & 3611 & $86-550$ & $290-825$ & 1855 & 063 & 782 & $16-78$ & $74-392$ & 213-662 & $209-555$ & 283-670 & $19-4$ \\
\hline
\end{tabular}

Figure 19: Right lung weight per sample subgroup. Mass in grams; age in years; $\sigma=s t a n d a r d$ deviation.

The average male's right lung was $425 \mathrm{~g}$, with the average female's right lung weighing $63 \mathrm{~g}$ less, which is not significant $(p=0.08)$. The average African decedent's right lung weighed 402g; the average White decedent's right lung weighed $31 \mathrm{~g}$ more, which is significant $(p=0.02)$. The mean right lung weight in Coloured decedents was not significantly different to that of the African decedents $(p=0.49)$, but was significantly less than the White group (38g less; $p=0.00$ ).

\begin{tabular}{|l|l|ll|}
\hline \multicolumn{2}{|l|}{ RIGHT LUNG WEIGHT PREDICTORS } & \multicolumn{2}{|l|}{ MODEL DETAILS } \\
Female & $-53.23^{* * *}(10.83)$ & Constant & $207.2^{* *}(101.4)$ \\
Age & $1.048^{* * *}(0.267)$ & Observations & 560 \\
Height & $0.863^{*}(0.628)$ & $\mathbf{R}^{2}$ & 0.132 \\
Weight & $0.437(0.272)$ & & \\
White & $7.636(12.64)$ & & \\
Coloured & $-10.69(9.519)$ & & \\
\hline
\end{tabular}
corresponding $p$-values: ${ }^{* *} p<0.01,{ }^{* *} p<0.05,{ }^{*} p<0.1$. Standard errors in parentheses.

Using the basic independent variables only, without considering interaction terms, the only significant predictors of right lung weights are sex and age. 


\subsubsection{Left Lung Weights}

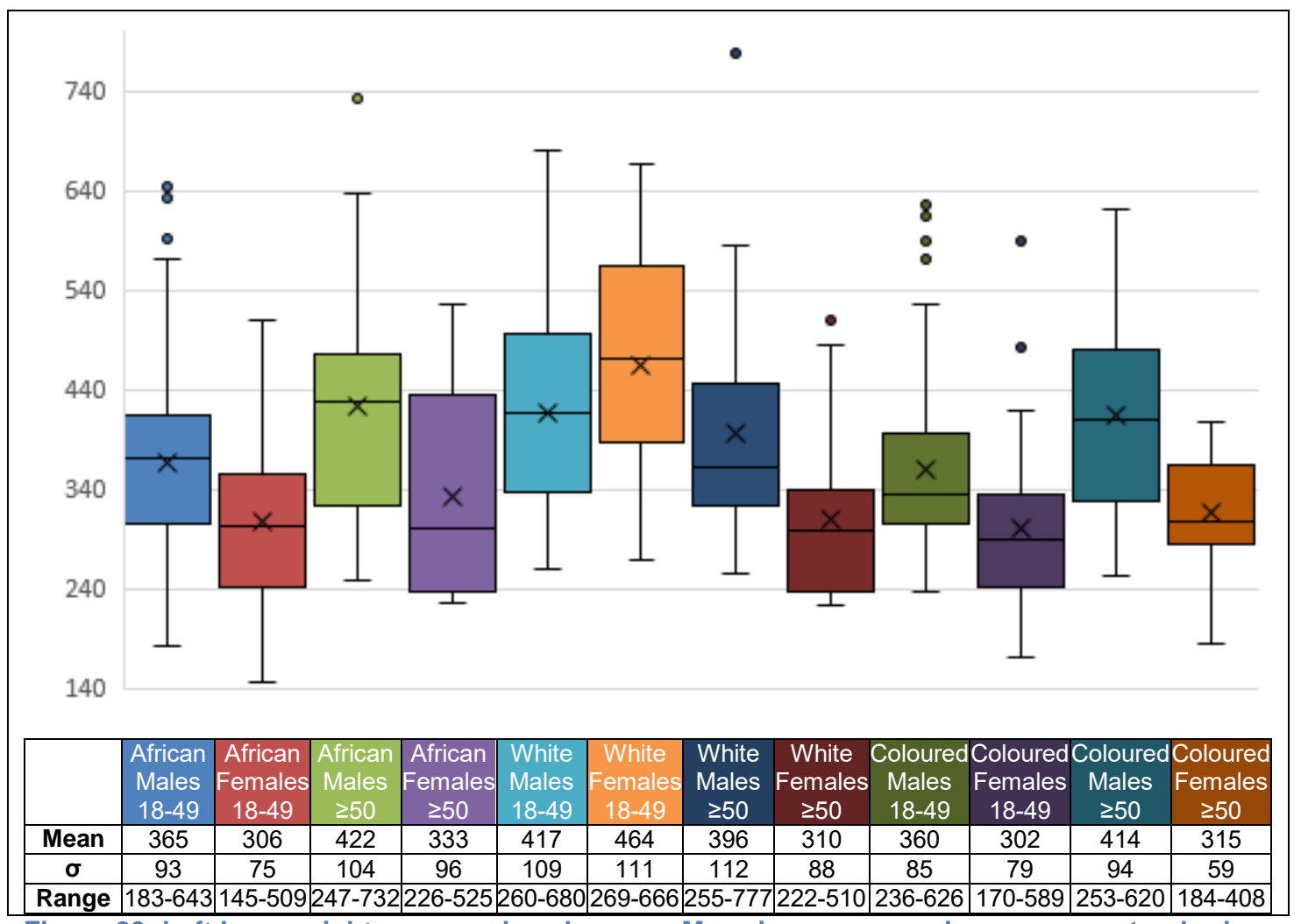

Figure 20: Left lung weight per sample subgroup. Mass in grams; age in years; $\sigma=$ standard deviation.

The average male's left lung was $388 \mathrm{~g}$, with the average female's left lung weighing $64 \mathrm{~g}$ less, which is significant $(p=0.00)$. The average African decedent's left lung weighed 358g; the average White decedent's left lung weighed $46 \mathrm{~g}$ more, which is significant $(p=0.00)$. As before, the mean left lung weight in Coloured decedents was insignificantly different to that of the African decedents $(p=0.9)$ but significantly less than that of the White group ( $46 \mathrm{~g} ; \mathrm{p}=0.00)$.

\begin{tabular}{|ll|ll|}
\hline \multicolumn{2}{|l|}{ LEFT LUNG WEIGHT PREDICTORS } & MODEL DETAILS \\
Female & $-39.21^{* * *}(10.78)$ & Constant & $-26.57(100.6)$ \\
Age & $0.832^{* * *}(0.624)$ & Observations & 525 \\
Height & $2.149^{* * *}(0.263)$ & $\mathbf{R}^{2}$ & 0.157 \\
Weight & $0.155(0.270)$ & & \\
White & $21.18^{*}(12.15)$ & & \\
Coloured & $-3.878(9.426)$ & & \\
\hline
\end{tabular}

Table 12: Multiple linear regression model for left lung weight. Beta values given with corresponding $p$-values: ${ }^{* \star} p<0.01,{ }^{* \star} p<0.05,{ }^{*} p<0.1$. Standard errors in parentheses.

Similar to the right lung model, sex and age are significant. In addition, regressing these data shows that height contributes to the variability of the left lung's weight. The effect of race alone does not meet our required significance level of $<0.05$. 


\subsubsection{Liver Weights}

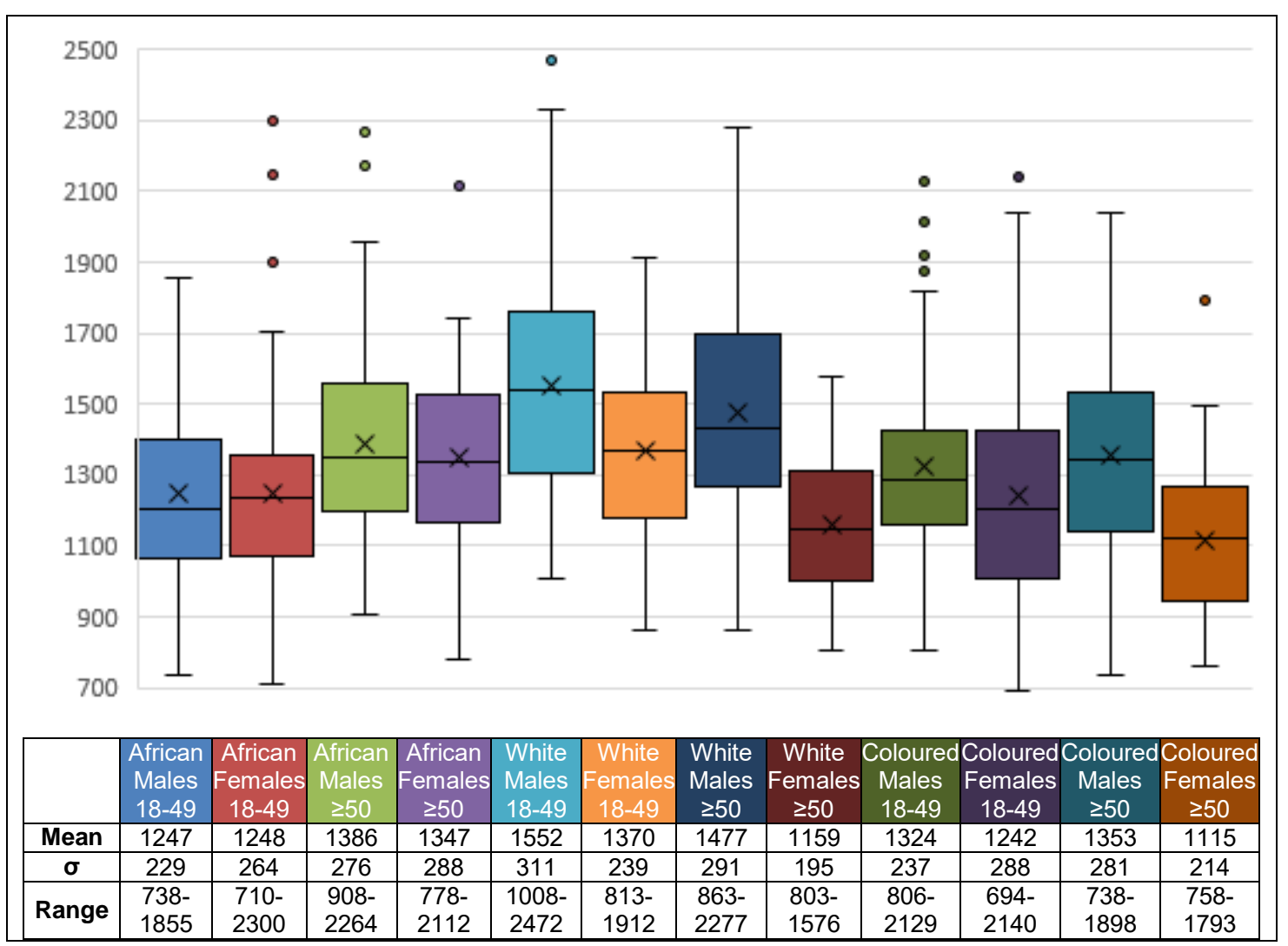

Figure 21: Liver weight per sample subgroup. Mass in grams; age in years; $\sigma=$ standard deviation.

The average male's liver was $1350 \mathrm{~g}$, with the average female's liver weighing $102 \mathrm{~g}$ less, which is significant $(p=0.00)$. The average African decedent's liver weighed 1291g; the average White decedent's liver weighed $157 \mathrm{~g}$ more, which is significant $(p=0.00)$. The mean liver weight in Coloured decedents was insignificantly different to that of the African decedents ( $p=0.69$ ), but significantly less than the White group $(149 g ; p=0.00)$.

\begin{tabular}{|ll|ll|}
\hline \multicolumn{2}{|l|}{ LIVER WEIGHT PREDICTORS } & MODEL DETAILS \\
Female & $-60.97^{* * *}(18.45)$ & Constant & $324.4^{*}(172.0)$ \\
Age & $-0.287(0.435)$ & Observations & 525 \\
Height & $2.747^{* *}(1.071)$ & $\mathbf{R}^{2}$ & 0.287 \\
Weight & $7.759^{* * *}(0.527)$ & & \\
White & $104.6^{* * *}(21.65)$ & & \\
Coloured & $54.23^{* * *}(16.12)$ & & \\
\hline
\end{tabular}

Table 13: Multiple linear regression model for liver weight. Beta values given with

corresponding $p$-values: ${ }^{\star * \star} p<0.01,{ }^{* *} p<0.05,{ }^{*} p<0.1$. Standard errors in parentheses.

All independent variables are significant predictors of liver weight, except for age. Body weight has a particularly marked positive correlation. 


\subsubsection{Right Kidney Weights}

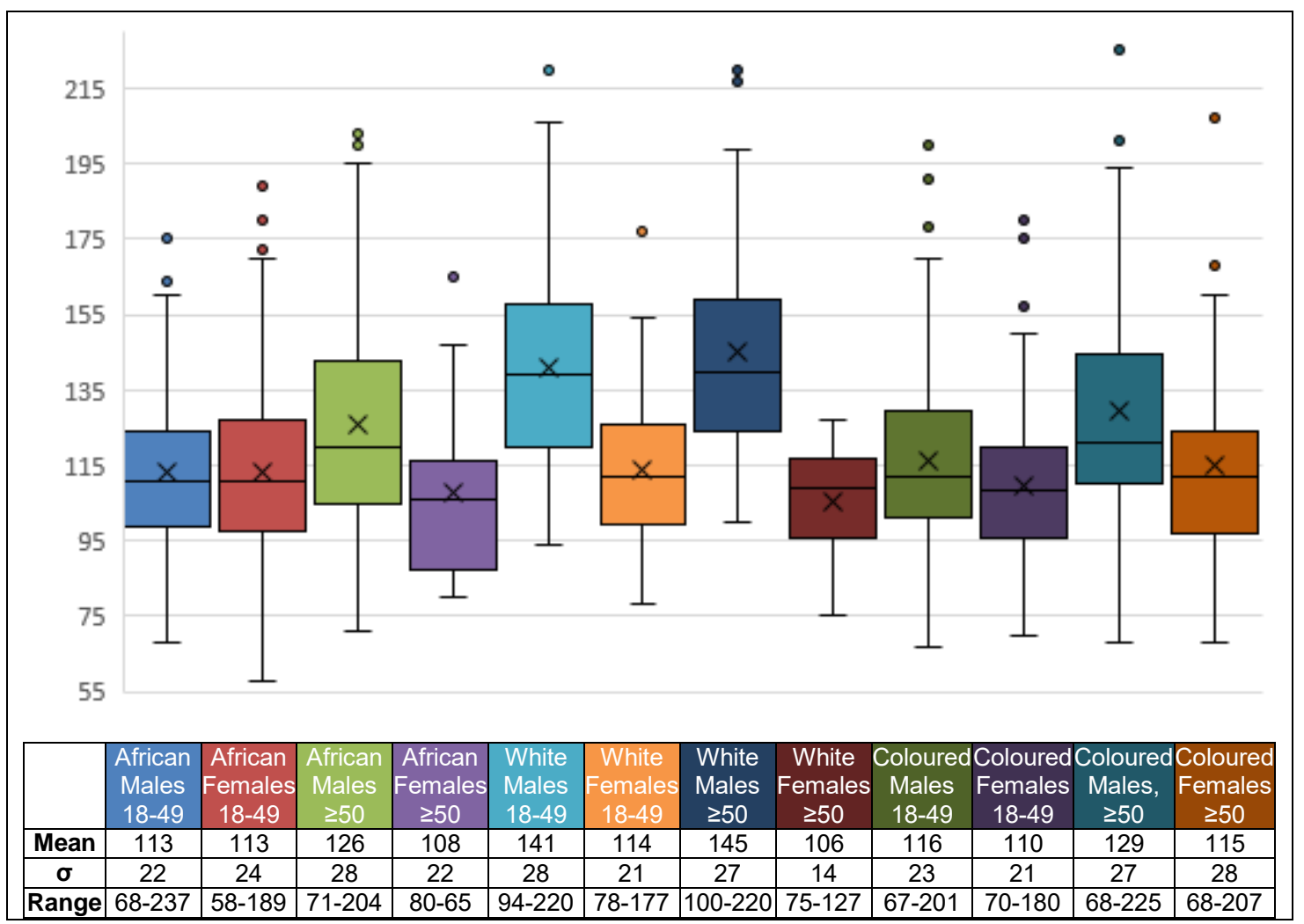

Figure 22: Right kidney weight per sample subgroup. Mass in grams; age in years; $\sigma=$

standard deviation.

The average male's right kidney was $124 \mathrm{~g}$, with the average female's right kidney weighing $12 \mathrm{~g}$ less, which is significant $(p=0.00)$. The average African decedent's right kidney weighed $116 \mathrm{~g}$; the average White decedent's right kidney weighed $17 \mathrm{~g}$ more, which is significant $(p=0.00)$. The mean right kidney weight in Coloured decedents was insignificantly different to that of the African decedents $(p=0.69)$, and significantly less than the White group $(16 \mathrm{~g} ; \mathrm{p}=0.00)$.

\begin{tabular}{|ll|ll|}
\hline RIGHT KIDNEY WEIGHT PREDICTORS & MODEL DETAILS \\
\hline Female & $-7.253^{\star * *}(1.719)$ & Constant & $15.55(16.21)$ \\
Age & $0.148^{* * *}(0.0450)$ & Observations & 1001 \\
Height & $0.287^{* \star *}(0.1000)$ & $\mathbf{R}^{2}$ & 0.346 \\
Weight & $0.698^{* * *}(0.0447)$ & & \\
White & $9.329^{* \star *}(2.002)$ & & \\
Coloured & $6.320^{* \star *}(1.540)$ & & \\
\hline
\end{tabular}

Table 14: Multiple linear regression model for right kidney weight. Beta values given with corresponding $p$-values: ${ }^{* *} p<0.01,{ }^{* *} p<0.05,{ }^{*} p<0.1$. Standard errors in parentheses.

Regression shows all independent variables considered to be significant, with sex and race playing a prominent role in accounting for right kidney weight variability. 


\subsubsection{Left Kidney Weights}

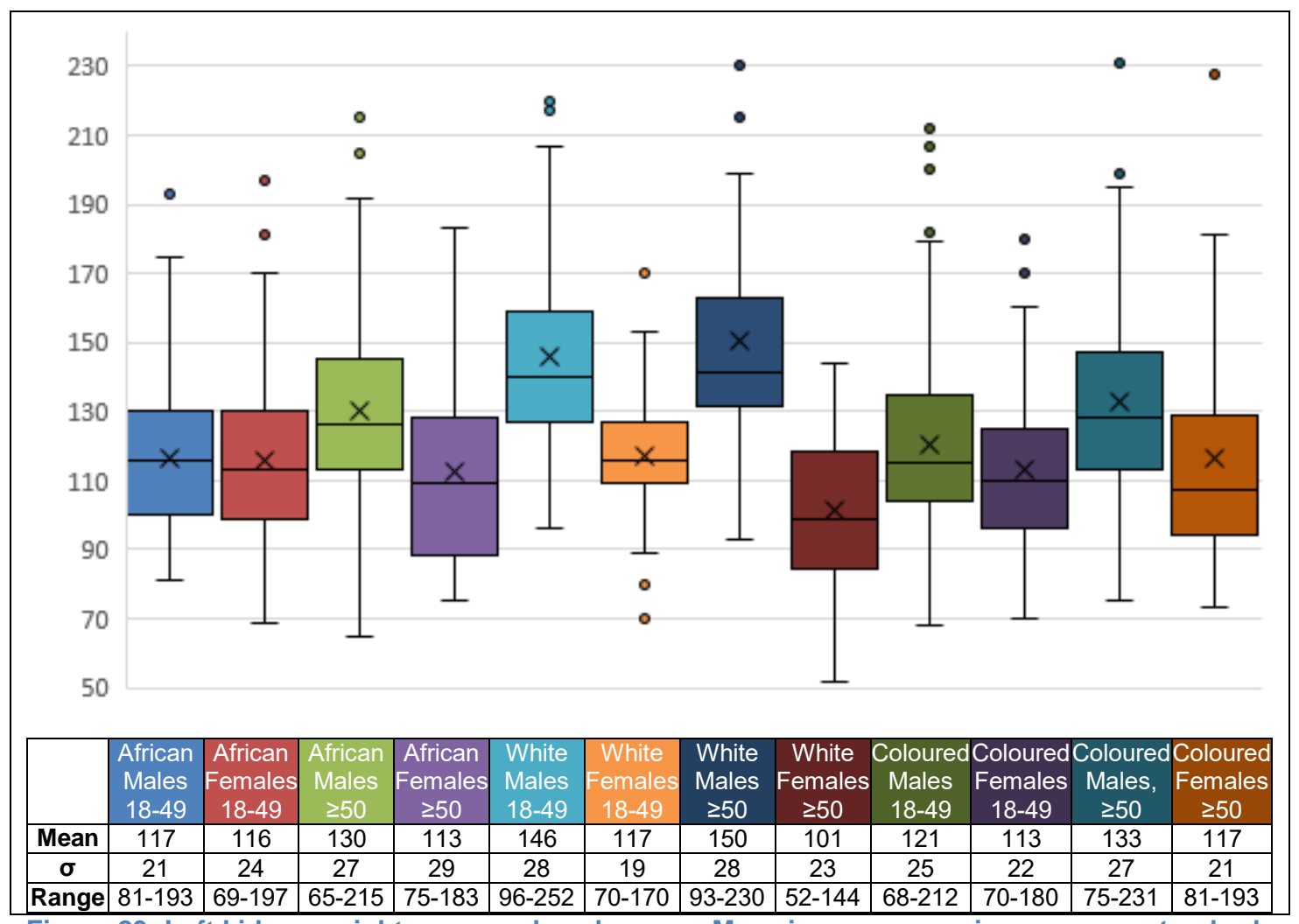

Figure 23: Left kidney weight per sample subgroup. Mass in grams; age in years; $\sigma=$ standard deviation.

The average male's left kidney was $128 \mathrm{~g}$, with the average female's left kidney weighing $14 \mathrm{~g}$ less, which is significant $(p=0.00)$. The average African decedent's left kidney weighed 120g; the average White decedent's left kidney weighed $18 \mathrm{~g}$ more, which is significant $(p=0.00)$. The mean left kidney weight in Coloured decedents was insignificantly different to the African decedents $(p=0.3)$, and again $14 \mathrm{~g}$ less than the White decedents, which is significant $(p=0.00)$.

\begin{tabular}{|ll|ll|}
\hline \multicolumn{2}{|l|}{ LEFT KIDNEY WEIGHT PREDICTORS } & MODEL DETAILS \\
\hline Female & $-8.360^{* * *}(1.757)$ & Constant & $7.098(16.57)$ \\
Age & $0.144^{* * *}(0.0461)$ & Observations & 998 \\
Height & $0.698^{* * *}(0.0447)$ & $\mathbf{R}^{2}$ & 0.352 \\
Weight & $0.695^{* * *}(0.0457)$ & & \\
White & $9.061^{* * *}(2.043)$ & & \\
Coloured & $6.460^{* * *}(1.573)$ & & \\
\hline
\end{tabular}

Table 15: Multiple linear regression model for right kidney weight. Beta values given with corresponding $p$-values: ${ }^{* *} p<0.01,{ }^{* *} p<0.05,{ }^{*} p<0.1$. Standard errors in parentheses.

The left kidney weight's associations follow those of the right kidney: all variables are significant with sex and race having relatively large impacts. 


\subsubsection{Spleen Weights}

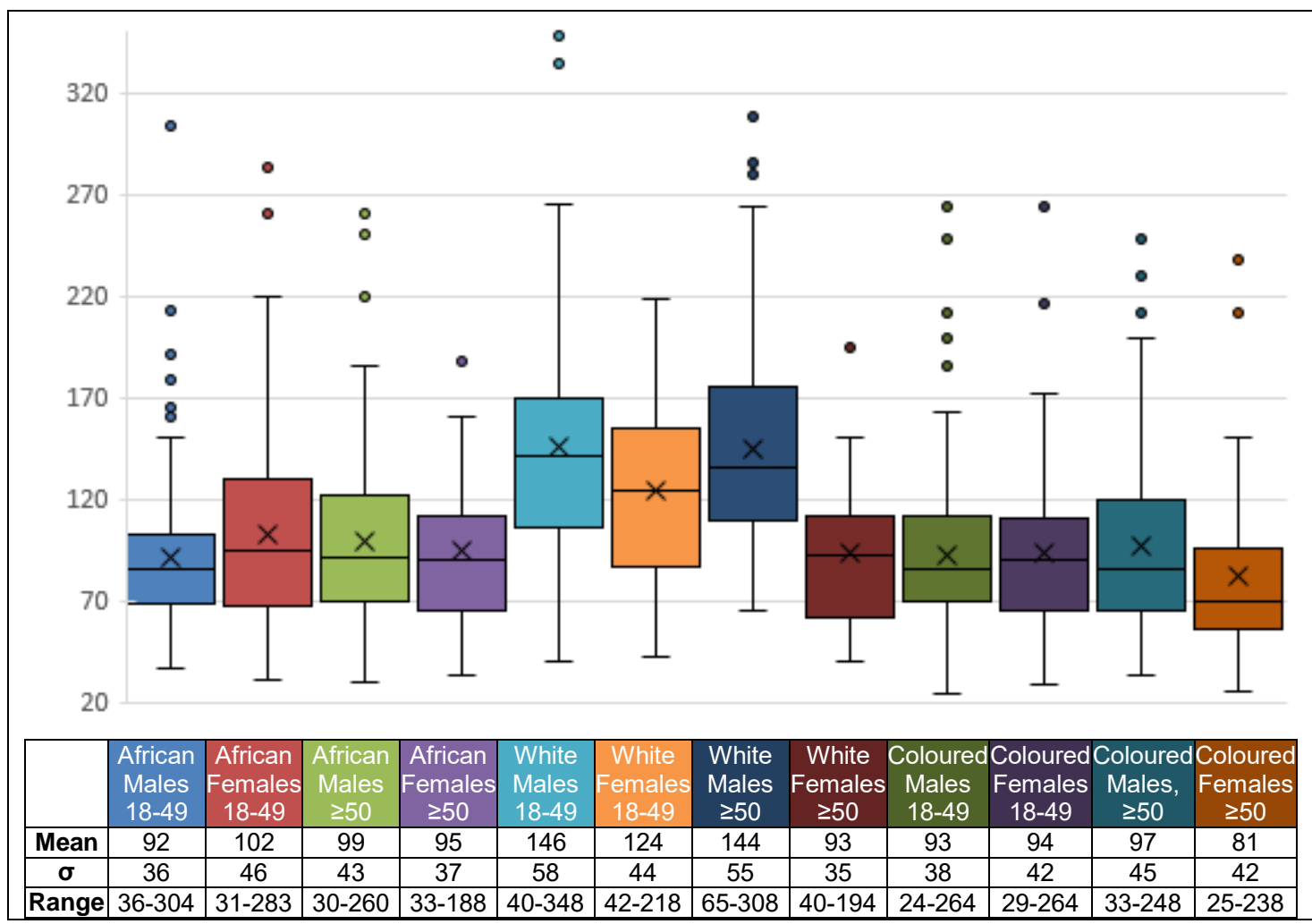

Figure 24: Spleen weight according to sample subgroup. Mass in grams; age in years; $\sigma=$

standard deviation.

The average male's spleen was $105 \mathrm{~g}$, with the average female's spleen weighing $6 \mathrm{~g}$ less, which is not significant $(\mathrm{p}=0.07)$. The average African decedent's spleen weighed 97g; the average White decedent's spleen weighed $37 \mathrm{~g}$ more, which is significant $(p=0.00)$. The mean spleen weight in Coloured decedents was insignificantly different to that of the African decedents $(p=0.19)$, but significantly less than the White group $(41 \mathrm{~g} ; \mathrm{p}=0.00)$.

\begin{tabular}{|ll|ll|}
\hline SPLEEN WEIGHT PREDICTORS & \multicolumn{2}{|l|}{ MODEL DETAILS } \\
Female & $-0.769(3.141)$ & Constant & $-26.95(29.79)$ \\
Age & $-0.216^{* *}(0.0732)$ & Observations & 1078 \\
Height & $0.370^{* *}(0.185)$ & $\mathbf{R}^{2}$ & 0.266 \\
Weight & $0.984^{* * *}(0.0804)$ & & \\
White & $32.36^{* * *}(3.533)$ & & \\
Coloured & $3.948(2.824)$ & & \\
\hline
\end{tabular}

Table 16: Multiple linear regression model for right kidney weight. Beta values given with corresponding $p$-values: *** $p<0.01,{ }^{* *} p<0.05,{ }^{*} p<0.1$. Standard errors in parentheses.

Unique among the organs studied, sex is not a significant predictor of spleen weight in this sample. White race adds $32 \mathrm{~g}$ to the African male baseline spleen weight, which is substantial considering the average spleen weights found. 


\subsection{Model Building}

Multiple linear regression model building was used to fit estimation models for each organ weight, based on the initial regressions presented previously. This was done by initially fitting maximal models, including all possible interaction variables. Interaction effects between predictor variables occur when the relationship between each predictor and their dependent variable depends on the value of the other interacting variable. For example, if the coefficient of the interaction variable Female*Age is negative and significant within the brain weight regression model, then this means that the age-related decline in brain weight occurs to a greater extent in women. The interaction variables considered were those between the categorical variables Race and Sex and each of the continuous variables age, height and weight. Once this maximal model was fitted, stepwise regression was used to evaluate and drop terms to ensure that all remaining predictor variables had statistically significant effects on the outcome.

\subsubsection{Assumption Testing}

During the process of model building, the data were tested for the assumptions that underpin linear regression analysis. The first assumption, which certainly holds, is that the dependent variable (organ weight) is continuous, while the independent variables are continuous (age, height and weight) or categorical (sex and race).

The assumption of normal data distribution was assessed by pooling organ weight observations from all subgroups and plotting them as histograms. The distributions for all organs was visually judged to conform to a normal curve, except for that of the liver, spleen, and both kidneys, which appear to be right skewed. This is illustrated in Figure 25 below. 

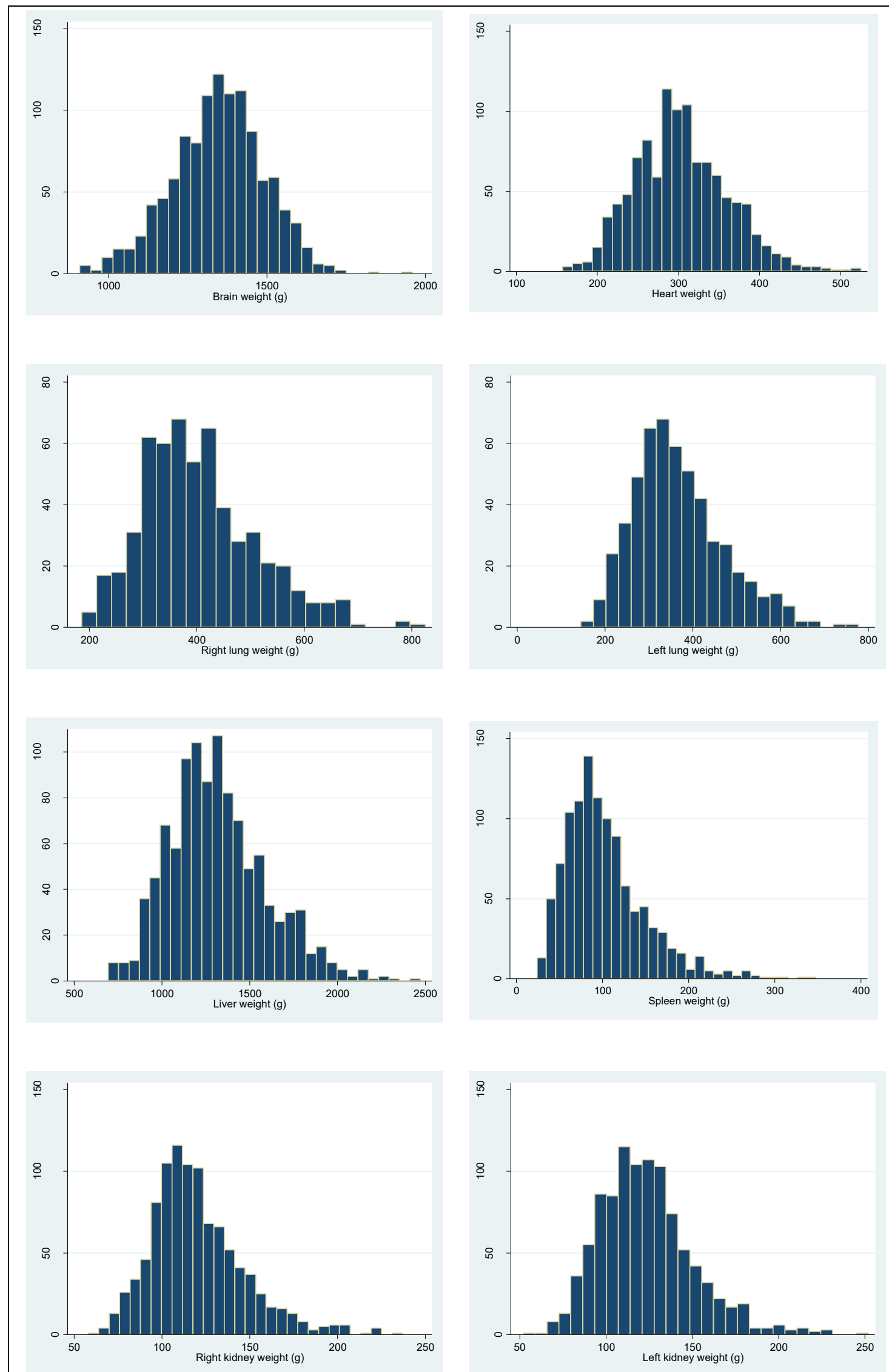

Figure 25: Histograms of pooled organ weight data. 
The organ weight data from the liver, spleen, and both kidneys were logtransformed to reduce this skewness; histograms of the transformed data are shown in Figure 26. Subsequently, the stepwise model building process was reapplied to the log-transformed data and these models and data were used for all further assumption testing.

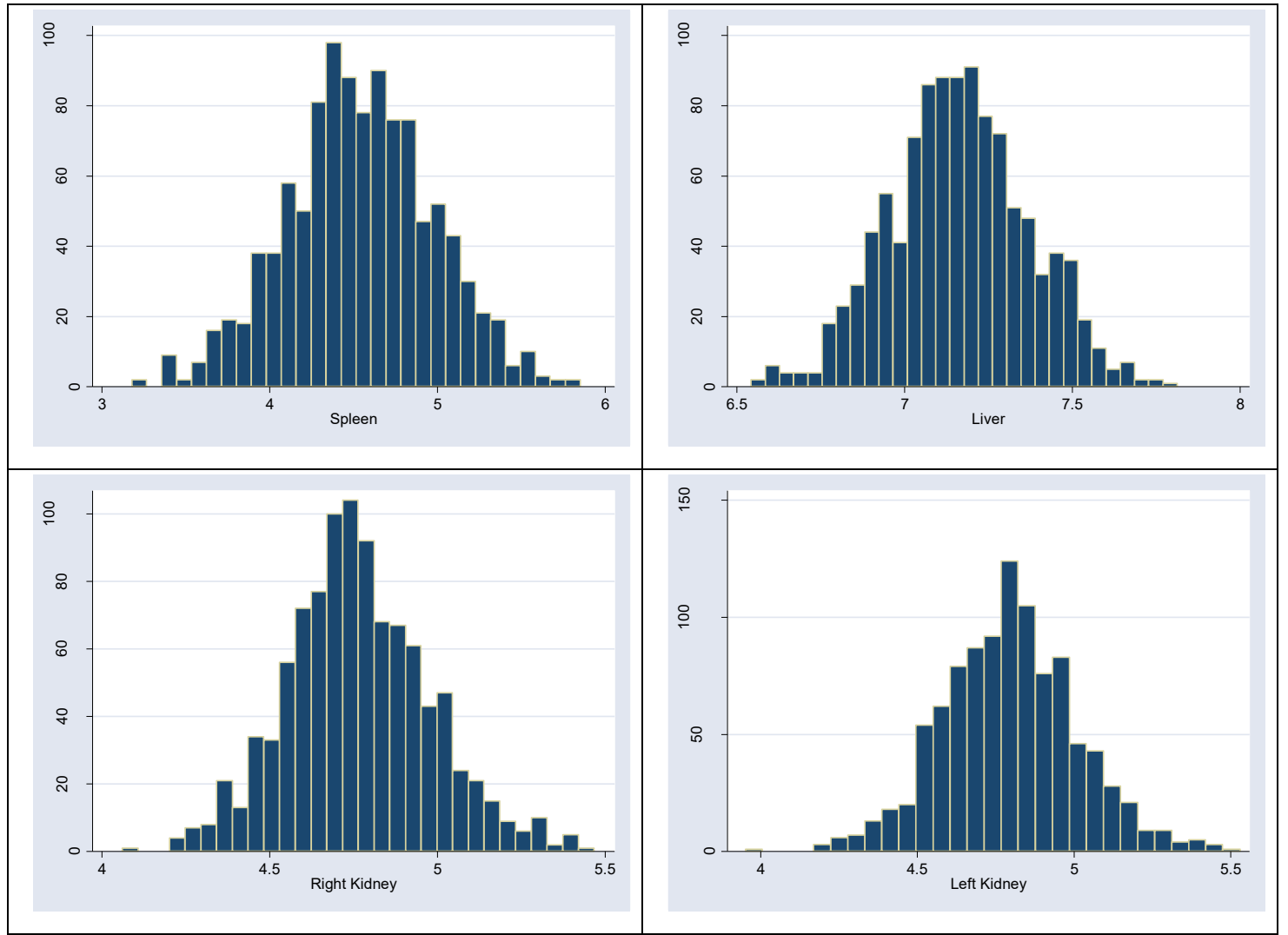

Figure 26: Log-transformations of selected pooled organ weight data

There is an assumption that the data should contain no outliers or influential points. These are certainly identified, and can also been seen in the box plots of Figures 17-24 above. The cases in question were drawn and individually reviewed for adherence to exclusion criteria, which were found to have been satisfied. One case of a $28 \mathrm{~kg}$ woman was excluded because of undue influence of this single point on the fitted lines. It was decided not to exclude others merely for the sake of the model. They are valid individual cases, giving insight into the trends of organ weight at the extremes of age, weight, and height.

The visual linear relationship of the organ masses with each predictor variable that is assumed, was confirmed by drawing up augmented partial residual plots with lowess smoothing lines (Figure 27). The lowess lines were found to be very close to the estimated linear regression lines. 


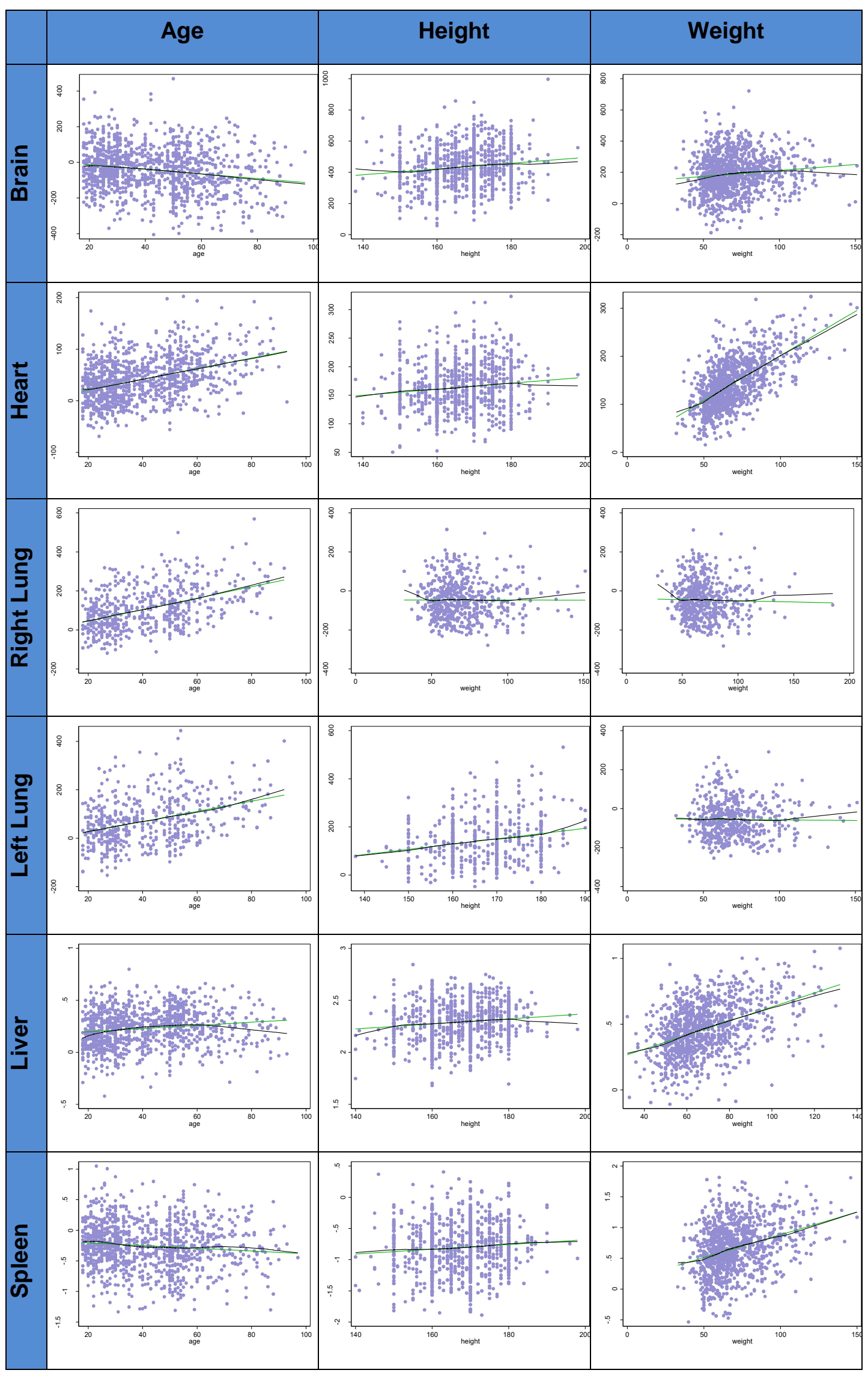




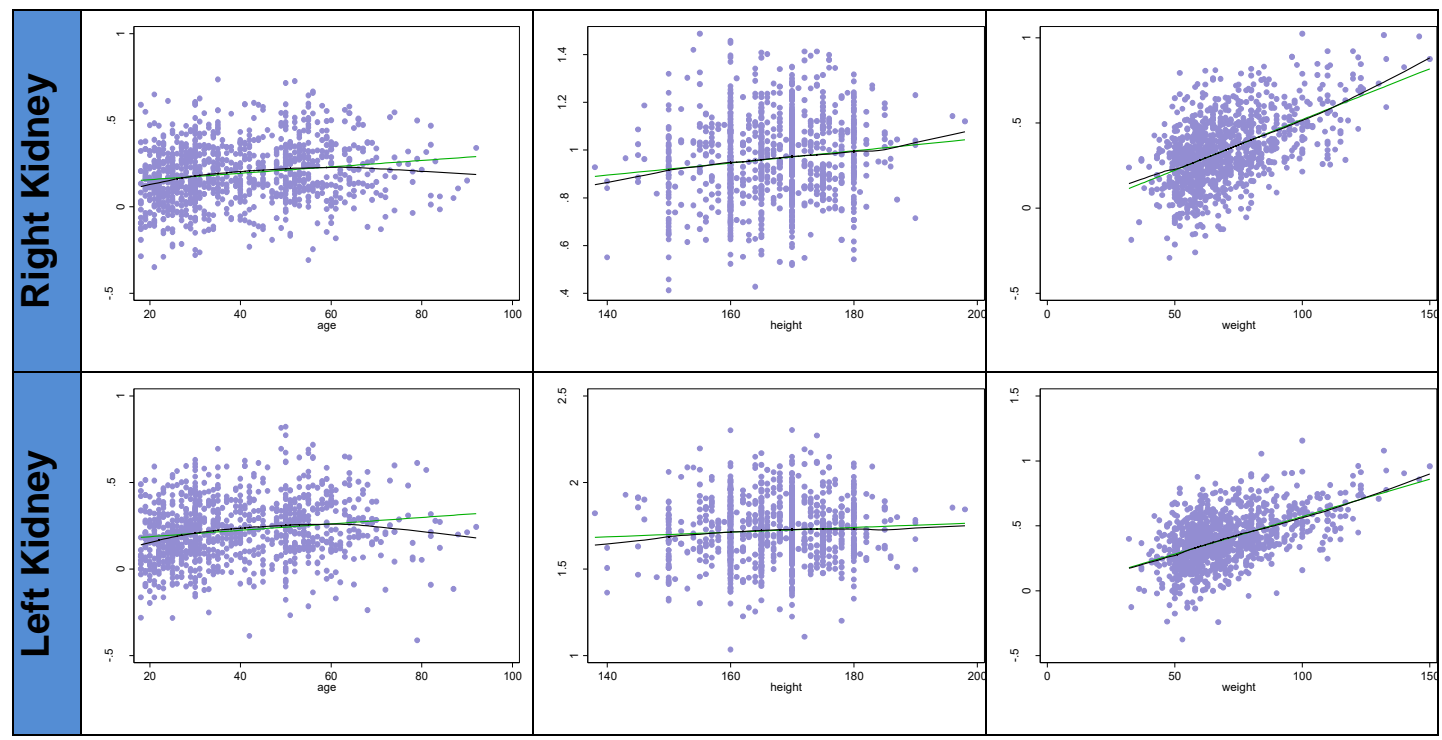

Figure 27: Augmented partial residual plots with fitted values (green) and lowess lines (black) for each continuous predictor variable, per organ. Liver, spleen and kidney weights used were the log transformation of the data.

There was no need to perform a Dubin-Watson test statistic as these data have no 'time' element; observed organ weights do not interact with one another. There is therefore no possibility of violating the assumption of an absence of autocorrelation.

The assumption of homoscedasticity was assessed for and confirmed by plotting the residuals about the linear fitted values; these graphs are presented in Table 27 below where no divergences are seen.

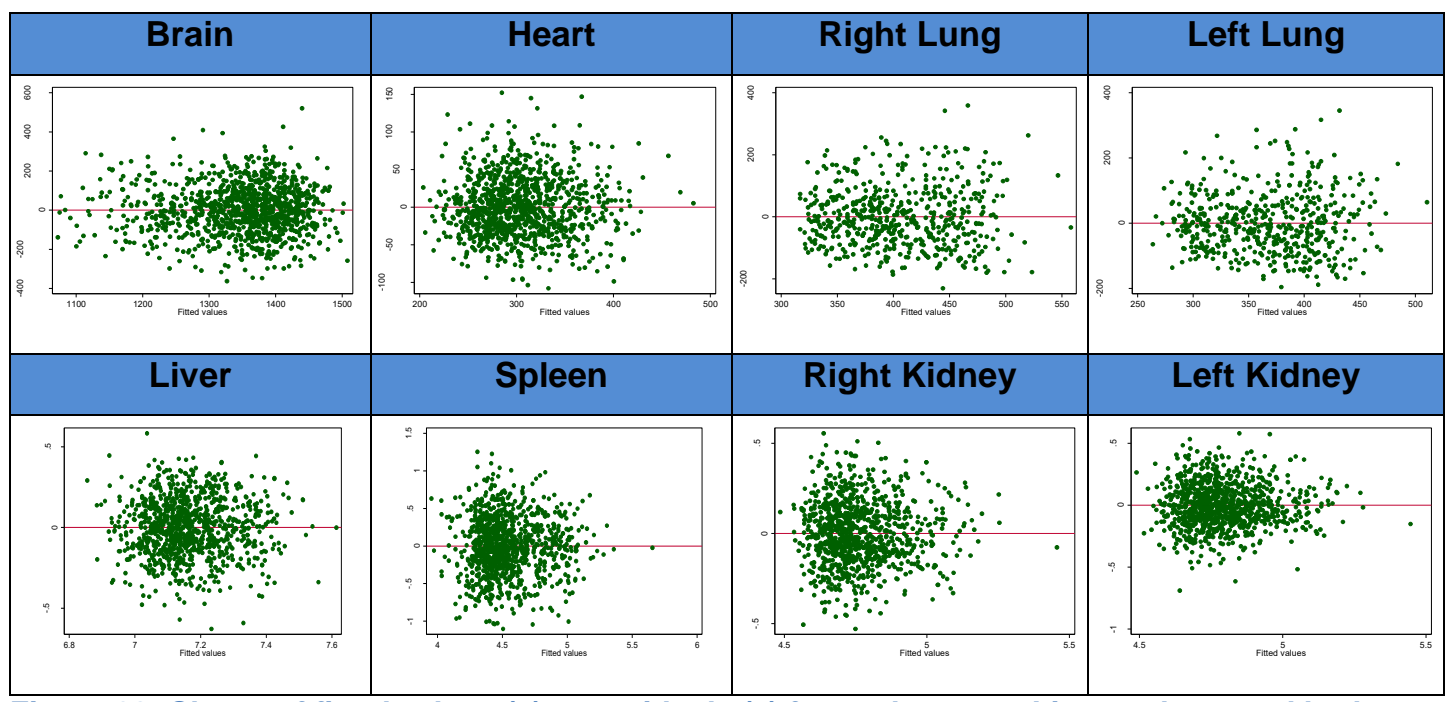

Figure 28: Charts of fitted values (x) vs residuals (y) for each organ. Liver, spleen, and both kidney weights used were the log transformations of the data.

Variance inflation factors were computed for the predictor variables within each final organ weight model. Ignoring spurious collinearity between interaction variables and 
their components, as well as that between levels of categorical variables, none was found. Variance inflation factors were uniformly less than 3 , which indicates that the predictor variables indeed meet the assumption of no collinearity.

The distribution of the errors of the regression equation were tested for normality by creating quantile-quantile plots, illustrated in Figure 29. Deviation from normal can be seen at the range extremes, as is expected. This fit is good enough to satisfy the final assumption that the errors are normally distributed.

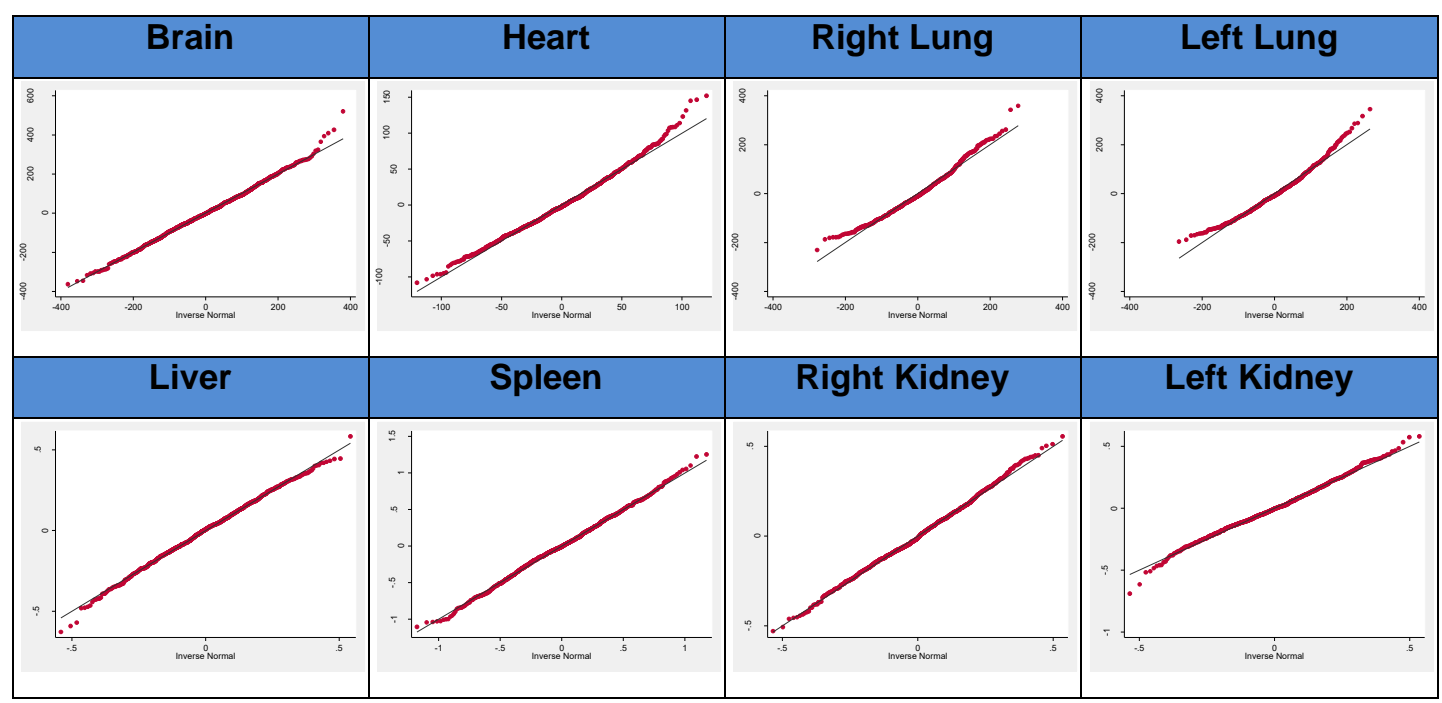

Figure 29: Quantile-quantile plots for each organ model. Liver, spleen, and kidney weights used were the log transformed data.

\subsubsection{Final Multiple Linear Regression Models}

The final linear regression models for each organ are presented in Tables 17-24 below. The trends of the significant predictor variables for each organ follow those discussed in the basic models of Tables 9-16. Additionally, the effects of the interaction variables found to be significant can be appreciated. Where an interaction variable is significant and included, the main variables that it consists of must also be included in the model, even if alone they are not significant. Included in these models are the standardised regression coefficients, in the column marked $\beta$. Their absolute values may be directly compared to assess the relative strength of the predictor variables.

\begin{tabular}{|c|c|c|c|c|c|}
\hline Source & SS & df & MS & $\begin{array}{l}\text { Number of } \\
\text { observations }\end{array}$ & 1136 \\
\hline \multirow[t]{2}{*}{ Model } & \multirow{2}{*}{$\begin{array}{l}69379 \\
35\end{array}$} & \multirow[t]{2}{*}{9} & \multirow{2}{*}{$\begin{array}{l}770881 . \\
7\end{array}$} & $F(9,1126)$ & 51.93 \\
\hline & & & & Probability > F & 0 \\
\hline
\end{tabular}




\begin{tabular}{|c|c|c|c|c|c|c|}
\hline Residual & $\begin{array}{l}16714 \\
301\end{array}$ & 1126 & $\begin{array}{l}14843.9 \\
6\end{array}$ & \multicolumn{2}{|l|}{$\mathbf{R}^{2}$} & 0.293 \\
\hline \multirow[t]{2}{*}{ Total } & \multirow{2}{*}{$\begin{array}{l}23652 \\
236\end{array}$} & \multirow[t]{2}{*}{1135} & \multirow{2}{*}{$\begin{array}{l}20838.9 \\
7\end{array}$} & \multicolumn{2}{|l|}{ Adjusted $\mathbf{R}^{2}$} & 0.287 \\
\hline & & & & \multicolumn{2}{|l|}{ Root MSE } & 121.84 \\
\hline Brain & Coef. & Std. Err. & $\bar{\beta}$ & Probability>t & \multicolumn{2}{|c|}{$\begin{array}{l}\text { 95\% Confidence } \\
\text { Interval }\end{array}$} \\
\hline Female & -61.21 & 21.467 & -0.198 & 0.004 & -103.34 & $\mid-19.09$ \\
\hline White & 14.97 & 12.667 & 0.041 & 0.238 & -9.883 & 39.824 \\
\hline Coloured & -48.39 & 9.793 & -0.164 & 0 & -67.600 & -29.17 \\
\hline Age & -1.232 & 0.266 & -0.148 & 0 & -1.755 & -0.708 \\
\hline Height & 1.846 & 0.534 & 0.114 & 0.001 & 0.798 & 2.894 \\
\hline Weight & 0.683 & 0.237 & 0.086 & 0.004 & 0.217 & 1.149 \\
\hline Female*Age & -1.561 & 0.454 & -0.241 & 0.001 & -2.454 & -0.668 \\
\hline Female*White & 48.13 & 22.709 & 0.080 & 0.034 & 3.574 & 92.689 \\
\hline Female ${ }^{\star}$ Coloured & 17.41 & 17.790 & 0.039 & 0.328 & -17.492 & 52.319 \\
\hline Baseline & 1095.8 & 86.206 & & 0 & 926.66 & 1264.9 \\
\hline
\end{tabular}

Table 17: Final multiple linear regression model for brain weight. SS = sum of squares; df = degrees of freedom; MS = mean squares; MSE = mean square error; Coef. = coefficient; Std.

Err. = standard error.

The above model for brain weight reveals that in addition to all the independent variables considered, the interactions of sex with age and race are important. Together, these can statistically significantly predict brain weight, with this model accounting for $29 \%$ of this organ's weight variability.

\begin{tabular}{|c|c|c|c|c|c|c|}
\hline Source & SS & df & MS & \multicolumn{2}{|l|}{$\begin{array}{l}\text { Number of } \\
\text { observations }\end{array}$} & 1085 \\
\hline \multirow[t]{2}{*}{ Model } & \multirow{2}{*}{$\begin{array}{l}19361 \\
57\end{array}$} & \multirow[t]{2}{*}{9} & \multirow[t]{2}{*}{215129} & \multicolumn{2}{|l|}{$F(9,1075)$} & 143.21 \\
\hline & & & & \multicolumn{2}{|l|}{ Probability $>$ F } & 0 \\
\hline Residual & $\begin{array}{l}16148 \\
94\end{array}$ & 1075 & 1502.2 & \multicolumn{2}{|l|}{$\mathbf{R}^{2}$} & 0.545 \\
\hline \multirow[t]{2}{*}{ Total } & \multirow{2}{*}{$\begin{array}{l}35510 \\
51\end{array}$} & \multirow[t]{2}{*}{1084} & \multirow{2}{*}{$\begin{array}{l}3275.8 \\
8\end{array}$} & \multicolumn{2}{|l|}{ Adjusted $\mathrm{R}^{2}$} & 0.541 \\
\hline & & & & \multicolumn{2}{|l|}{ Root MSE } & 38.759 \\
\hline Heart & Coef. & $\begin{array}{l}\text { Std. } \\
\text { Err. }\end{array}$ & $\beta$ & Probability>t & \multicolumn{2}{|c|}{$\begin{array}{l}95 \% \text { Confidence } \\
\text { Interval }\end{array}$} \\
\hline Female & -7.886 & 11.453 & -0.065 & 0.491 & -30.36 & 14.588 \\
\hline White & 9.761 & 4.476 & 0.062 & 0.029 & 0.977 & 18.544 \\
\hline Coloured & -5.299 & 3.148 & -0.046 & 0.093 & -11.477 & 0.878 \\
\hline Age & 1.035 & 0.075 & 0.289 & 0 & 0.887 & 1.183 \\
\hline Height & 0.526 & 0.171 & 0.082 & 0.002 & 0.189 & 0.863 \\
\hline Weight & 1.870 & 0.104 & 0.551 & 0 & 1.666 & 2.074 \\
\hline Female*Weight & -0.588 & 0.149 & -0.350 & 0 & -0.882 & -0.294 \\
\hline Female*White & 4.621 & 7.562 & 0.018 & 0.541 & -10.21 & 19.461 \\
\hline Female ${ }^{\star}$ Coloured & 21.35 & 5.672 & 0.125 & 0 & 10.221 & 32.480 \\
\hline Baseline & 60.08 & 28.049 & 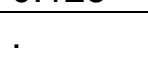 & 0.032 & 5.045 & 115.12 \\
\hline
\end{tabular}

Table 18: Final multiple linear regression model for heart weight. Notation as for Table 17. 
The heart weight model shows that body weight, age, height and race are significant predictors, with the interactions of sex with weight and race also being influential. Together, these can statistically significantly predict heart weight, with this model accounting for $54 \%$ of this organ's weight variability.

\begin{tabular}{|c|c|c|c|c|c|c|}
\hline Source & SS & df & MS & \multicolumn{2}{|l|}{$\begin{array}{l}\text { Number of } \\
\text { observations }\end{array}$} & 559 \\
\hline \multirow[t]{2}{*}{ Model } & \multirow{2}{*}{$\begin{array}{l}12598 \\
25\end{array}$} & \multirow[t]{2}{*}{13} & \multirow{2}{*}{$\begin{array}{l}96909 . \\
6\end{array}$} & \multicolumn{2}{|l|}{$F(13,545)$} & 10.41 \\
\hline & & & & \multicolumn{2}{|l|}{ Probability $>$ F } & 0 \\
\hline Residual & $\begin{array}{l}50719 \\
82\end{array}$ & 545 & 9306.4 & \multicolumn{2}{|l|}{ R-squared } & 0.199 \\
\hline \multirow[t]{2}{*}{ Total } & \multirow{2}{*}{$\begin{array}{l}63318 \\
06\end{array}$} & \multirow[t]{2}{*}{558} & \multirow{2}{*}{$\begin{array}{l}11347 . \\
3\end{array}$} & \multicolumn{2}{|l|}{ Adjusted $\mathbf{R}^{2}$} & 0.179 \\
\hline & & & & \multicolumn{2}{|l|}{ Root MSE } & 96.47 \\
\hline Right lung & Coef. & $\begin{array}{l}\text { Std. } \\
\text { Err. }\end{array}$ & $\beta$ & Probability>t & \multicolumn{2}{|c|}{$\begin{array}{l}95 \% \text { Confidence } \\
\text { Interval }\end{array}$} \\
\hline Female & 21.68 & 24.214 & 0.096 & 0.371 & -25.884 & 69.246 \\
\hline White & -14.88 & 57.634 & -0.054 & 0.796 & -128.1 & 98.330 \\
\hline Coloured & -2.632 & 42.062 & -0.012 & 0.95 & -85.256 & 79.992 \\
\hline Age & 2.710 & 0.508 & 0.421 & 0 & 1.710 & 3.709 \\
\hline Height & 0.745 & 0.212 & 0.065 & 0.022 & 0.457 & 1.033 \\
\hline Weight & 0.029 & 0.383 & 0.005 & 0.938 & -0.722 & 0.782 \\
\hline Female*Age & -1.977 & 0.542 & -0.407 & 0 & -3.043 & -0.911 \\
\hline Female*White & 113.3 & 28.081 & 0.247 & 0 & 58.092 & 168.42 \\
\hline Female ${ }^{\star}$ Coloured & -18.02 & 19.991 & -0.055 & 0.368 & -57.285 & 21.253 \\
\hline White*Age & -2.583 & 0.697 & -0.504 & 0 & -3.953 & -1.213 \\
\hline White`Weight & 1.403 & 0.590 & 0.419 & 0.018 & 0.242 & 2.564 \\
\hline ColouredAge & -0.625 & 0.616 & -0.134 & 0.31 & -1.836 & 0.584 \\
\hline Coloured ${ }^{\star W e i g h t ~}$ & 0.315 & 0.545 & 0.100 & 0.563 & -0.755 & 1.386 \\
\hline Baseline & 190.4 & 99.909 & & 0.057 & -5.851 & 386.66 \\
\hline
\end{tabular}

Table 19: Final multiple linear regression model for right lung weight. Notation as for Table 17.

The multiple linear regression model for right lung weight reveals that in addition to age and height, there are significant interactions sex with age and race, and race with age and height. Together, these can statistically significantly predict right lung weight, with this model accounting for $18 \%$ of this organ's weight variability.

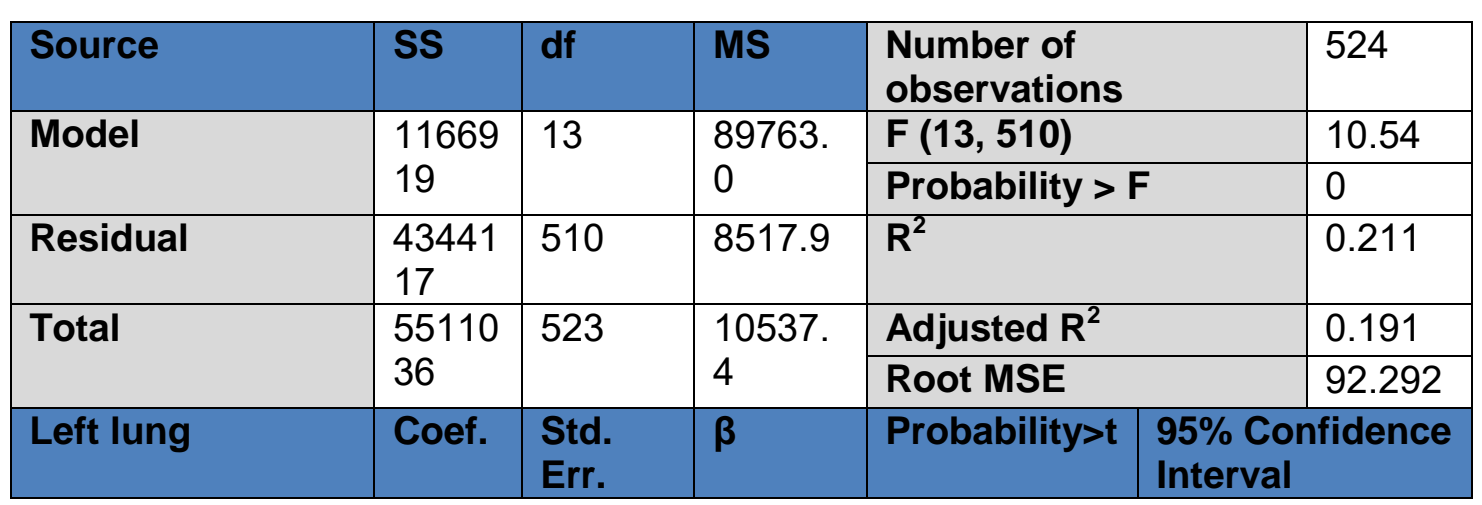




\begin{tabular}{|l|l|l|l|l|l|l|}
\hline Female & -10.11 & 23.841 & -0.046 & 0.672 & -56.952 & 36.726 \\
\hline White & 28.15 & 55.861 & 0.109 & 0.614 & -81.594 & 137.90 \\
\hline Coloured & 0.881 & 42.252 & 0.004 & 0.983 & -82.128 & 83.892 \\
\hline Age & 1.916 & 0.510 & 0.308 & 0 & 0.914 & 2.919 \\
\hline Height & 2.172 & 0.612 & 0.199 & 0 & 0.967 & 3.376 \\
\hline Weight & -0.022 & 0.371 & -0.004 & 0.951 & -0.753 & 0.708 \\
\hline Female*Age & -1.038 & 0.538 & -0.221 & 0.054 & -2.097 & 0.019 \\
\hline Female*White & 109.1 & 27.478 & 0.251 & 0 & 55.074 & 163.04 \\
\hline Female*Coloured & -0.799 & 19.890 & -0.003 & 0.968 & -39.877 & 38.278 \\
\hline White*Age & -2.483 & 0.685 & -0.503 & 0 & -3.830 & -1.137 \\
\hline White*Weight & 0.948 & 0.579 & 0.299 & 0.102 & -0.189 & 2.086 \\
\hline Coloured*Age & -0.146 & 0.621 & -0.033 & 0.814 & -1.367 & 1.074 \\
\hline Coloured*Weight & -0.016 & 0.557 & -0.005 & 0.976 & -1.110 & 1.078 \\
\hline Baseline & -56.32 & 100.43 & - & 0.575 & -253.63 & 140.98 \\
\hline
\end{tabular}

Table 20: Final multiple linear regression model for left lung weight. Notation as for Table 17.

The final regression for left lung weight confirms that in this paired organ, the same factors are predictive as those found in the right lung weight model. These variables statistically significantly predict left lung weight, with this model accounting for $19 \%$ of this organ's weight variability.

The regression models for the log-transformed data used to model the liver, spleen, and kidneys are interpreted slightly differently. Instead of coefficients, the geometric mean ratio is used. This reflects the proportional change in the predicted mean organ weight for every one unit increase in the variable in question. The geometric mean is used instead of arithmetic mean because the distribution was skewed. For example, in the liver weight model below, female sex results in a decrease in the organ weight to $95.8 \%$ of its value in a male decedent. Likewise, every $1 \mathrm{~kg}$ increase in body weight results in an increase to $100.5 \%$ of the baseline mean liver weight.

\begin{tabular}{|c|c|c|c|c|c|c|}
\hline Source & SS & df & MS & \multicolumn{2}{|c|}{$\begin{array}{l}\text { Number of } \\
\text { observations }\end{array}$} & $=1054$ \\
\hline \multirow[t]{2}{*}{ Model } & \multirow{2}{*}{$\begin{array}{l}13.408393 \\
8\end{array}$} & \multirow[t]{2}{*}{8} & \multirow{2}{*}{$\begin{array}{l}1.6760 \\
4922\end{array}$} & \multicolumn{2}{|c|}{$F(8,1045)$} & $=54.73$ \\
\hline & & & & \multicolumn{2}{|l|}{ Prob $>$ F } & $=0$ \\
\hline Residual & 32.000279 & 1045 & .03062 & \multicolumn{2}{|c|}{ R-squared } & $=0.2953$ \\
\hline \multirow[t]{2}{*}{ Total } & \multirow{2}{*}{$\begin{array}{l}45.408672 \\
3\end{array}$} & \multirow[t]{2}{*}{1053} & \multirow{2}{*}{$\begin{array}{l}0.0431 \\
23146\end{array}$} & \multicolumn{2}{|c|}{ Adj R-squared } & $=0.2899$ \\
\hline & & & & \multicolumn{2}{|c|}{ Root MSE } & $\begin{array}{l}=0.1749 \\
9\end{array}$ \\
\hline Liver & GM/Ratio & $\begin{array}{l}\text { Std. } \\
\text { Err. }\end{array}$ & $\bar{\beta}$ & $\begin{array}{l}\text { Probability } \\
>t\end{array}$ & \multicolumn{2}{|c|}{$\begin{array}{l}95 \% \text { Confidence } \\
\text { Interval }\end{array}$} \\
\hline Female & 0.958 & 0.013 & -0.094 & 0.002 & 0.933 & 0.984 \\
\hline White & 1.278 & 0.053 & 0.440 & 0 & 1.177 & 1.387 \\
\hline
\end{tabular}




\begin{tabular}{|l|l|l|l|l|l|l|}
\hline Coloured & 1.183 & 0.037 & 0.400 & 0 & 1.112 & 1.259 \\
\hline Age & 1.002 & 0.000 & 0.176 & 0 & 1.001 & 1.003 \\
\hline Height & 1.002 & 0.000 & 0.103 & 0.003 & 1.000 & 1.003 \\
\hline Weight & 1.005 & 0.000 & 0.404 & 0 & 1.004 & 1.006 \\
\hline White*Age & 0.995 & 0.000 & -0.369 & 0 & 0.994 & 0.997 \\
\hline Coloured*Age & 0.996 & 0.000 & -0.369 & 0 & 0.995 & 0.998 \\
\hline Baseline & 547.403 & 70.805 & & 0 & 424.696 & $\begin{array}{l}705.56 \\
3\end{array}$ \\
\hline
\end{tabular}

Table 21: Final multiple linear regression model for liver weight. SS = sum of squares; df = degrees of freedom; MS = mean squares; MSE = mean square error; GM/Ratio= geometric mean ratio; Std. Err. = standard error.

The multiple linear regression model for liver weight shows all independent variables considered to be significant predictors, and additionally the interaction of race with age is important. This model statistically significantly predicts liver weight, and accounts for $29 \%$ of this organ's weight variability.

\begin{tabular}{|c|c|c|c|c|c|c|}
\hline Source & SS & df & MS & \multicolumn{2}{|c|}{$\begin{array}{l}\text { Number of } \\
\text { observations }\end{array}$} & 1078 \\
\hline \multirow[t]{2}{*}{ Model } & \multirow{2}{*}{$\begin{array}{l}55.891534 \\
1\end{array}$} & \multirow[t]{2}{*}{7} & \multirow{2}{*}{$\begin{array}{l}7.9845 \\
0487\end{array}$} & \multicolumn{2}{|c|}{$F(7,1070)$} & 55.62 \\
\hline & & & & \multicolumn{2}{|c|}{ Probability > F } & 0 \\
\hline Residual & 153.599 & 1070 & 0.1436 & $\mathbf{R}^{2}$ & & 0.2668 \\
\hline \multirow[t]{2}{*}{ Total } & \multirow{2}{*}{$\begin{array}{l}209.48057 \\
1\end{array}$} & \multirow[t]{2}{*}{1077} & \multirow{2}{*}{$\begin{array}{l}0.1945 \\
13065\end{array}$} & \multicolumn{2}{|l|}{ Adjusted $\mathbf{R}^{2}$} & 0.2620 \\
\hline & & & & \multicolumn{2}{|l|}{ Root MSE } & 0.3789 \\
\hline Spleen & GM/Ratio & $\begin{array}{l}\text { Std. } \\
\text { Err. }\end{array}$ & $\beta$ & $\begin{array}{l}\text { Probabilit } \\
y>t\end{array}$ & \multicolumn{2}{|c|}{$\begin{array}{l}\text { 95\% Confidence } \\
\text { Interval }\end{array}$} \\
\hline White & 1.138 & 0.150 & 0.117 & 0.327 & 0.877 & 1.477 \\
\hline Coloured & 0.742 & 0.079 & -0.331 & 0.006 & 0.601 & 0.917 \\
\hline Age & 0.997 & 0.000 & -0.091 & 0.001 & 0.996 & 0.999 \\
\hline Height & 1.003 & 0.001 & 0.076 & 0.012 & 1.000 & 1.006 \\
\hline Weight & 1.007 & 0.000 & 0.292 & 0 & 1.005 & 1.009 \\
\hline White`Weight & 1.002 & 0.001 & 0.149 & 0.224 & 0.998 & 1.005 \\
\hline ColouredWeight & 1.004 & 0.001 & 0.359 & 0.002 & 1.001 & 1.007 \\
\hline Baseline & 31.082 & 7.691 & & 0 & 19.13 & 50.509 \\
\hline
\end{tabular}

Table 22: Final multiple linear regression model for spleen weight. Notation as for Table 21.

The linear regression model above reveals that sex is not a significant predictor of spleen weight. Race, age, height, and weight are important, as are the interactions of race with weight. Together, these can statistically significantly predict spleen weight, with this model accounting for $26 \%$ of this organ's weight variability.

\begin{tabular}{|l|l|l|l|l|l|}
\hline Source & SS & df & MS & $\begin{array}{l}\text { Number of } \\
\text { observations }\end{array}$ & 1000 \\
\hline Model & 22709.93 & 9 & 2523 & $\mathbf{F ~ ( 8 , ~ 9 9 1 ) ~}$ & 65.77 \\
\cline { 5 - 6 } & & & & Probability > F & 0 \\
\hline
\end{tabular}




\begin{tabular}{|c|c|c|c|c|c|c|}
\hline Residual & 29.865 & 991 & 0.03 & \multicolumn{2}{|l|}{$\mathbf{R}^{2}$} & 0.3468 \\
\hline \multirow[t]{2}{*}{ Total } & \multirow[t]{2}{*}{22739.79} & \multirow[t]{2}{*}{1000} & \multirow[t]{2}{*}{22.7} & \multicolumn{2}{|l|}{ Adjusted $\mathbf{R}^{2}$} & 0.3415 \\
\hline & & & & \multicolumn{2}{|l|}{ Root MSE } & 0.1736 \\
\hline Right Kidney & GM/Ratio & $\begin{array}{l}\text { Std. } \\
\text { Err. }\end{array}$ & $\bar{\beta}$ & Probability>t & \multicolumn{2}{|c|}{$\begin{array}{l}95 \% \text { Confidence } \\
\text { Interval }\end{array}$} \\
\hline Female & 1.199 & 0.064 & 0.394 & 0.001 & 1.079 & 1.331 \\
\hline White & 1.069 & 0.017 & 0.121 & 0 & 1.035 & 1.105 \\
\hline Coloured & 1.049 & 0.013 & 0.111 & 0 & 1.024 & 1.075 \\
\hline Age & 1.001 & 0.000 & 0.139 & 0 & 1.001 & 1.002 \\
\hline Height & 1.002 & 0.000 & 0.106 & 0.002 & 1.000 & 1.004 \\
\hline Weight & 1.006 & 0.000 & 0.502 & 0 & 1.005 & 1.006 \\
\hline Female $^{\star}$ Age & 0.997 & 0.000 & -0.217 & 0.002 & 0.996 & 0.999 \\
\hline Female*Weight & 0.997 & 0.000 & -0.340 & 0.001 & 0.996 & 0.999 \\
\hline Baseline & 45.869 & 5.991 & & 0 & 35.498 & 59.272 \\
\hline
\end{tabular}

Table 23: Final multiple linear regression model for right kidney weight. Notation as for Table 21.

The right kidney weight model shows that all independent variables considered are significant predictors, with the interactions of sex with weight and age also being influential. Together, these can statistically significantly predict right kidney weight, with this model accounting for $34 \%$ of this organ's weight variability.

\begin{tabular}{|c|c|c|c|c|c|c|}
\hline Source & SS & $d f$ & MS & \multicolumn{2}{|l|}{$\begin{array}{l}\text { Number of } \\
\text { observations }\end{array}$} & 998 \\
\hline \multirow[t]{2}{*}{ Model } & \multirow[t]{2}{*}{16.568361} & \multirow[t]{2}{*}{8} & \multirow[t]{2}{*}{2550} & \multicolumn{2}{|l|}{$F(8,989)$} & 68.50 \\
\hline & & & & \multicolumn{2}{|l|}{ Probability $>F$} & 0 \\
\hline Residual & 29.90133 & 989 & 0.03 & \multicolumn{2}{|l|}{$\mathbf{R}^{2}$} & 0.3565 \\
\hline \multirow[t]{2}{*}{ Total } & \multirow[t]{2}{*}{46.469694} & \multirow[t]{2}{*}{997} & \multirow[t]{2}{*}{23.0} & \multicolumn{2}{|l|}{ Adjusted $R^{2}$} & 0.3513 \\
\hline & & & & \multicolumn{2}{|l|}{ Root MSE } & 0.17389 \\
\hline Left Kidney & GM/Ratio & $\begin{array}{l}\text { Std. } \\
\text { Err. }\end{array}$ & $\beta$ & Probability>t & \multicolumn{2}{|c|}{$\begin{array}{l}95 \% \text { Confidence } \\
\text { Interval }\end{array}$} \\
\hline Female & 1.175 & 0.062 & 0.348 & 0.003 & 1.058 & 1.305 \\
\hline White & 1.065 & 0.017 & 0.112 & 0 & 1.031 & 1.100 \\
\hline Coloured & 1.049 & 0.013 & 0.110 & 0 & 1.024 & 1.075 \\
\hline Age & 1.001 & 0.000 & 0.139 & 0 & 1.001 & 1.002 \\
\hline Height & 1.002 & 0.000 & 0.122 & 0 & 1.001 & 1.004 \\
\hline Weight & 1.005 & 0.000 & 0.481 & 0 & 1.004 & 1.006 \\
\hline Female $^{\star}$ Age & 0.997 & 0.000 & -0.275 & 0 & 0.995 & 0.998 \\
\hline Female $^{\star}$ Weight & 0.998 & 0.000 & -0.264 & 0.011 & 0.997 & 0.999 \\
\hline Baseline & 44.923 & 5.889 & & 0 & 34.732 & 58.103 \\
\hline
\end{tabular}

Table 24: Final multiple linear regression model for left kidney weight. Notation as for Table 21.

Like the right kidney, all independent variables studied are significant predictors, and the interactions of sex with age and weight are important. This linear regression model statistically significantly predicts left kidney weight, with the model accounting for $35 \%$ of this organ's weight variability. 


\section{Discussion}

\subsection{General Comments}

The organ weight reference ranges currently in use at UCT are not acceptable because of methodological failings and the fact that they do not represent our South African population. These issues notwithstanding, time alone makes them unusable today.

This study gathered data on a suitable non-hospital population, using clinical criteria at autopsy to exclude unhealthy organs. Disproportionate randomized stratified sampling was performed to obtain sufficient case numbers from all subpopulations presenting to our mortuary. The total of 1262 decedents used is significantly more than many previous studies and provides a robust sample size. It must be borne in mind that certain groups, particularly White women and older African women are still relatively underrepresented. This means that conclusions that are drawn from these data may not be accurate in terms of the true population parameters. We were also only able to include approximately half the number of lungs, compared to the other organs studied. This is because these organs were often excluded due to injury or terminal fluid shifts. In addition, there was also an unprecedented burden of pulmonary tuberculosis noted at autopsy in our sample, especially among older Coloured decedents.

The figures of organ exclusions are important because they provide accountability for the data and give an indication of the distribution of pathologies in the decedents considered. They reveal not only the advance of natural disease with age, but also social risk factors, such as the large numbers of suicide deaths in White decedents, gunshot deaths in younger Coloured men, and blunt force trauma (mostly pedestrian vehicle accidents) in older African women. These trends cannot be commented on further as the study was not designed to evaluate them. 


\subsection{Analysis of Factors Influencing Organ Weights}

One factor which must be mentioned is the laterality of paired organs. This study confirms that right lung weights are significantly heavier than left lung weights. Our data also shows that left kidney weights in the Salt River Mortuary population are consistently higher than the right kidney weights, for all population subgroups. This agrees with Molina but contrasts with de la Grandmaison's work, which found that the right kidney was heavier than the left.

The associations of organ weight with age, height, body weight and sex in other studies have been inconsistent and often contradictory. Along with race as an additional factor, these independent variables were selected to investigate whether they have any bearing on organ weights in our population.

\subsubsection{Sex}

Most research has found organ weights to be bigger in males than females. ${ }^{10,11,17,20,26}$ However, some reports suggest that after controlling for other variables, certain organ weights are actually similar between the sexes: in various studies the heart and spleen, ${ }^{26}$ the lungs, ${ }^{13}$ and the kidneys. ${ }^{24}$

In the current study, without controlling for any other factors, sex was found to have $\mathrm{R}^{2}$ values of between 0.17 (brain) and 0 (spleen). After running regression analyses on the data, which controlled for age, height, weight and race, it was found that in line with most previous research, female sex was associated with significantly lower organ weights for all organs except the spleen.

In the final multiple linear regression models, which controlled for all variables and interactions considered, comparison of the magnitudes of the standardised regression coefficients allows deeper insight into the relative importance of each variable. In this case, they show that indeed, sex as well as its interaction with age are the strongest predictors of brain weight, where a negative correlation between female sex and brain weight was found. Sex also has an important impact on heart weight, where its interaction with body weight is the second most influential predictor variable. The coefficients indicate that both sexes gain $1.9 \mathrm{~g}$ of heart weight per kilogram body weight, but there is an additional negative term for 
females: $0.6 \mathrm{~g}$ lower predicted heart weight per kilogram body weight, meaning that a man's heart weight increases to a greater extent than a woman's with increasing body weight. It is possible that this reflects the relative protection from cardiovascular disease enjoyed by pre-menopausal women. ${ }^{59}$ The kidneys are the other organs significantly impacted by sex, which also has significant interactions with age and weight in the regression models.

On the other hand, sex alone is statistically significant but relatively unimportant in the liver and lung weight models, where again female sex was a negative predictor. It should be noted that in the lung models there are significant interactions with age and race. There was no statistically significant effect of sex on the spleen weights observed, which agrees with one of the studies mentioned.

These findings on the impact of sex on organ weight are useful because they may indicate that different organ weight reference ranges are required for men and women.

\subsubsection{Age}

Research on both the living and the dead has found that organ weights decrease with age, particularly the brain. ${ }^{10,39}$ This is consistent with our data, where the negative predictive value of age on brain weight was confirmed on initial multivariable regression. The final model showed that is an effect particularly strong in women.

The exception to the trend of declining organ weight with age is the weight of the heart, which possibly reflects age-related cardiac pathology. ${ }^{10,26}$ Univariate analysis of our data produced an $\mathrm{R}^{2}$ value of 0.12 , which was the largest of all the organs. In the final multiple linear regression models, standardised regression coefficients show that age has a comparatively important positive association with heart weight, although the effect of body weight is much more dominant. It must be noted that Zeek's classical study found that age only affects the weight of healthy hearts after the ages of 69 and 49 years in men and women respectively. ${ }^{23}$ Fortuitously, 50 years was the watershed age in our stratified sampling of different age groups. Reviewing Figure 18, it can be observed that indeed mean heart weights are substantially larger in the African and Coloured women older than 49 years, 
compared to their younger counterparts. The same effect is not seen in the White women.

Univariate analyses found $\mathrm{R}^{2}$ values for age of 0 for the liver and spleen. However, after controlling for other variables a statistically significant negative association with spleen weight was found, in line with previous research. Age alone did not significantly predict liver weight without considering interaction effects. There was an unexpected finding with respect to lung and kidney weights in this study, as initial multivariable regression analyses yielded statistically significantly increased weights of these organs with age.

In the final multiple linear regression models, there are statistically significant but relatively unimportant negative correlations of age with kidney and liver weights, where it was found that most of its negative effects pertain to older women (kidneys) and White/Coloured older people (liver). Age also has a statistically significant negative correlation with spleen weight, although again it is of minimal predictive power in these data. An unexpectedly strong association of age with lung weights was found. This effect is positive, however equally strong are the negative interactions of age with female sex and White race, meaning that the increased lung weights with age occurs in African and Coloured men. When we consider the organ exclusions detailed in Figures 7 and 15, a possible reason for this may be the large burden of lung disease in these subpopulations. If this was not always noted by the Pathologist at autopsy, then heavy, diseased lungs could have been inadvertently included in our sample.

The result of this discussion on the effects of age on organ weights is important, as it reaffirms what other researchers have found, which validates our study. This exercise also highlights the importance of understanding and controlling for confounding variables in data analysis, because very different results can be obtained.

\subsubsection{Body Weight}

Previous research shows that body weight positively corresponds to organ weight, especially to that of the heart. ${ }^{10,17,26,27,40}$ Univariate analyses of these data yielded various coefficients of correlation. The largest $R^{2}$ was for the heart at 0.29 , which fell short of the 0.53 and 0.66 reported by Molina for men and women respectively, bearing in mind that their studies partially control for age. ${ }^{17,36} \mathrm{We}$ found associations 
with body weight of similar magnitude for the liver, kidney and spleen weights. Like Molina's sample, our data showed poor correlation of body weight with lung and brain weight. All organs studied showed statistically significant positive associations with body weight after the initial regression analyses, controlling for sex, age, height, and race.

The standardised regression coefficients from the final multiple linear regression models confirm that body weight is the most important predictor of heart weight. This supports Smith's work from 1933 wherein he proposed predicted heart weights based on body weight. Body weight is also the most influential variable in kidney weight determination, and it is the second strongest predictor of liver weight. In the spleen, body weight alone is significant, and its interaction with race (specifically, Coloured race) is the predictor with the most effect. In the lung model, there is a significant interaction of body weight with race, specifically White race. In all these cases the increased body weight is associated with increased organ weight. An exception to these findings is the statistically significant, but relatively unimportant, positive correlation of body weight with brain weight.

The outcome of this investigation into the relationship of body weight to organ weights makes logical sense. We find that the weight of solid organs, apart from the central nervous system, are considerably dependent on body weight. This notwithstanding, the variability in organ weight accounted for by body weight alone is too small to responsibly predict specific organ weights based on this factor alone.

\subsubsection{Height}

Many studies show a positive association between heart weight and height. ${ }^{10,17,27}$ Zeek's research yielded correlation coefficients of 0.33 (men) and 0.29 (women) ${ }^{23}$ while Molina's produced lower $R^{2}$ values of 0.13 for both sexes. ${ }^{17,36}$ Our univariate analysis resulted in an intermediate $R^{2}$ value of 0.18 . Regarding the liver and spleen, de la Grandmaison, controlling for sex, also found strong positive correlations to height. Molina found $R^{2}$ values of 0.06 (men) and 0.2 (women) for the liver, whereas our univariate regression produced an $R^{2}$ value of 0.13 . For the spleen, Molina reported values of 0.07 (men) and 0.11 (women); ours was calculated as 0.9 , which is in line with their findings. Most previous research has found that the correlation with height was weak or not significant for other 
organs. ${ }^{10,26}$ This is also true for our data, except for the kidneys, which both had $\mathrm{R}^{2}$ values of 0.26 .

After running initial regression analyses on the data, which controlled for age, height, weight and race, there remained a positive predictive influence of height on all the organs considered. In the final multiple linear regression models, standardised regression coefficients show that although height remains a statistically significant predictor of organ weight, it is at best of intermediate importance (in the brain, liver, kidneys and lungs) and is frankly trivial in the heart and spleen weights. There are moreover no significant interaction terms involving height.

The finding that height is only of intermediate, or little significance to organ weight is somewhat surprising. This should inform special caution in using a predictive range for organ weight based on height, such as Zeek's, which was developed without controlling for other confounding factors. To provide concrete figures, our model suggests that height is only $1 / 6^{\text {th }}$ as predictive of heart weight as is body weight.

\subsubsection{Ethnicity}

MRI studies in living patients, which investigated organ weight disparity between racial groups, report conflicting results. One showed that the mean summed weight of high metabolic rate organs (liver, heart, spleen, kidneys, and brain), is significantly higher in White compared to African American patients, ${ }^{41}$ while another found minimal variation. ${ }^{38}$ In post-mortem research, most comparisons of organ weights in different race groups have not find significant differences, after controlling for other factors. ${ }^{1224}$

It must be emphasised that this study has treated ethnicity as a categorical variable, whereas indubitably in South Africa there is a spectrum of the cultural and genetic diversity that we identify as race. Apart from the potential racially associated genetic differences, we have the unique recent history of Apartheid. This means that in South Africa race may in fact serve as a proxy variable for other factors, for example prenatal nutrition, which may in turn affect organ weight.

When comparing organ weight data between the race groups in our sample, it was found that for every organ except the brain, the mean organ weight is significantly 
more in White compared to African decedents, and insignificantly different between African and Coloured decedents. Only in the brain is there also significant variation between the Coloured and African mean weights. Univariate regression on our data showed uniformly weak coefficients of correlation of race with organ weight; the largest was the spleen, at 0.10 . However, the initial multivariable regression showed that race remained a statistically significant predictor of the weight of all organs, except the lungs, even after controlling for any age, sex, height, and weight confounders.

The final multiple linear regression analyses further refined these results, allowing a clearer picture to be appreciated. Inspecting the standardised regression coefficients suggests that race and its interactions are statistically significant, but relatively unimportant, predictors of heart, kidney, and brain weights. White race predicted a heavier heart, and the kidneys of White and Coloured decedents were consistently respectively $7 \%$ and $5 \%$ heavier than their African counterparts. For the brain, Coloured race predicts a $48 \mathrm{~g}$ smaller brain mass, while a White female decedent should have a $48 \mathrm{~g}$ heavier brain than the African baseline group. In the lungs, race alone is not statistically significant, but it does have significant interactions with weight and sex as previously discussed.

The organs where race was both statistically and clinically significant were the liver and spleen. Race was the chief determinant of liver weight in our sample, and its interaction with age was also significant. White and Coloured race predicted heavier liver weights, amounting to $128 \%$ and $118 \%$ of the African baseline weight respectively. The explanation for this finding is uncertain: it could relate to racial variation in the weights of highly metabolically active organs, or to some other factor such as differences in prevalence of microscopic fatty change which could increase organ weight.

The most influential determinant of spleen weight was also race. Here, White race predicted a spleen weight of $114 \%$ of the baseline, while Coloured race was associated with a markedly smaller value of $74 \%$ of the baseline. Race also had a significant interaction with weight, the other important predictor variable in spleen weight. This may be a true representation of racial differences in population parameters, but an alternative hypothesis could be that spleen weights are larger in White decedents due to fewer cases of exsanguination prior to death. Reviewing Figures 2 and 3, there are apparent differences in the causes of death among the 
racial groups, with African and especially Coloured decedents more often stabbed and shot, compared to the blunt force trauma suffered by the White groups. Spleens with wrinkled capsules due to extrusion of their pooled red cells in response to shock were excluded, but it is possible that not all cases were documented, or perhaps changes were not always appreciable macroscopically.

\subsection{Organ Weight Reference Ranges}

\subsubsection{Generation of Appropriate Reference Ranges}

The formulae which are the outcomes of the final multiple linear regression analyses predict the mean organ weights expected in a decedent of a particular sex, race, age, height, and weight. The models generated are statistically significant, however their coefficients of correlation ( $R^{2}$ values) must be considered. These indicate the proportion of that organ's weight variability that is accounted for by the predictor variables in the model. The $\mathrm{R}^{2}$ values obtained are $29 \%$ (brain), 55\% (heart), $20 \%$ (right lung), 21\% (left lung), 30\% (liver), 27\% (spleen), 35\% (right kidney) and 36\% (left kidney).

Zeek provides a single value for predicted heart weight, using the independent variable 'height' alone, despite only obtaining $R^{2}$ values of $33 \%$ (men) and $29 \%$ (women) from his models. ${ }^{23}$ Our heart weight model has a substantially higher $\mathrm{R}^{2}$ value, but it is thought that even this is not enough to allow for specific predictions to be made. One solution is to rather provide the prediction interval around the mean organ weight calculated for a certain combination of variables. This prediction interval is distinct from a confidence interval, which indicates the range within which it is $95 \%$ certain that the true mean value lies. Instead, the prediction interval allows for the fact that around each expected mean weight, there lies a Gaussian distribution of individual values. It takes into account the standard error of the mean itself, as well as scatter of individual data points around this mean. It therefore gives a wider, but more representative range within which one can be $95 \%$ certain that a new observation of organ weight will lie, given the variable inputs in question.

Prediction intervals are certainly the most accurate way of providing the expected range of organ weight values specific to an individual decedent. Unfortunately, this requires variable input and statistical computation to obtain a result, making it less 
accessible for everyday use. It was therefore decided to also generate set 'ideal' reference ranges, especially for use in routine cases where organ abnormality is not suspected.

It is standard practice to provide different organ weight reference ranges for men and women. In our sample, statistically significant differences were confirmed in the mean organ weights observed, with $p$-values of 0.00 for all organs except the spleen, the weight of which was not statistically significantly different between the sexes. The clinical significance of these statistical differences was evaluated by inspecting the actual percentage differences in the mean organ weights. The male organ weights were always higher than the females', by the following amounts: brain-10\%; heart-16\%; right lung-17\%; left lung-19\%; liver-8\%, right kidney-11\% and left kidney-12\%. These values are in line with what has been found in other studies.

The differences between the White and African, as well as the White and Coloured decedents' organ weights were likewise in all cases statistically significant $(p \leq 0.02)$. In contrast to this, no statistically significant differences were found between African and Coloured decedents' organ weights except for the brain, where the Coloured decedents mean was found to be $4 \%$ less than that of the African decedents. As was done for the sexes, the clinical significance of these statistical differences was evaluated by inspecting the actual percentage differences in mean organ weight. In all cases the mean organ weights of the White decedents were more than those of the African and Coloured decedents respectively, by the following amounts: brain-2 and $6 \%$; heart-11 and $12 \%$; right lung-8 and 10\%; left lung-13 and $13 \%$; liver-12 and $11 \%$; right kidney-15 and $14 \%$; left kidney-15 and $13 \%$; and spleen-38 and $44 \%$.

In this sample therefore, there are similar actual mean organ weight differences between race groups as there are between the sexes, although much of these differences is due to confounders. This applies to all organs except the brain, and is in some cases quite substantial. Since in practice it is justified to use different reference ranges for men and women based on this extent of clinical difference, it would also be necessary to use different ranges for White decedents, compared to the African and Coloured race groups.

Most researchers publish reference ranges using data from their whole sample, across the range of ages, heights, and weights found. Molina has argued that 
emaciation or obesity are departures from health and affected decedents should not be included in a sample used for the determination of ideal organ weight standards. ${ }^{20}$ Similarly, they restricted their study population to adults less than 35 years old, arguing that this limits the inclusion of age-related pathologies.

Applying the same ideology to our sample, data subsets can be produced consisting of decedents who were aged 18-35 years, with BMI values of $\geq 18.5$ but $<25$ (the 'normal' range), ${ }^{60}$ and which were additionally separated by sex and race. Regrettably, the sample sizes obtained for some of the organs were insufficient to allow confirmation of significant mean differences between the race groups at the desired power and sensitivity levels. Furthermore, the absolute number of White female decedents who fell into the 'ideal' age and BMI groups was limited, making valid reference ranges based on these few observations problematic. It was therefore decided to pool the race groups and only offer ideal reference ranges separated by sex.

\subsubsection{Comparison to Previous Research}

Moar investigated kidney weights in South African Blacks in the early 1980 s. $^{14}$ Data were presented as mean combined renal weights together with sample size, for each of 8 tribal groups identified. No standard deviations were reported, preventing use of classical hypothesis tests such as the t-test. Many of these subsamples were small, despite combining men and women in the same group, but it is noteworthy that the average combined kidney mass of the Zulu decedents - chosen because at 172 it is by far the largest group - is $229 \mathrm{~g}$, equating to approximately $115 \mathrm{~g}$ per kidney. This is very similar to the mean kidney weights for men found in this study.

The organ weight reference ranges found in 'The Forensic ABC in Medical Practice' by Schwär et $\mathrm{al}^{35}$ are commonly used in our department. They have been reproduced for convenience below, and may be compared to our proposed reference ranges in Table 28. Several observations can be made about these values. It is noted that differential ranges for men and women are only supplied for the heart and brain. Only a single value is provided for each kidney, which curtails the meaning and usefulness of the offering in the context of biological data. The values themselves are notably rounded and the ranges very narrow; in fact it has to 
be questioned whether they were based on empirical data, or rather on an experienced Pathologist's best estimate of normal.

Means and standard deviations could be back-calculated from these ranges, but since no sample sizes are available, t-tests still cannot be applied. Nonetheless, inspecting their ranges in comparison to ours show that our ranges are wider, especially at the lower border, indicating that our organs are generally weigh less than what is proposed by Schwär.

\begin{tabular}{|c|c|}
\hline Organ & \begin{tabular}{c} 
Reference Range \\
\hline Heart
\end{tabular} \\
\hline Brain & 275-340g (men) and 230-290g (women) \\
\hline Liver & $1400-1600 \mathrm{~g}(\mathrm{men})$ and 1400-1450g (women) \\
\hline Spleen & $125-195 \mathrm{~g}$ \\
\hline Right Lung & $450-550 \mathrm{~g}$ \\
\hline Left Lung & $310 \pm 105 \mathrm{~g}(45)$ \\
\hline Right Kidney & $140 \mathrm{~g}$ \\
\hline Left Kidney & $150 \mathrm{~g}$ \\
\hline
\end{tabular}

Table 25: Organ weight reference ranges taken from 'The Forensic ABC in Medical Practice' by Schwär et al ${ }^{35}$

Throughout this report, reference has been made to Molina's papers, which culminate in proposed ideal organ weight reference ranges for men and women in the USA. ${ }^{17,20,36,37}$ Meaningful comparison of the current research with these papers requires an understanding of the differences between them.

There are a few small discrepancies between their methods and those used here. Their post-mortem interval was $<24$ hours, while ours was $\leq 3$ days, and the scales used were slightly less accurate than those at Salt River Mortuary. These factors are assessed as being unimportant in terms of their potential to affect mean organ weights.

Both studies accepted pale/exsanguinated organs; however, in contrast to our study, Molina also accepted macroscopically observed congestion. Molina's analysis of their own findings suggest that congestion can increase the spleen, kidney and lung weights in men, and the kidney and lung weights in women. Therefore, the presence of congestion may contribute to increased mean weights of these organs in Molina's study compared to those found in our population. It should 
be noted that there is no obvious reason why men and women's spleen weights should respond differently to congestion, as was found in their study. This merely demonstrates the fallibility of all research in reporting effects that may not be there.

Ethnic composition between the studies also differed, with Molina's sample consisting of $>80 \%$ White decedents, compared to $<20 \%$ decedents in our sample identified as White. This notwithstanding, the overarching key differences between the studies' methodologies are Molina's additional use of histological and toxicological exclusion criteria.

The number of cases this study could obtain significantly exceeds that of Molina, and by design includes a wider age range. In order to accurately compare 'ideal' organ weight reference range statistics, we have also distilled our sample to individuals aged 18-35 years with normal BMls. The tables below present Molina's means, standard deviations, and sample sizes, juxtaposed with the same information gleaned from our study.

Variance comparison tests were performed, using a 95\% confidence level. The comparison shows that in all organs where the variances were unequal, the observed variance in our data was actually narrower than Molina's. This is remarkable because it implies that Molina's stricter exclusion criteria, including the use of toxicology and histology does not necessarily further narrow the range of observed organ weights.

The p-values obtained from Student's t-test are also included in Tables 26 and 27; Satterthwaite's t-test was used in the cases of unequal variances. These tests calculate whether significant differences exist in the organ weight means. Cases where the p-values are not statistically significant (defined here as $<0.05$ ), as is seen more often in the female sample, do not necessarily have similar means; it can only be stated that the sample sizes were too small to demonstrate mean differences at the desired power and sensitivity.

\begin{tabular}{|c|c|c|c|c|}
\hline Organ & $\begin{array}{c}m \pm \sigma(n) \\
- \text { Molina }\end{array}$ & $\begin{array}{c}m \pm \sigma(n) \\
- \text { Current study }\end{array}$ & $\begin{array}{c}\text { Variances } \\
\text { Similar* }\end{array}$ & $\begin{array}{c}\text { p-value and \% } \\
\text { difference in the } \\
\text { means }^{* *}\end{array}$ \\
\hline Brain & $1400 \pm 113 g(77)$ & $1398 \pm 113 g(230)$ & Yes & $p=0.89$ \\
\hline
\end{tabular}




\begin{tabular}{|c|c|c|c|c|}
\hline Heart & $308 \pm 38 \mathrm{~g} \mathrm{(108)}$ & $293 \pm 41 \mathrm{~g} \mathrm{(252)}$ & Yes & $\mathrm{p}=0.00(5 \%)$ \\
\hline Right Lung & $437 \pm 144 \mathrm{~g}(105)$ & $397 \pm 92 \mathrm{~g}(118)$ & No & $\mathrm{p}=0.01(10 \%)$ \\
\hline Left Lung & $393 \pm 144 \mathrm{~g}(106)$ & $363 \pm 93 \mathrm{~g} \mathrm{(107)}$ & No & $\mathrm{p}=0.07$ \\
\hline Liver & $1414 \pm 228 \mathrm{~g}(103)$ & $1296 \pm 235 \mathrm{~g} \mathrm{(252)}$ & Yes & $\mathrm{p}=0.00(9 \%)$ \\
\hline Spleen & $127 \pm 51 \mathrm{~g} \mathrm{(105)}$ & $96 \pm 40 \mathrm{~g}(228)$ & No & $\mathrm{p}=0.00(32 \%)$ \\
\hline Right Kidney & $121 \pm 20 \mathrm{~g} \mathrm{(105)}$ & $114 \pm 21 \mathrm{~g} \mathrm{(232)}$ & Yes & $\mathrm{p}=0.00(6 \%)$ \\
\hline Left Kidney & $129 \pm 24 \mathrm{~g}(106)$ & $118 \pm 21 \mathrm{~g} \mathrm{(231)}$ & Yes & $\mathrm{p}=0.00(9 \%)$ \\
\hline
\end{tabular}

Table 26: Comparison of organ weight statistics for men aged 18-35 years with normal BMI indices. $\mathrm{m}=$ mean weight; $\sigma=$ standard deviation; $\mathbf{n}=$ sample size; $\mathbf{g}=$ grams. * ${ }^{*}$ variance comparison test performed at $95 \%$ confidence level. ${ }^{* *}=$ percentage difference in the means supplied where $\mathrm{p}<0.05$, with mean of current study used as divisor.

\begin{tabular}{|c|c|c|c|c|}
\hline Organ & $\begin{array}{c}\mathrm{m} \pm \sigma(\mathrm{n}) \\
- \text { Molina }\end{array}$ & $\begin{array}{c}\mathrm{m} \pm \sigma(\mathrm{n}) \\
- \text { Current study }\end{array}$ & $\begin{array}{c}\text { Variances } \\
\text { Similar }\end{array}$ & $\begin{array}{c}\text { Percentage } \\
\text { difference and } \mathrm{p} \text { - } \\
\text { value }\end{array}$ \\
\hline Brain & $1218 \pm 95 \mathrm{~g}(27)$ & $1282 \pm 122 \mathrm{~g}(74)$ & Yes & $\mathrm{p}=0.02(-5 \%)$ \\
\hline Heart & $222 \pm 38 \mathrm{~g}(45)$ & $241 \pm 39 \mathrm{~g}(84)$ & Yes & $\mathrm{p}=0.01(-8 \%)$ \\
\hline Right Lung & $345 \pm 125 \mathrm{~g}(45)$ & $359 \pm 107 \mathrm{~g}(40)$ & Yes & $\mathrm{p}=0.58$ \\
\hline Left Lung & $310 \pm 105 \mathrm{~g}(45)$ & $320 \pm 90 \mathrm{~g}(37)$ & Yes & $\mathrm{p}=0.65$ \\
\hline Liver & $1185 \pm 297 \mathrm{~g}(44)$ & $1184 \pm 244 \mathrm{~g}(81)$ & Yes & $\mathrm{p}=0.98$ \\
\hline Spleen & $116 \mathrm{~g}(45)$ & $97 \pm 47 \mathrm{~g}(70)$ & - & - \\
\hline Right Kidney & $106 \pm 35 \mathrm{~g}(45)$ & $106 \pm 23 \mathrm{~g}(75)$ & No & $\mathrm{p}=1.00$ \\
\hline Left Kidney & $114 \pm 40 \mathrm{~g}(45)$ & $109 \pm 23(75)$ & No & $\mathrm{p}=0.45$ \\
\hline
\end{tabular}

Table 27: Comparison of organ weight statistics for women aged 18-35 years with normal BMI indices. Notation as for Table 26.

The men from Molina's US sample have significantly bigger mean weights of the heart, right lung, spleen, liver, and both kidneys. The actual difference is largest for the spleen. Although their mean left lung weight is $30 \mathrm{~g}$ more than ours, this difference is not statistically significant. Again, this may relate to suboptimal sample sizes. There is no significant difference in mean brain weights; indeed, the values are almost exactly the same.

As discussed, the comparison of the women's samples was compromised by small sample sizes. It was found that the mean brain weight in the US sample is $5 \%$ smaller than ours, and the mean heart weight $8 \%$ less. No statistically significant mean differences exist for the other organs. 


\subsection{Study Limitations}

A problem encountered in the performance of this study was that the number of patients that could be included was less than planned, although the minimum sample sizes calculated in order to allow comparison to Molina's work were easily exceeded. This dearth of cases was especially so in certain subgroups such as women greater than 50 years old, reflecting the demographics of traumatic deaths in Cape Town. Cases were restricted to those autopsied only after the mortuary scales were replaced in early 2013 , in order to ensure acceptable accuracy of weights. In addition, a few autopsy reports could not be located in the archives and were not available for perusal electronically, but this did not significantly affect case numbers.

Another issue with sample cases is that no Asians or Subcontinental Indians were included in the study, resulting in a lack of data from these groups. This means that a Pathologist using the predicted ranges derived from this research will have to arbitrarily assign such a decedent to another ethnic group. In contrast, some racially 'White' or 'African' decedents included in our sample are not actually South African, but rather tourists or recent immigrants. This concern is mitigated by the fact that in most cases race appears to have a relatively small effect on organ weights. Certainly, another option would be to instead use other available references that focus specifically on the population group in question.

A methodological flaw which introduces error into this study relates to work-flow practice at Salt River Mortuary, where bodies are weighed clothed if that is how they present to the facility. This error would apply to the vast majority decedents in this study, since a criterion is that they died at the scene of incident. The proportionally small change in body weight between clothed and unclothed decedents would likely not have a significant effect on the calculated coefficients for the effect of body weight, and definitely would not change the directions of association. Furthermore, it could be argued that the models developed here must be useful in our setting, where it is standard procedure to weigh bodies before removing any clothing.

As with all retrospective data collection studies, the authors relied on the observations of non-researchers. In the case of the decedents' length and weight, 
these depended on the Forensic Pathology Officers involved, and in the case of the actual organ weights, on the Forensic Pathologists themselves. The accuracy and precision of information recorded by these individuals could be called into question. An example of this issue can be seen in the scatter plots of age and height vs organ weights in Figure 27. These show some rounding error with vertical line trends representing multiple values entered at particular ages, and especially heights.

Accuracy is also a concern as it pertains to exclusion criteria. This study was not blinded, and during the data collection phase it was noted that in certain instances an organ weight would seem abnormal, however if an abnormality was not specifically mentioned in the report then it had to be included. An example would be a liver weighing $2500 \mathrm{~g}$, with the Pathologist merely leaving their pro-forma autopsy report in place without a statement on the presence of fatty change. It is hoped that the number of true errors of this nature is small, considering the medico-legal nature of our work and the calibre of Pathologists in our Division.

In line with the above, some exclusion criteria could have been better defined to more broadly encompass disease states. With reference to the heart, a decision was made to not exclude hearts showing atherosclerotic coronary artery disease, unless there was concomitant evidence of previous myocardial infarction, left ventricular hypertrophy, or chamber dilation which could affect organ weight. It was once more noticed in reviewing reports that some hearts with partially occluded coronary arteries appeared to be heavy without the doctor specifically mentioning these changes. Many lungs that showed 'severe' anthracosis were included, because anthracosis per se is not a disease state. The report must have specifically stated signs of Chronic Obstructive Pulmonary Disease for the organ to have been excluded.

A potential criticism may be the fact that injured organs were included, albeit only those without tissue loss or mincing/pulping injuries. It must be borne in mind that organs are dissected prior to weighing anyhow, thus artefactually creating incised wounds or lacerations. Furthermore, it is difficult to logically see how, for example, a penetrating incised wound to an organ could materially affect its weight.

Given the traumatic causes of death involved, it is likely that a very common mechanism of death would have been haemorrhagic shock. Organ pallor was not excluded and the potential effect of this is difficult to assess given conflicting 
previous research. Oedema and congestion of organs were excluded, however this again relied on the Pathologists' subjective judgement and attention to detail. This issue is further complicated by the possibility that the description in the report may have been coloured by the Pathologist's knowledge of the actual weight.

It is our experience at Salt River Mortuary that a large proportion of the decedents use illicit drugs, and it is well established that drugs such as methamphetamine and cocaine can affect organ weight, especially that of the heart. Clinical history is rarely available and toxicology testing is not routinely undertaken in traumatic deaths, therefore drug users were not excluded from the present study. Cardiac hypertrophy or dilatation resulting from said use are covered by our exclusion criteria, nonetheless this is potentially an important confounder in the organ weights obtained.

A critical limitation of this study is that it did not involve histological evaluation of the organs. It could be argued that microscopic changes without gross abnormalities would not materially affect organ weights, however this should have been done to ensure that the quality of data is in line with modern standards of evaluating for the presence of disease, as epitomised by Molina's work. 


\section{Outcomes}

There is certainly a strong association of extreme weight loss or obesity with disease, as these can be both a contributing cause, or a result of illness. Likewise, age heralds an increased prevalence of pathology that may affect organ weight. These are worthy arguments, however the issue remains that a significant proportion of decedents are older than 35 years, or fall outside of ideal BMI ranges. It is clearly still important to determine whether organ weights found in these individuals are different from expected due to underlying pathology, or due to age changes or body weight differences alone. For this reason, two different outcomes of this research are offered. The first is ideal organ weight reference tables, for routine use. The second is a way to calculate organ weight ranges specific to an individual decedent who may fall outside of the 'ideal' age and BMI group, or where it is particularly important to have an accurate and personalized range.

In line with the principles in Chapter 36 of the Declaration of Helsinki, the results of this work will be made publicly available. ${ }^{1}$ The authors plan to publish an article describing the study in an appropriate journal, to make the findings known to the wider scientific community. In addition, we will disseminate our findings by email to other departments of Forensic Pathology in South Africa.

\subsection{Tables}

The ideal organ weight reference ranges presented in the table below have been generated based on autopsy observations made using the technical methods and exclusion criteria described. Each range was calculated using the mean $\pm 1.96 *$ standard deviation. They are thus the ranges within which the expected weight of the organ in question may vary without there being clinical evidence of abnormality, in 95\% of decedents aged 18-35 years who have normal BMI indices. It is advised that these established reference ranges be used with the caveat that organs were not excluded due to blood loss and thus weight ranges may be shifted towards lower values. 


\begin{tabular}{|c|c|c|}
\hline Organ & Men & Women \\
\hline Heart & $212-373 \mathrm{~g}$ & $164-317 \mathrm{~g}$ \\
\hline Brain & $1175-1621 \mathrm{~g}$ & $1043-1521 \mathrm{~g}$ \\
\hline Liver & $833-1758 \mathrm{~g}$ & $707-1662 \mathrm{~g}$ \\
\hline Spleen & $18-174 \mathrm{~g}$ & $<189 \mathrm{~g}$ \\
\hline Right Lung & $217-576 \mathrm{~g}$ & $148-569 \mathrm{~g}$ \\
\hline Left Lung & $181-546 \mathrm{~g}$ & $145-496 \mathrm{~g}$ \\
\hline Right Kidney & $73-155 \mathrm{~g}$ & $60-151 \mathrm{~g}$ \\
\hline Left Kidney & $77-159$ & $64-154 \mathrm{~g}$ \\
\hline
\end{tabular}

Table 28: Proposed post-mortem ideal organ weight reference ranges for South African Mortuaries.

\subsection{Smartphone Application}

A smartphone application has been developed for Android operating systems allowing simple, accessible retrieval of the predicted organ weight ranges for reference in the mortuary or office environment. It is named 'South African Organ Weights' and can be downloaded free of charge from the Google Play Store. An alternative is to access this facility from the UCT Division of Forensic Medicine and Toxicology's website: http://www.forensicmedicine.uct.ac.za. 


\section{Final thoughts}

\subsection{Future Research and Recommendations}

Future researchers could expand on this study by adding histological criteria to exclude the possible confounder of microscopically diseased organs, and to determine whether isolated microscopic pathology indeed has any effect on organ weights. Additionally, to improve the quality of the data all subjects should be screened for drug intoxication at the time of death using blood and urine, as well as for previous or chronic drug use using toxicological evaluation of hair specimens.

A glaring lack of organ weight reference ranges specific to South Africa exists for children and infants, which were not included in this initial study. Children grow and develop quickly as they age and thus multiple age-dependent subgroups need to be formulated and data collected for each, requiring significant time and effort.

As has been repeatedly emphasised, all references need to be regularly revised. It is not clear for what duration of time they remain valid, however a repeat of this study, preferably with the above refinements and including minors, would certainly be indicated. Research funding may be needed to ensure that the manpower, time, and money are available to facilitate this exercise.

It is recommended that South African Pathologists carefully consider which organ weight references they use, as the ones commonly cited are substantially outdated and derived from poor quality studies. It is thought that Molina's work reflects the best modern research practice, although it has its own limitations. Pathologists may also make use of the ideal organ weight reference tables proposed here and generated from local population data. The 'South African Organ Weights' smartphone application may also be used to provide more specific, tailored organ weight predictive ranges. 


\subsection{Conclusion}

In forensic autopsies, organ weights are used to support the pathologist's opinion on the state of health of the organs. This is the first study on post-mortem organ weights at a South African mortuary and provides data representative of the adult population dying traumatic deaths in Cape Town.

Statistically significant multiple linear regression models were derived, providing insight into the magnitude of effect and interactions of the variables sex, race, age, height, and body weight. The best modelled organ was the heart, with an $\mathrm{R}^{2}$ value of 0.55 , which is not strong enough for specific weight prediction without accounting for data variability. Instead, a smartphone application is offered, which calculates tailored prediction intervals for individual cases. Alternatively, ideal organ weight reference ranges based on local data are proposed for routine use.

While there are limitations to this work, it provides a good foundation for future comparisons and research. 


\section{REFERENCES}

1. Brinkmann B. Harmonisation of medico-legal autopsy rules. Int J Legal Med. 1999;113(1):1-14.

2. Stewart S, Hart CL, Hole DJ, McMurray JJ. Population prevalence, incidence, and predictors of atrial fibrillation in the renfrew/paisley study. Heart. 2001;86(5):516-521.

3. Sandvik L, Erikssen J, Thaulow E, Erikssen G, Mundal R, Aakhus T. Heart volume and cardiovascular mortality. A 16 year follow-up study of 1984 healthy middle-aged men. Eur Heart J. 1993;14(5):592-596.

4. Holmes DR, Davis K, Gersh BJ, Mock MB, Pettinger MB. Risk factor profiles of patients with sudden cardiac death and death from other cardiac causes: A report from the coronary artery surgery study (CASS). Journal of the American College of Cardiology. 1989;13(3):524-530.

5. Sheikhazadi A, Sadr SS, Ghadyani MH, et al. Study of the normal internal organ weights in tehran's population. J Forensic Leg Med. 2010;17(2):78-83.

6. Mehrpour O, Sheikhazadi A, Ghadyani MH, Jafarzadeh M, Hooshyar H. Brain weight of iranian population; the first report. J Forensic Leg Med. 2010;17(8):426-431.

7. Mathuramon P, Chirachariyavej T, Peonim AV, Rochanawutanon M. Correlation of internal organ weight with body weight and length in normal thai adults. Medical journal of the Medical Association of Thailand. 2009;92(2):250.

8. Inoue T OS. Statistical analysis of the organ weights in 1,000 autopsy cases of japanese aged over 60 years. Acta Pathol Jpn. 1987;37(3):343-59.

9. Singh $\mathrm{D}$. Weights of human organs at autopsy in chandigarh zone of north-west india. jiafm. 2004;26(3).

10. de la Grandmaison GL, Clairand I, Durigon M. Organ weight in 684 adult autopsies: New tables for a caucasoid population. Forensic Sci Int. 2001;119(2):149-154.

11. Garby L, Lammert O, Kock KF, Thobo-Carlsen B. Weights of brain, heart, liver, kidneys, and spleen in healthy and apparently healthy adult danish subjects. Am J Hum Biol. 1993;5(3):291-296.

12. Young JF, Luecke RH, Pearce BA, et al. Human organ/tissue growth algorithms that include obese individuals and black/white population organ weight similarities from autopsy data. J Toxicol Environ Health A. 2009;72(8):527-540.

13. Whimster WF. Normal lung weights in jamaicans. Am Rev Respir Dis. 1971;103(1):8590.

14. Moar JJ, Reinach SG. Renal weights in the southern african black population. Am J Phys Anthropol. 1988;76(1):105-110.

15. de Wit E, Delport W, Rugamika CE, et al. Genome-wide analysis of the structure of the south african coloured population in the western cape. Hum Genet. 2010;128(2):145-153.

16. Wisner B. Commodity relations and nutrition under apartheid: A note on South Africa. Soc Sci Med. 1989;28(5):441-446.

17. Molina DK, DiMaio VJ. Normal organ weights in men: Part I-the heart. Am J Forensic Med Pathol. 2012;33(4):362-367.

18. Smith HL. The relation of the weight of the heart to the weight of the body and of the weight of the heart to age. Am Heart J. 1928;4(1):79-93.

19. Boyd E. Normal variability in weight of the adult human liver and spleen. Arch Pathol. 1933;16:350-372. 
20. Molina DK, DiMaio VJ. Normal organ weights in men: Part II-the brain, lungs, liver, spleen, and kidneys. Am J Forensic Med Pathol. 2012;33(4):368-372.

21. Knight B, Saukko P. Knight's forensic pathology. 3rd ed. London: CRC Press; 2004.

22. Knight B, Saukko P. Knight's forensic pathology. 4th ed. London: CRC Press; 2015.

23. Zeek PM. Heart weight. I. the weight of the normal human heart. Arch Pathol. 1942;34:820-832.

24. Kasiske BL, Umen AJ. The influence of age, sex, race, and body habitus on kidney weight in humans. Arch Pathol Lab Med. 1986;110(1):55-60.

25. Whimster WF, Macfarlane AJ. Normal lung weights in a white population. Am Rev Respir Dis. 1974;110(4):478-483.

26. Kim Y, Kim D, Cho SY, et al. Statistical analysis for organ weights in korean adult autopsies. 대한해부학회지 제. 2009;42(4).

27. Kitzman DW, Scholz DG, Hagen PT, Ilstrup DM, Edwards WD. Age-related changes in normal human hearts during the first 10 decades of life. part II (maturity): A quantitative anatomic study of 765 specimens from subjects 20 to 99 years old. . 1988;63(2):137-146.

28. Smith HL. The relation of the weight of the heart to the weight of the body and of the weight of the heart to age. Am Heart J. 1928;4(1):79-93.

29. Altman PL, Dittmer D. Growth: Including reproduction and morphological development. Federation of American Societies for Experimental Biology; 1962.

30. Boyd E. An introduction to human biology and anatomy for first year medical students. Child Research Council; 1952.

31. Sunderman FW, Boerner F. Normal values in clinical medicine. Saunders; 1949.

32. Ludwig J. Handbook of autopsy practice. Springer Science \& Business Media; 2002.

33. Vierordt $\mathrm{H}$. Anatomische, physiologische und physikalische, daten und tabellen zum gebrauche für mediciner. Tübingen: Jena, Fischer; 1888.

34. Bischoff T. Das gehirnewicht des menschen. Bonn: Neusser; 1880.

35. Schwär, T. G., Olivier, J. A., Loubser,J.D.,. The forensic ABC in medical practice : A practical guide. Pretoria: Haum Educational Publishers; 1988.

36. Molina DK, DiMaio VJ. Normal organ weights in women: Part I-the heart. Am J Forensic Med Pathol. 2015;36(3):176-181.

37. Molina DK, DiMaio VJ. Normal organ weights in women: Part II-the brain, lungs, liver, spleen, and kidneys. Am J Forensic Med Pathol. 2015;36(3):182-187.

38. He Q, Heshka S, Albu J, et al. Smaller organ mass with greater age, except for heart. J Appl Physiol (1985). 2009;106(6):1780-1784.

39. Inoue T, Otsu S. Statistical analysis of the organ weights in 1,000 autopsy cases of japanese aged over 60 years. Acta Pathol Jpn. 1987;37(3):343-359.

40. Gaitskell K, Perera R, Soilleux EJ. Derivation of new reference tables for human heart weights in light of increasing body mass index. J Clin Pathol. 2010:jcp. 2010.084574.

41. Gallagher D, Albu J, He Q, et al. Small organs with a high metabolic rate explain lower resting energy expenditure in african american than in white adults. Am J Clin Nutr. 2006;83(5):1062-1067. 
42. Valentin J. Basic anatomical and physiological data for use in radiological protection: Reference values: ICRP publication 89. Ann ICRP. 2002;32(3):1-277.

43. Boyd EM, Knight LM. Postmortem shifts in the weight and water levels of body organs. Toxicol Appl Pharmacol. 1963;5(1):119-128.

44. Pryce JW, Bamber AR, Ashworth MT, Kiho L, Malone M, Sebire NJ. Reference ranges for organ weights of infants at autopsy: Results of $>1,000$ consecutive cases from a single centre. BMC Clinical Pathology. 2014;14(1):1-12.

45. Hall JE. Guyton and hall textbook of medical physiology. Elsevier Health Sciences; 2015.

46. Myers J, Segal RJ. Weight of the spleen. I. range of normal in a nonhospital population. Arch Pathol. 1974;98(1):33-35.

47. Auckloo MBKM. A post-mortem toxicological investigation: Understanding the role of drugs of abuse in violent fatalities in cape town, south africa. [MPhil]. UCT repository; http://hdl.handle.net/11427/20515: University of Cape Town; 2016.

48. Kaye S, McKetin R, Duflou J, Darke S. Methamphetamine and cardiovascular pathology: A review of the evidence. Addiction. 2007;102(8):1204-1211.

49. Lange RA, Hillis LD. Cardiovascular complications of cocaine use. N Engl J Med. 2001;345(5):351-358.

50. Hognestad J, Teisberg P. Heart pathology in chronic alcoholism. Acta Pathologica Microbiologica Scandinavica Section A Pathology. 1973;81A(3):315-322.

51. Wong JL, Arango-Viana JC, Squires T. Heart, liver and spleen pathology in chronic alcohol and drug users. J Forensic Leg Med. 2008;15(3):141-147.

52. Cohn SM, Dolich MO. Complications in surgery and trauma, second edition. CRC Press; 2014.

53. Hadley JA, Fowler DR. Organ weight effects of drowning and asphyxiation on the lungs, liver, brain, heart, kidneys, and spleen. Forensic Sci Int. 2003;133(3):190-196.

54. Kumar V, Abbas AK, Fausto N, Aster JC. Robbins \& cotran pathologic basis of disease. Elsevier Health Sciences; 2009:856.

55. Gordon, I., Shapiro,H.A.,. Forensic medicine : A guide to principles. Edinburgh; New York; New York: Churchill Livingstone ; Distributed by Longman; 1975.

56. Pollitzer WS, Anderson JJ. Ethnic and genetic differences in bone mass: A review with a hereditary vs environmental perspective. Am J Clin Nutr. 1989;50(6):1244-1259.

57. Asala SA. Sex determination from the head of the femur of south african whites and blacks. Forensic Sci Int. 2001;117(1-2):15-22.

58. Sagnella GA. Why is plasma renin activity lower in populations of african origin? J Hum Hypertens. 2001;15(1):17-25.

59. Rosano GMC, Vitale C, Marazzi G, Volterrani M. Menopause and cardiovascular disease: The evidence. Climacteric. 2007;10:19-24.

60. The use and interpretation of anthropometry report of a WHO expert committee technical report series, no 854. Geneva: WHO. 1995.

61. World Medical Association. World medical association declaration of helsinki: Ethical principles for medical research involving human subjects. JAMA. 2013;310(20):2191-2194. 


\section{APPENDICES}

\section{Appendix A - Method of weighing organs at autopsy:}

The organs should be weighed by the pathologist personally, and the scale 'tared' or 'zeroed' between organs.

The brain should be weighed before dissection, with the superior part of the dura still attached at the superior sagittal sinus. Any extra- or subdural haemorrhage should be washed off before weighing. This specimen should include cerebrum, cerebellum, and brainstem including the proximal centimetre or two of spinal cord. ${ }^{1}$

The lungs should be weighed separately before dissection. They should be trimmed at the hilum and not have extraneous hilar tissue attached.

The heart should be weighed after dissection and blood clot should be washed out. The pericardium should be removed but epicardial fat left intact. The great vessels should be transected $2-3 \mathrm{~cm}$ above the base of the heart.

The liver should be weighed after dissection. The gallbladder may be removed or the contents expressed before weighing.

The spleen should be weighed after dissection.

The kidneys should be weighed after dissection. They should have their capsules with surrounding perirenal soft tissue stripped off.

\footnotetext{
${ }^{1}$ It is noted that in some centres brains are weighed after removing the dura. To give an indication of the possible effect of this, 15 adult dural weights were recorded at Salt River Mortuary. The mean weight was $30.5 \mathrm{~g}$, with a range of $23-43 \mathrm{~g}$. The variability in brainstem length certainly exceeds this, and these figures are not intended to be used as a dural weight correction factor.
} 


\section{Appendix B - Calibration certificates}

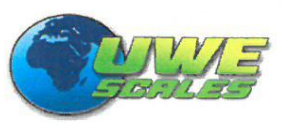

\section{tsanas}

1 Otto Road Beaconvale Parow, PO Box 1556 Parow 7499

Tel: $0219335403 \quad$ Fax:0219335409

UWE Scales Mass Laboratory Calibration Certificate

Customer Details: Company Name:

Address:
Forensic Pathology Service Durham Ave

Salt River

Western Cape

Contact:

Date Of Calibration:

Issue Date:

Recalibration Date:
Mr.Mitten

31/03/2016

04/04/2016

Yearly
Calibration Details:

Make and Model:

Serial Number

Unit of Measure:

Capacity:

Resolution:

Description:

Unit Condition:

Location:

Type of Calibration:
Laboratory No. 1468

Calibration Results

\begin{tabular}{|c|c|c|c|c|}
\hline $\begin{array}{c}\text { Test Load } \\
\text { kg }\end{array}$ & $\begin{array}{c}\text { As Found } \\
\text { kg }\end{array}$ & $\begin{array}{c}\text { After Adjustment } \\
\text { kg }\end{array}$ & $\begin{array}{c}\text { Uncertainties } \\
\text { kg }\end{array}$ & $\begin{array}{c}\text { Weights Used \# } \\
\text { S Set }\end{array}$ \\
\hline 0.000 & 0.000 & 0.000 & Repeatability & Repeatability @ \\
$\pm 80 \%$ Capacity
\end{tabular}

All Standards are traceable to International Measurement Standards, Calibration performend to Quality Procedure QP/UWE/02

Remarks: Calibration

Signatories:

\section{Technical Signatory}

G.Grobier

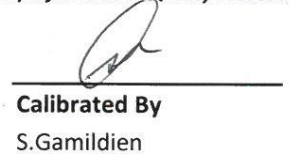

S.Gamildien

The reported expanded uncertainty is based on a standard uncertainty multiplied by a coverage factor $k=2$

Providing a level of confidence of approximately $95 \%$, the uncertainty of measurement has been calculated in accordance with the principles defined in the GUM, Guide to Uncertainty of Measurement, ISO, Geneva, 1993.

This certificate is issued in accordance with ISO IEC 17025, the conditions approved by SANAS and the policies of UWE Scales. It is a correct record of measurements made and relate only to the items calibrated. This certificate may not be reproduced other than in full, accept with a prior written approval of the issuing laboratory. The values in this certificate are valid at the time calibration. Subsequently the accuracy shall depend on such factors as the care exercised in handling, use of the instrument and frequency of use. Re-calibration should be preformed after a period which has been chosen to ensure that the instrument's accuracy remains within the desired limits. The applicant hereby indemnifies, holds harmless and absolves UWE Scales and the Mass Laboratory, from any damage whatsoever and any legal liability in the event of a mistake in the services performed for the applicant.

Page 1 of 1

End of Certificate 


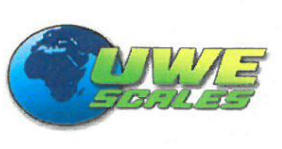

fsanas

1 Otto Road Beaconvale Parow, PO Box 1556 Parow 7499

Laboratory No. 1468

Tel: $0219335403 \quad$ Fax: 0219335409

UWE Scales Mass Laboratory Calibration Certificate

\begin{abstract}
Customer Details Company Name: Address:
\end{abstract}

Forensic Pathology Service Durham Ave Salt River Western Cape

Contact: Date Of Calibration: Issue Date: Mr.Mitten 31/03/2016 04/04/2016 Recalibration Date: Yearly
Calibration Details: Make and Model: Serial Number: Unit of Measure: Capacity: Resolution: Description: Unit Condition: Location: Type of Calibration:
Certificate No. $27035 / 4$ Issue No. 1

Micro T7E 1303090021 $\mathrm{kg}$

0.001

Electronic Scale

Satisfactory

Salt River

Full

Calibration Results

\begin{tabular}{|c|c|c|c|c|}
\hline $\begin{array}{c}\text { Test Load } \\
\text { kg }\end{array}$ & $\begin{array}{c}\text { As Found } \\
\text { kg }\end{array}$ & $\begin{array}{c}\text { After Adjustment } \\
\text { kg }\end{array}$ & $\begin{array}{c}\text { Uncertainties } \\
\text { kg }\end{array}$ & $\begin{array}{c}\text { Weights Used \# } \\
\text { S Set }\end{array}$ \\
\hline 0.000 & 0.000 & 0.000 & Repeatability & Repeatability @ \\
$\pm 80 \%$ Capacity
\end{tabular}

All Standards are traceable to International Measurement Standards, Calibration performend to Quality Procedure QP/UWE/02

Remarks: Calibration

Signatories:

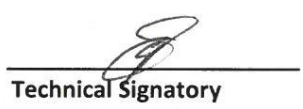

G.Grobler

S.Gamildien

The reported expanded uncertainty is based on a standard uncertainty multiplied by a coverage factor $k=2$ Providing a level of confidence of approximately $95 \%$, the uncertainty of measurement has been calculated in accordance with the principles defined in the GUM, Guide to Uncertainty of Measurement, ISO, Geneva, 1993.

This certificate is issued in accordance with ISO IEC 17025, the conditions approved by SANAS and the policies of UWE Scales. It is a correct record of measurements made and relate only to the items calibrated. This certificate may not be reproduced other than in full, accept with a prior written approval of the issuing laboratory. The values in this certificate are valid at the time calibration. Subsequently the accuracy shall depend on such factors as the care exercised in handling, use of the instrument and frequency of use. Re-calibration should be preformed after a period which has been chosen to ensure that the instrument's accuracy remains within the desired limits. The applicant hereby indemnifies, holds harmless and absolves UWE Scales and the Mass Laboratory, from any damage whatsoever and any legal liability in the event of a mistake in the services performed for the applicant.

Page 1 of 1

End of Certificate 


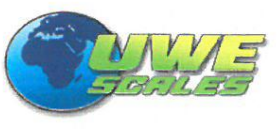

tsanas

1 Otto Road Beaconvale Parow, PO Box 1556 Parow 7499

Laboratory No. 1468

Tel: $0219335403 \quad$ Fax:0219335409

UWE Scales Mass Laboratory Calibration Certificate

$\begin{array}{ll}\begin{array}{ll}\text { Customer Details: } \\ \text { Company Name: } \\ \text { Address: }\end{array} & \begin{array}{l}\text { Forensic Pathology Service } \\ \text { Durham Ave } \\ \text { Salt River } \\ \text { Western Cape }\end{array} \\ & \text { Mr.Mitten } \\ \text { Contact: } & \begin{array}{l}\text { 31/03/2016 } \\ \text { Date Of Calibration: } \\ \text { Issue Date: }\end{array} \\ \text { Recalibration Date: } & \begin{array}{l}\text { Yearly } \\ \text { Reth }\end{array}\end{array}$

Calibration Details:

Make and Model:

Serial Number:

Unit of Measure:

Capacity:

Resolution:

Description:

Unit Condition:

Location:

Type of Calibration:
Certificate No. 27035/5

Issue No. 1

Sasco WP003

07050140

6000

0.5

Electronic Scale

Satisfactory

Salt River

Full

Calibration Results

\begin{tabular}{|c|c|c|c|c|}
\hline $\begin{array}{c}\text { Test Load } \\
\mathrm{g} \\
\end{array}$ & $\begin{array}{c}\text { As Found } \\
\mathrm{g}\end{array}$ & $\begin{array}{c}\text { After Adjustment } \\
\text { g }\end{array}$ & $\begin{array}{c}\text { Uncertainties } \\
\mathrm{g}\end{array}$ & $\begin{array}{l}\text { Weights Used \# } \\
\text { S Set }\end{array}$ \\
\hline 0.0 & 0.0 & 0.0 & \multirow{2}{*}{$\begin{array}{c}\text { Repeatability } \\
0.2 \\
\end{array}$} & \multirow{2}{*}{$\begin{array}{l}\text { Repeatability @ } \\
\pm 80 \% \text { Capacity }\end{array}$} \\
\hline 500.0 & 498.5 & 500.0 & & \\
\hline 1000.0 & 999.0 & 999.5 & \multirow{2}{*}{$\begin{array}{c}\text { Corner load error } \\
1 \\
\end{array}$} & \multirow{2}{*}{$\begin{array}{l}\text { Corner Load Errors } \\
\qquad 1 / 4-1 / 3 \\
\end{array}$} \\
\hline 3000.0 & 2996.5 & 3000.0 & & \\
\hline 5000.0 & 4994.5 & 4999.9 & \multirow{2}{*}{$\begin{array}{l}\text { Linearity error } \\
0.5\end{array}$} & \multirow{2}{*}{$\begin{array}{c}\text { STD's Traceability } \\
\text { SG16/001 }\end{array}$} \\
\hline 6000.0 & 5993.0 & 5999.5 & & \\
\hline & & & \multirow{3}{*}{\multicolumn{2}{|c|}{$\begin{array}{l}\text { Total Uncertainty of Measurement @ } \\
95 \% \text { Confidence Level of } \pm \\
1.0 \mathrm{~g}\end{array}$}} \\
\hline & & & & \\
\hline & & & & \\
\hline
\end{tabular}

All Standards are traceable to International Measurement Standards, Calibration performend to Quality Procedure QP/UWE/02

Remarks: Calibration

Signatories:

\section{Technical Signatory}

G.Grobler

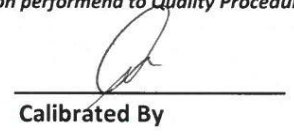

S.Gamildien

The reported expanded uncertainty is based on a standard uncertainty multiplied by a coverage factor $k=2$

Providing a level of confidence of approximately 95\%, the uncertainty of measurement has been calculated in accordance with the principles defined in the GUM, Guide to Uncertainty of Measurement, ISO, Geneva, 1993.

This certificate is issued in accordance with ISO IEC 17025, the conditions approved by SANAS and the policies of UWE Scales. It is a correct record of measurements made and relate only to the items calibrated. This certificate may not be reproduced other than in full, accept with a prior written approval of the issuing laboratory. The values in this certificate are valid at the time calibration. Subsequently the accuracy shall depend on such factors as the care exercised in handling, use of the instrument and frequency of use. Re-calibration should be preformed after a period which has been chosen to ensure that the instrument's accuracy remains within the desired limits. The applicant hereby indemnifies, holds harmless and absolves UWE Scales and the Mass Laboratory, from any damage whatsoever and any legal liability in the event of a mistake in the services performed for the applicant.

Page 1 of 1

End of Certificate 


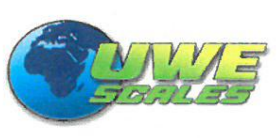

fanas

1 Otto Road Beaconvale Parow, PO Box 1556 Parow 7499

Laboratory No. 1468

Tel: $0219335403 \quad$ Fax: 0219335409

UWE Scales Mass Laboratory Calibration Certificate

Customer Details:
Company Name:
Address:
Forensic Pathology Service

Durham Ave

Salt River

Western Cape

Contact:

Date Of Calibration:

Issue Date:

Mr.Mitten

31/03/2016

06/04/2016

Yearly
Calibration Details:

Make and Model:

Serial Number:

Unit of Measure:

Capacity:

Resolution:

Description:

Unit Condition:

Location:

Type of Calibration:
Certificate No. 27035/6

Issue No. 1

Sasco WP003

07050140

g

6000

0.5

Electronic Scale

Satisfactory

Salt River

Full

\section{Calibration Results}

\begin{tabular}{|c|c|c|c|c|}
\hline $\begin{array}{c}\text { Test Load } \\
\text { g }\end{array}$ & $\begin{array}{c}\text { As Found } \\
\mathrm{g}\end{array}$ & $\begin{array}{c}\text { After Adjustment } \\
\text { g }\end{array}$ & $\begin{array}{l}\text { Uncertainties } \\
\qquad \mathrm{g}\end{array}$ & $\begin{array}{l}\text { Weights Used \# } \\
\text { S Set }\end{array}$ \\
\hline 0.0 & 0.0 & 0.0 & \multirow{2}{*}{$\begin{array}{c}\text { Repeatability } \\
0.3 \\
\end{array}$} & \multirow{2}{*}{$\begin{array}{l}\text { Repeatability @ } \\
\pm 80 \% \text { Capacity }\end{array}$} \\
\hline 500.0 & 499.5 & 499.8 & & \\
\hline 1000.0 & 999.0 & 1000.0 & \multirow{2}{*}{$\begin{array}{c}\text { Corner load error } \\
0 \\
\end{array}$} & \multirow{2}{*}{$\begin{array}{l}\text { Corner Load Errors } \\
\qquad 1 / 4-1 / 3 \\
\end{array}$} \\
\hline 3000.0 & 2995.5 & 2999.0 & & \\
\hline 5000.0 & 4993.0 & 4998.8 & \multirow{2}{*}{$\begin{array}{c}\text { Linearity error } \\
1.2 \\
\end{array}$} & \multirow{2}{*}{$\begin{array}{c}\text { STD's Traceability } \\
\text { SG16/001 }\end{array}$} \\
\hline 6000.0 & 5992.5 & 6000.0 & & \\
\hline & & & \multirow{3}{*}{\multicolumn{2}{|c|}{$\begin{array}{c}\text { Total Uncertainty of Measurement @ } \\
95 \% \text { Confidence Level of } \pm \\
1.0 \mathrm{~g}\end{array}$}} \\
\hline & & & & \\
\hline & & & & \\
\hline
\end{tabular}

All Standards are traceable to International Measurement Standards, Calibration performend to Quality Procedure QP/UWE/02

Remarks: Calibration

Signatories:

Technical signatory

G.Grobler
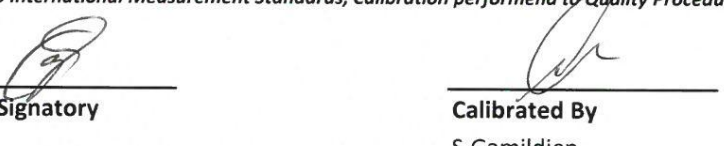

The reported expanded uncertainty is based on a standard uncertainty multiplied by a coverage factor $k=2$

Providing a level of confidence of approximately $95 \%$, the uncertainty of measurement has been calculated in accordance with the principles defined in the GUM, Guide to Uncertainty of Measurement, ISO, Geneva, 1993.

This certificate is issued in accordance with ISO IEC 17025, the conditions approved by SANAS and the policies of UWE Scales. It is a correct record of measurements made and relate only to the items calibrated. This certificate may not be reproduced other than in full, accept with a prior written approval of the issuing laboratory. The values in this certificate are valid at the time calibration. Subsequently the accuracy shall depend on such factors as the care exercised in handling, use of the instrument and frequency of use. Re-calibration should be preformed after a period which has been chosen to ensure that the instrument's accuracy remains within the desired limits. The applicant hereby indemnifies, holds harmless and absolves UWE Scales and the Mass Laboratory, from any damage whatsoever and any legal liability in the event of a mistake in the services performed for the applicant.

\section{End of Certificate}

Page 1 of 1 


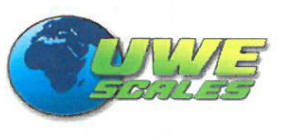

f sanas

1 Otto Road Beaconvale Parow, PO Box 1556 Parow 7499

Laboratory No. 1468

Tel: $0219335403 \quad$ Fax:0219335409

UWE Scales Mass Laboratory Calibration Certificate

$\begin{array}{ll}\begin{array}{ll}\text { Customer Details: } \\ \text { Company Name: }\end{array} & \begin{array}{l}\text { Forensic Pathology Service } \\ \text { Durham Ave } \\ \text { Salt River } \\ \text { Western Cape }\end{array} \\ & \text { Mr.Mitten } \\ & \begin{array}{l}\text { Contact: } \\ \text { Date Of Calibration: } \\ \text { Issue Date: }\end{array} \\ \text { Recalibration Date: } & \begin{array}{l}\text { Y4/04/2016 } \\ \text { Yearly }\end{array}\end{array}$

Calibration Details:

Make and Model:

Serial Number:

Unit of Measure:

Capacity:

Resolution:

Description:

Unit Condition:

Location:

Type of Calibration:

Calibration Results

Certificate No. 27035/7

Issue No. 1

UWE APF

A1183

$\mathrm{kg}$

500

0.1

Electronic Scale

Satisfactory

Salt River

Partail

\begin{tabular}{|c|c|c|c|c|}
\hline $\begin{array}{c}\text { Test Load } \\
\text { kg }\end{array}$ & $\begin{array}{c}\text { As Found } \\
\text { kg }\end{array}$ & $\begin{array}{c}\text { After Adjustment } \\
\text { kg }\end{array}$ & $\begin{array}{c}\text { Uncertainties } \\
\text { kg }\end{array}$ & $\begin{array}{c}\text { Weights Used \# } \\
\text { U1-U10 }\end{array}$ \\
\hline 0.0 & 0.0 & 0.0 & Repeatability & Repeatability @ \\
$\pm 80 \%$ Capacity
\end{tabular}

All Standards are traceable to International Measurement Standards, Calibration performend to Quality Procedure QP/UWE/02

Remarks: Loadcell wire (shielding pinched)

Signatories:

$$
\begin{aligned}
& \text { Technical Signatory } \\
& \text { G.Grobler }
\end{aligned}
$$

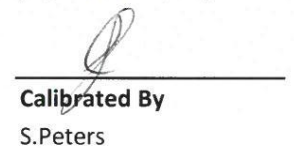

The reported expanded uncertainty is based on a standard uncertainty multiplied by a coverage factor $k=2$

Providing a level of confidence of approximately $95 \%$, the uncertainty of measurement has been calculated in accordance with the principles defined in the GUM, Guide to Uncertainty of Measurement, ISO, Geneva, 1993.

This certificate is issued in accordance with ISO IEC 17025, the conditions approved by SANAS and the policies of UWE Scales. It is a correct record of measurements made and relate only to the items calibrated. This certificate may not be reproduced other than in full, accept with a prior written approval of the issuing laboratory. The values in this certificate are valid at the time calibration. Subsequently the accuracy shall depend on such factors as the care exercised in handling, use of the instrument and frequency of use. Re-calibration should be preformed after a period which has been chosen to ensure that the instrument's accuracy remains within the desired limits. The applicant hereby indemnifies, holds harmless and absolves UWE Scales and the Mass Laboratory, from any damage whatsoever and any legal liability in the event of a mistake in the services performed for the applicant.

Page 1 of 1

\section{End of Certificate}




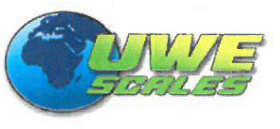

f sanas

1 Otto Road Beaconvale Parow, PO Box 1556 Parow 7499

Laboratory No. 1468

Tel: $0219335403 \quad$ Fax: 0219335409

UWE Scales Mass Laboratory Calibration Certificate

\begin{tabular}{|c|c|}
\hline Customer Details: & \\
\hline Company Name: & Forensic Pathology Service \\
\hline Address: & Durham Ave \\
\hline & Salt River \\
\hline & Western Cape \\
\hline Contact: & Mr.Mitten \\
\hline Date Of Calibration: & $31 / 03 / 2016$ \\
\hline Issue Date: & $06 / 04 / 2016$ \\
\hline Recalibration Date: & Yearly \\
\hline
\end{tabular}

Calibration Details:

Make and Model:

Serial Number:

Unit of Measure:

Capacity:

Resolution:

Description:

Unit Condition:

Location:

Type of Calibration:
Certificate No. 27035/2

Issue No. 1

Micro T7E

1303090065

$\mathrm{kg}$

30

0.001

Electronic Scale

Satisfactory

Salt River

Full

Calibration Results

\begin{tabular}{|c|c|c|c|c|}
\hline $\begin{array}{c}\text { Test Load } \\
\text { kg }\end{array}$ & $\begin{array}{c}\text { As Found } \\
\text { kg }\end{array}$ & $\begin{array}{c}\text { After Adjustment } \\
\mathrm{kg}\end{array}$ & $\begin{array}{c}\text { Uncertainties } \\
\text { kg }\end{array}$ & $\begin{array}{c}\text { Weights Used \# } \\
\text { S Set }\end{array}$ \\
\hline 0.000 & 0.000 & 0.000 & \multirow{2}{*}{$\begin{array}{c}\text { Repeatability } \\
0.001 \\
\end{array}$} & \multirow{2}{*}{$\begin{array}{l}\text { Repeatability @ } \\
\pm 80 \% \text { Capacity }\end{array}$} \\
\hline 2.000 & 1.986 & 2.000 & & \\
\hline 5.000 & 4.965 & 4.999 & \multirow{2}{*}{$\begin{array}{c}\text { Corner load error } \\
0.005 \\
\end{array}$} & \multirow{2}{*}{$\begin{array}{c}\text { Corner Load Errors } \\
\qquad 1 / 4-1 / 3 \\
\end{array}$} \\
\hline 10.000 & 9.931 & 9.999 & & \\
\hline 20.000 & 19.862 & 19.999 & \multirow{2}{*}{$\begin{array}{c}\text { Linearity error } \\
0.002\end{array}$} & \multirow{2}{*}{$\begin{array}{c}\text { STD's Traceability } \\
\text { SG16/001 }\end{array}$} \\
\hline 30.000 & 29.795 & 29.998 & & \\
\hline & & & \multirow{3}{*}{\multicolumn{2}{|c|}{$\begin{array}{l}\text { Total Uncertainty of Measurement @ } \\
95 \% \text { Confidence Level of } \pm \\
0.004 \mathrm{~kg}\end{array}$}} \\
\hline & & & & \\
\hline & & & & \\
\hline
\end{tabular}

All Standards are traceable to International Measurement Standards, Calibration performend to Quality Procedure QP/UWE/02

Remarks: Calibration

Signatories:
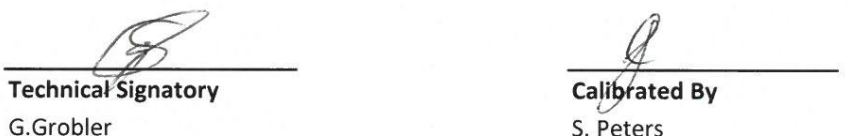

The reported expanded uncertainty is based on a standard uncertainty multiplied by a coverage factor $k=2$

Providing a level of confidence of approximately 95\%, the uncertainty of measurement has been calculated in accordance with the principles defined in the GUM, Guide to Uncertainty of Measurement, ISO, Geneva, 1993.

This certificate is issued in accordance with ISO IEC 17025, the conditions approved by SANAS and the policies of UWE Scales. It is a correct record of measurements made and relate only to the items calibrated. This certificate may not be reproduced other than in full, accept with a prior written approval of the issuing laboratory. The values in this certificate are valid at the time calibration. Subsequently the accuracy shall depend on such factors as the care exercised in handling, use of the instrument and frequency of use. Re-calibration should be preformed after a period which has been chosen to ensure that the instrument's accuracy remains within the desired limits. The applicant hereby indemnifies, holds harmless and absolves UWE Scales and the Mass Laboratory, from any damage whatsoever and any legal liability in the event of a mistake in the services performed for the applicant.

Page 1 of 1

\section{End of Certificate}




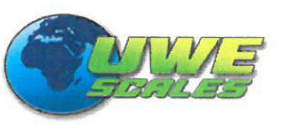

f sanas

1 Otto Road Beaconvale Parow, PO Box 1556 Parow 7499

Laboratory No. 1468

Tel: $0219335403 \quad$ Fax: 0219335409

UWE Scales Mass Laboratory Calibration Certificate

$\begin{array}{ll}\begin{array}{ll}\text { Customer Details: } \\ \text { Company Name: }\end{array} & \begin{array}{l}\text { Forensic Pathology Service } \\ \text { Durham Ave } \\ \text { Salt River } \\ \text { Western Cape }\end{array} \\ & \text { Mr.Mitten } \\ & \begin{array}{l}\text { Contact: } \\ \text { Date Of Calibration: }\end{array} \\ \begin{array}{l}\text { Issue Date: } \\ \text { Recalibration Date: }\end{array} & \begin{array}{l}\text { Yearly } / 2016 \\ \text { Yearly }\end{array}\end{array}$

Calibration Details:

Make and Model:

Serial Number:

Unit of Measure:

Capacity:

Resolution:

Description:

Unit Condition:

Location:

Type of Calibration:

Calibration Results

Certificate No. 27035/1

Issue No. 1

Micro T7E

1303090091

$\mathrm{kg}$

30

0.001

Electronic Scale

Satisfactory

Salt River

Full

\begin{tabular}{|c|c|c|c|c|}
\hline $\begin{array}{c}\text { Test Load } \\
\text { kg }\end{array}$ & $\begin{array}{c}\text { As Found } \\
\text { kg }\end{array}$ & $\begin{array}{c}\text { After Adjustment } \\
\text { kg }\end{array}$ & $\begin{array}{c}\text { Uncertainties } \\
\text { kg }\end{array}$ & $\begin{array}{c}\text { Weights Used \# } \\
\text { S Set }\end{array}$ \\
\hline 0.000 & 0.000 & 0.000 & Repeatability & Repeatability @ \\
$\pm 80 \%$ Capacity
\end{tabular}

All Standards are traceable to International Measurement Standards, Calibration performend to Quality Procedure QP/UWE/02

Remarks: Calibration

Signatories:

Technical Signatory
G.Grobler

Calibrated By

S. Peters

The reported expanded uncertainty is based on a standard uncertainty multiplied by a coverage factor $k=2$

Providing a level of confidence of approximately 95\%, the uncertainty of measurement has been calculated in accordance with the principles defined in the GUM, Guide to Uncertainty of Measurement, 1SO, Geneva, 1993.

This certificate is issued in accordance with ISO IEC 17025, the conditions approved by SANAS and the policies of UWE Scales. It is a correct record of measurements made and relate only to the items calibrated. This certificate may not be reproduced other than in full, accept with a prior written approval of the issuing laboratory. The values in this certificate are valid at the time calibration. Subsequently the accuracy shall depend on such factors as the care exercised in handling, use of the instrument and frequency of use. Re-calibration should be preformed after a period which has been chosen to ensure that the instrument's accuracy remains within the desired limits. The applicant hereby indemnifies, holds harmless and absolves UWE Scales and the Mass Laboratory, from any damage whatsoever and any legal liability in the event of a mistake in the services performed for the applicant.

Page 1 of 1

\section{End of Certificate}




\section{Appendix C - Ethics approval letter}

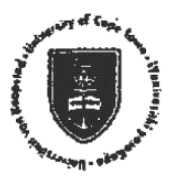

UNIVERSITY OF CAPE TOWN

Faculty of Health Sciences

Human Research Ethics Committee

Room E52-24 Oid Main Building Groote Schuur Hospital Obcervatory 7925

Telephone [021] 4066338 . Facsimile [021] 4066411 Email: nosits:ama@uct,ac.za Website: www health. uch.ac.za/fhs/research/humanethics/forms

07 April 2016

HREC REF: $164 / 2016$

Dr G KIrk

Forensic Medicine \& Toxicology

Entrance 3, Level 1

Falmouth Building

\section{Dear Dr Kirk}

PROJECT TITLE: POST MORTEM ORGAN WEIGHTS IN A SOUTH AFRICAN MORTUARY (MMEdcandidate-Dr L Peddle)

Thank you for your response letter to the Faculty of Health Sciences Human Research Ethics Committee dated 01 April 2016.

It is a pleasure to inform you that the HREC has formally approved the above-mentioned study.

Approval is granted for one year until 30 April 2017.

Please submit a progress form, using the standardised Annual Report Form if the study continues beyond the approval period. Please submit a Standard Closure form if the study is completed within the approval period.

(Forms can be found on our website: www.health.uct.ac.za/fhs/research/humanethics/forms)

Please quote the HREC REF in all your correspondence.

We acknowledge that the student $\operatorname{Dr} L$ Peddle will also be involved in this study

Please note that the ongoing ethical conduct of the study remains the responsibility of the principal Investigator.

Please note that for all studies approved by the HREC, the principal investigator must obtain appropriate institutional approval before the research may occur."

Yours sincerely

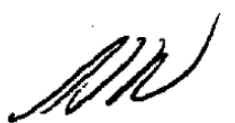

PROEESSOR MBLOCKMAN

CHATRPERSON. FHS HUMAN RESEARCHETHXCS COMMITTEE

Federal Wide Assurance Number: FWA00001637.

Institutional Review Board (IRB) number: IRB00001938

HREC 164/2016 


\section{Appendix D - Lab 27 example (fictional case)}

CONTEMPORANEOUS NOTE (LAB. 27) : SALT RTVER FORENSIC PATHOLOGY LABORATORY

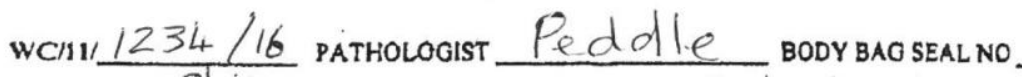
assistant Phillip.s DATE OF PM 01 103/2016 TIME OF PM O8h 30

1. RACE:

2. GENDER:

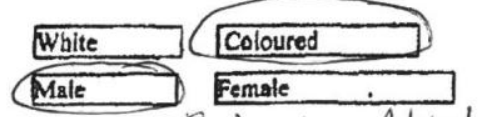

A. AGE:

Asiatic

Femate 3. AGE:

25

4. NAME OF DECEASED:

5. AREA OF DEATH: Rocklands

7. DATE OF DEATH: $28 / 02 / 2016$

6. SAPS STATION:

8. TIME OF DEATH: $22 \mathrm{~h} 3 \mathrm{O}$

9. DIED IN

\begin{tabular}{|l|l|l|l|l|}
\hline House & Shack & Rosd S & Dem & River \\
\hline Swimming pool & Bucket / Bln & Shebeen & Sea & Lake \\
\hline Hospital & Railway track & Open land & Tollat & Other \\
\hline
\end{tabular}

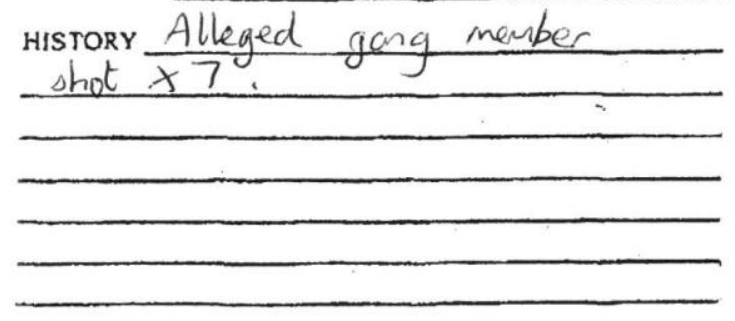

EXTERNAL FEATURES

ZHIEF POST-MORTEM FINDINGS
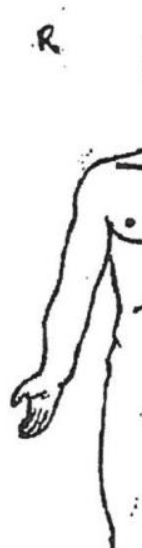

2

(2)

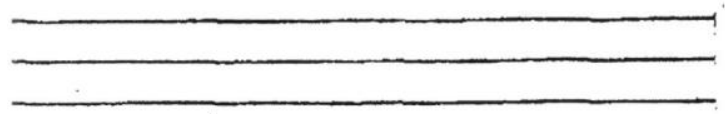

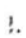

6.

I.

:AUSE OF DEATH Multiple gunshot wounds

\begin{tabular}{l|l|l|}
\hline ALCOHOL SEAL NUMBERS & Inner & Outer \\
Received by: & & \\
\hline Exhibits received by: & & \\
\hline
\end{tabular}

signature: CPedlle 